\title{
Enzymatic Regulation in the Liver of the Freeze- Tolerant Wood Frog in Metabolically Depressed States
}

\author{
by
}

Ranim Saleem

A thesis Submitted to the Faculty of Graduate and Postdoctoral Affairs in partial fulfillment of the requirements for the degree of

Master of Science

Biology, Specialization in Biochemistry

Carleton University

Ottawa, Ontario

(C) 2020

Ranim Saleem 
The undersigned hereby recommend to the Faculty of Graduate Studies and Research acceptance of this thesis

\title{
Enzymatic Regulation in the Liver of the Freeze- Tolerant Wood Frog in Metabolically Depressed States
}

\author{
Submitted by \\ Ranim Saleem
}

In partial fulfillment of the requirements for the degree of Master of Science

Chair, Department of Biology

Thesis Supervisor

Carleton University 


\begin{abstract}
The wood frog, Rana sylvatica, can tolerate high degrees of freeze-tolerance, a stress that also requires anoxia, dehydration and hyperglycemia tolerance. Frozen wood frogs show no heartbeat, brain activity, muscle movement or breathing, but phenomenally return to normal once thawed. Control of enzymatic activity is crucial for regulating metabolism and it is imperative for wood frog survival. This thesis investigates the properties of two key enzymes metabolic enzymes, glutamate dehydrogenase and glyceraldehyde-3-phosphate dehydrogenase in liver of the wood frogs exposed to freezing, dehydration and anoxia. Current data show that changes in activity, substrate affinity and stability of the enzymes play a major role in their regulation to support the survival of the wood frog during stress, and these regulations are partly controlled by post-translational modifications. Therefore, these enzymes undergo regulation at the level of posttranslational modification to contribute to the overall readjustment of energy production in the wood frog.
\end{abstract}




\section{Preface}

This Master's thesis is composed on two main research papers that are currently awaiting submission to the following journals:

Molecular and Cellular Biochemistry

Saleem, R. and Storey, K.B. (2020). Insight into the regulation of liver glutamate dehydrogenase during dehydration and anoxia exposure

Cell Biochemistry and Function

Saleem, R. and Storey, K.B. (2020). Purification and regulation of glyceraldehyde-3-phosphate dehydrogenase (GAPDH) from liver of freeze-tolerant Rana sylvatica in response to freezing, dehydration and anoxia 


\section{Acknowledgments}

First, I would like to thank my supervisor Dr. Kenneth Storey. Ken, thank you so much for agreeing to take me on and giving me the opportunity to work in your lab. Thank you for all your guidance, mentorship and for helping me develop my skills in the research world. I have learned a lot throughout these two years science and non-science related like enlightening me with your music suggestions. I would also like to thank Jan Storey for all her hard work and the things she does to help this lab run smoothly. Her dedication contributed to our success at the lab significantly. I would also like to personally thank Jan for her patience in editing my thesis and answering my questions.

Thank you to every Storey lab member that has crossed paths with me these past two years. Thank you so much for making my time spent here so memorable. I would like to give a special thank you to Stuart and Christie for all your guidance in teaching me the basics of enzymes and for all the time you invested in training me. Rasha, thank you for answering all my questions, for all the valuable scientific advice, and for being a great friend. Hanane, thank you for being an amazing friend and for all the fun times.

Finally, I would like to thank my mom and dad for all their love, guidance and support throughout the years. Leen, Sharif and Noha thank you for always being there for me and for constantly listening to me talk about my project. I am extremely grateful and blessed to know each and every person I mentioned earlier that has not only contributed to my success, but also believed in my abilities. Thank you all for being part of this journey with me. 


\section{Table of Content}

Table of Contents

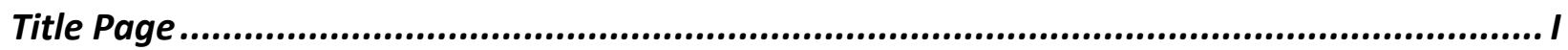

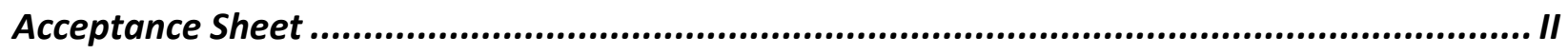

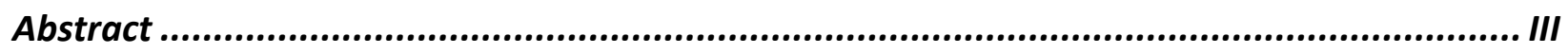

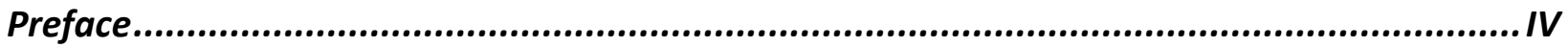

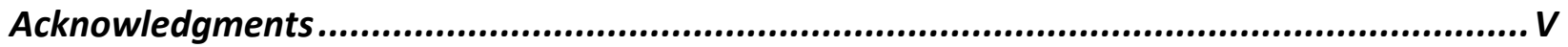

Table of Content .................................................................................................. VI

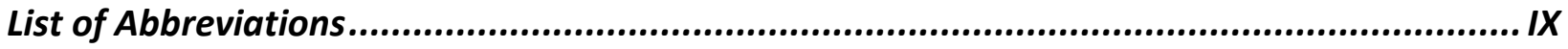

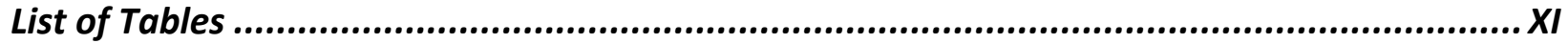

List of Figures ............................................................................................

Chapter 1 ................................................................................................... 1

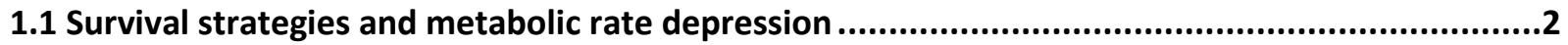

1.2 The wood frog, Rana sylvatica, as a model for adaptation to extreme environments .................4

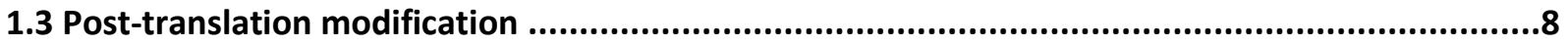

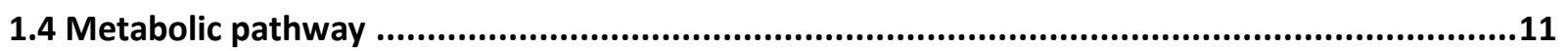

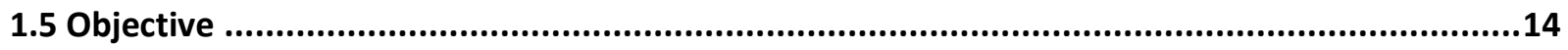

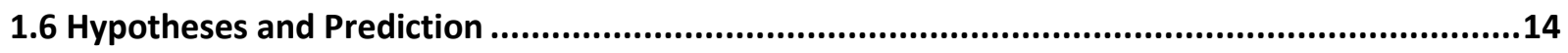

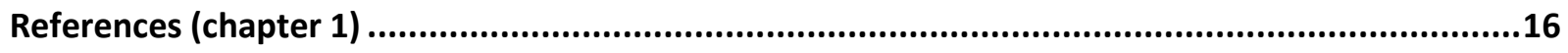

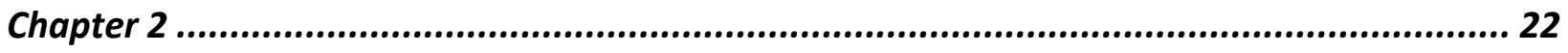

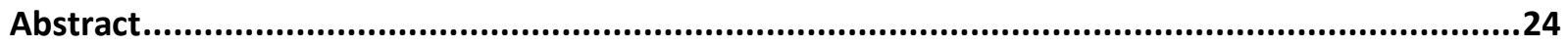

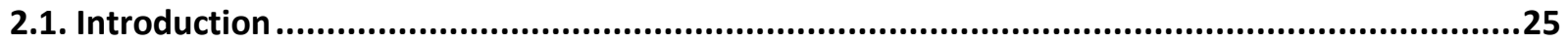

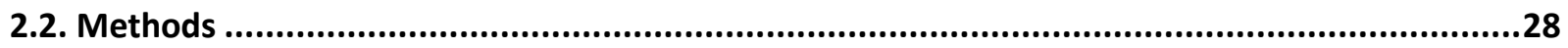

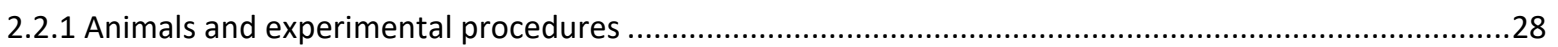

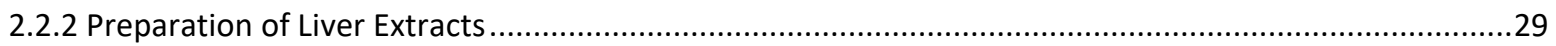

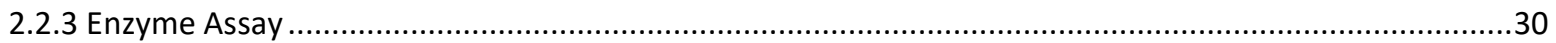

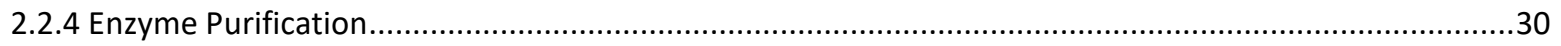

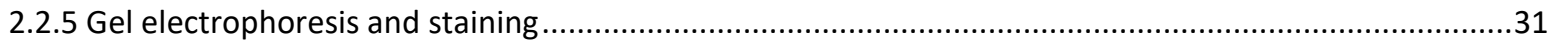

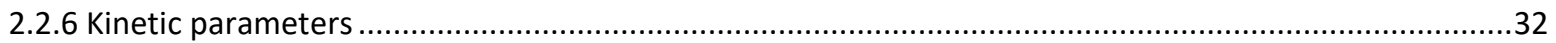

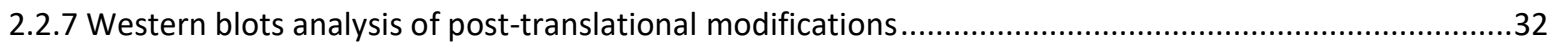

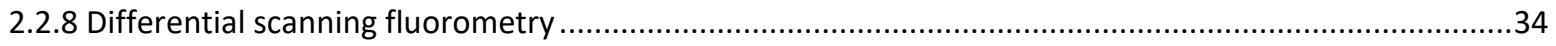

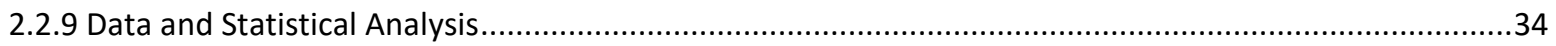

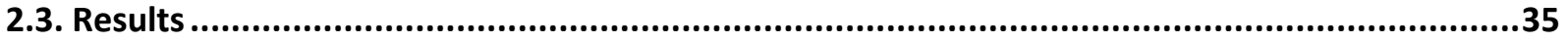

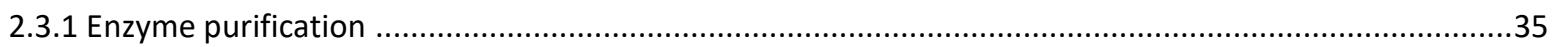

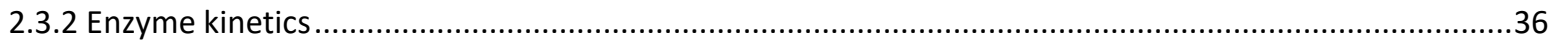


2.3.4 Western blots for posttranslational modification ............................................................................... 40

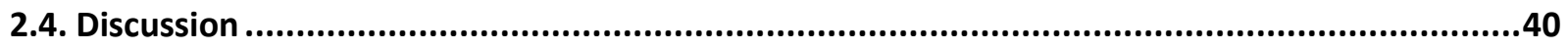

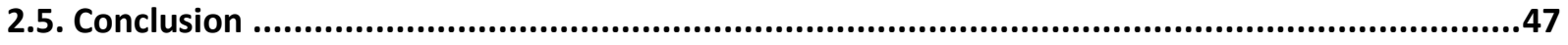

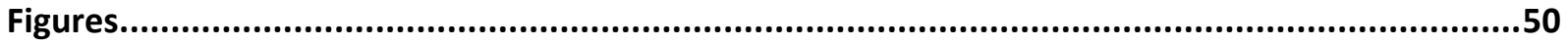

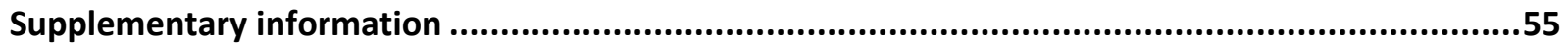

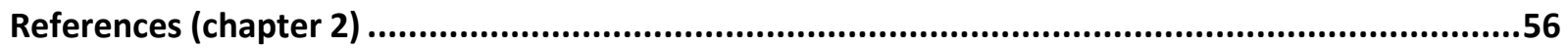

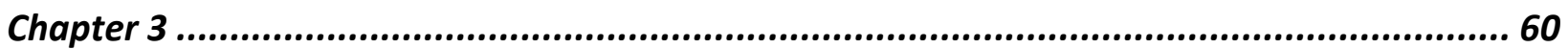

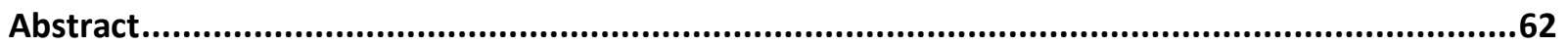

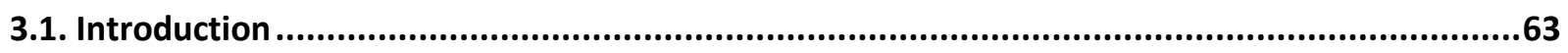

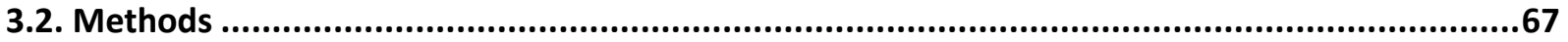

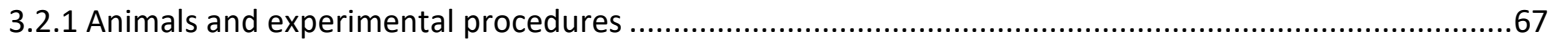

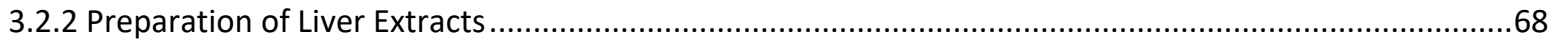

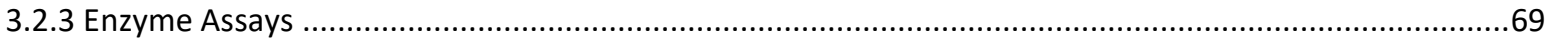

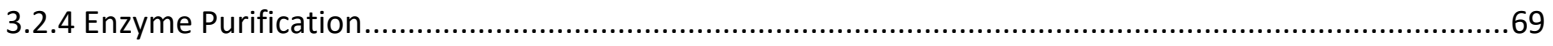

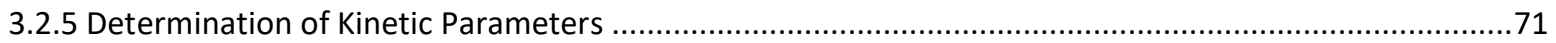

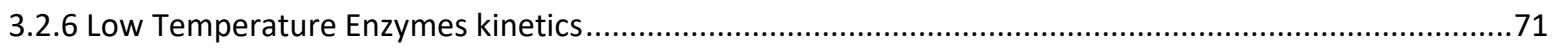

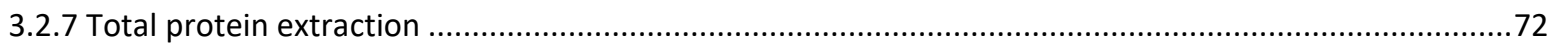

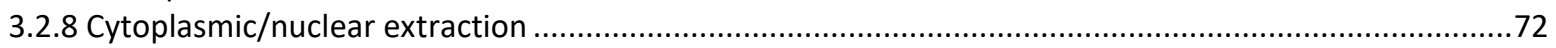

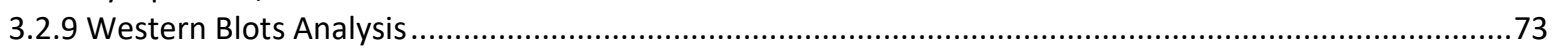

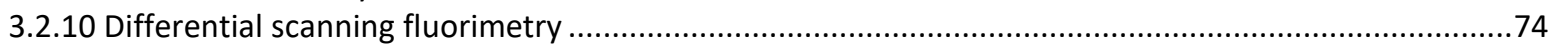

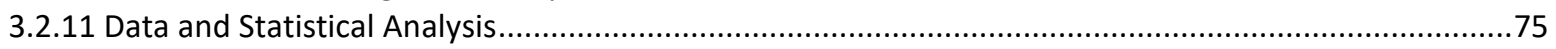

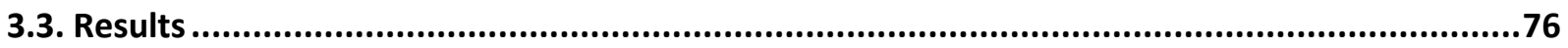

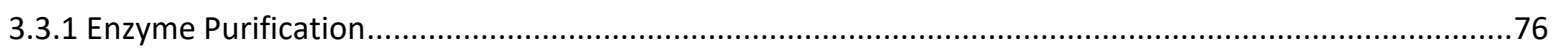

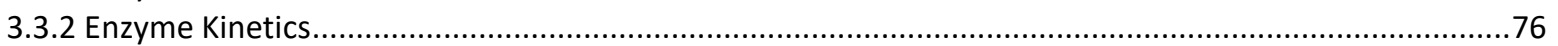

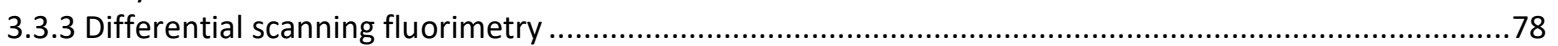

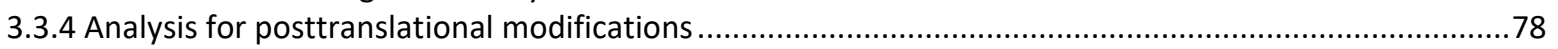

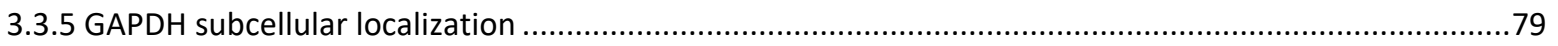

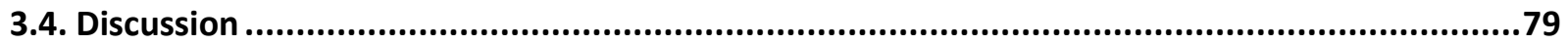

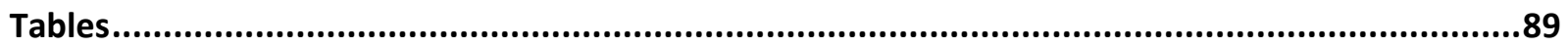

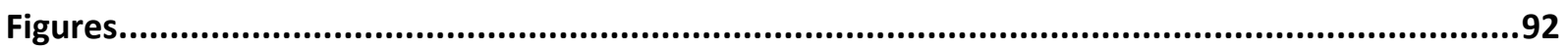

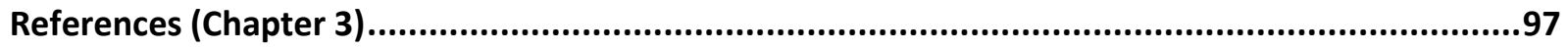

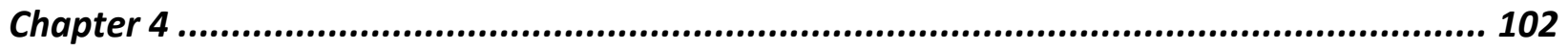

4.1 The role of GDH in wood frog liver during dehydration and anoxia ......................................106

4.2 Role of GAPDH in wood frog liver during freezing, dehydration and anoxia ...........................109

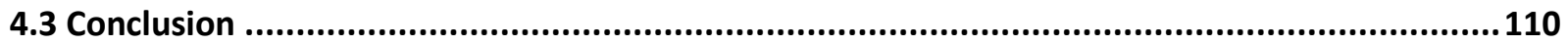

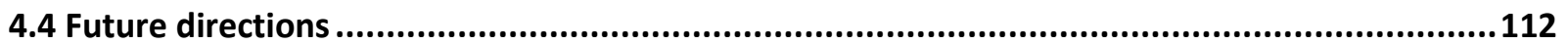

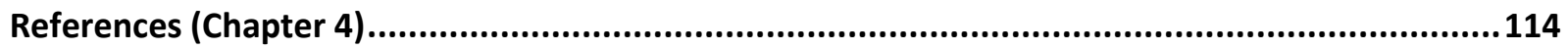

Appendix I: Representative western blots .................................................... 118 


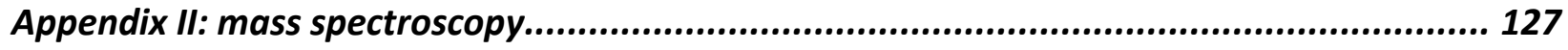

Appendix III: Conferences \& Publications ......................................................... 130 


\section{List of Abbreviations}

ADP, ATP- adenosine di-, or triphosphate

NAD $^{+}$, NADH- oxidized and reduced nicotinamide adenine dinucleotide

NADP ${ }^{+}$, NADPH- oxidized and reduced nicotinamide adenine dinucleotide phosphate

$\alpha-\mathbf{K G}-\alpha$-ketoglutaric acid

GAP- glycerldeyhde-3-phophate

1,3BPG-1,3-bisphosphateglycerate

3PG- 3-phosphoglycerate

F2,6P2- fructose-2,6-bisphosphate

EDTA- ethylenediamine tetraacetate

EGTA- ethyleneglycol bis tetraacetate

HEPES- (4-(2-hydroxyethyl)-1-piperazineethanesulfonic acid)

Tris- Tris[hydroxymethyl]aminomethane

PMSF- phenylmethylsulfonyl fluoride

GTP-guanosine-5' -triphosphate

TBS- Tris buffered saline

TBST- Tris buffered saline Tween-20

SDS- sodium dodecyl sulfate

SDS-PAGE- sodium dodecyl sulfate-polyacrylamide gel electrophoresis

PVDF- polyvinylidene fluoride

ECL- enhanced chemiluminescence

DSF- differential scanning fluorimetry 
MRD- metabolic rate depression

PTM- Posttranslational modification

ETC- electron transport chain

TCA cycle- tricarboxylic acid cycle

GDH- glutamate dehydrogenase

GAPDH- glyceraldehyde-3-phosphate dehydrogenase

PFK- phosphofructokinase

LDH- lactate dehydrogenase

$\mathbf{K}_{\mathbf{m}}$ - Michaelis-Menten Constant: substrate concentration producing half maximal enzyme activity

$\mathbf{K}_{\mathbf{a}}$ - half maximal activator concentration

$\mathbf{V}_{\max }$ - maximal enzyme velocity

I50- inhibitor concentration reducing enzyme velocity by $50 \%$

$\mathbf{T}_{\mathbf{m}}$ - melting temperature

KDa- kiloDalton

SEM- standard error of the mean 


\section{List of Tables}

Table 2.1: Purification scheme for purified GDH from control wood frog liver using a two-step chromatography method

Table 2.2: Comparison of purified liver GDH kinetic parameters from control, dehydrated and anoxic exposed wood frog in the forward and reverse reaction

Table 3.1: Representation of the purification scheme for purified liver GAPDH from control,

frozen, dehydrated and anoxic exposed wood frogs

Table 3.2: Kinetic parameters of purified liver GAPDH from control, frozen, dehydrated and anoxic frogs exposed frogs with respect to changing temperatures in the forward and reverse reaction

Table 3.3: The effect of urea and salts on purified liver GAPDH activity from control and frozen, dehydrated and anoxic exposed frogs in the forward reaction 


\section{List of Figures}

Figure 2.1: Coomassie stained SDS-PAGE gel demonstrating purification of GDH to homogeneity from control, dehydrated and anoxic wood frog liver

Figure 2.2: The effect of metabolites (ADP, urea and glucose) on the affinity of control and dehydrated wood frog liver purified GDH for its substrates in the forward and reverse reaction affinities

Figure 2.3: The effect of metabolites (ADP, urea and glucose) on the affinity of control and anoxic wood frog liver purified GDH for its substrates in the forward and reverse reaction affinities

Figure 2.4: The melting temperature for purified GDH from control, dehydrated and anoxic wood frogs in presence and absence of $100 \mathrm{mM}$ urea, using differential scanning fluorimetry 53 Figure 2.5: Western blots demonstrating relative degree of various PTMs in the control, dehydrated and anoxic wood frog liver GDH

Figure 3.1: Coomassie stained SDS-PAGE gel demonstrating 2-step purification of GAPDH to homogeneity from control Rana sylvatica liver

Figure 3.2: Differential scanning fluorimetry analysis of the relative thermal stability of purified GAPDH purified from liver Rana sylvatica comparing control to freezing, dehydration and

anoxia

Figure 3.3: Western blots analysis of posttranslational modification of partially purified GAPDH from liver of Rana sylvatica under control, frozen, dehydration and anoxia condition

Figure 3.4: Relative GAPDH expression levels in liver of Rana sylvatica from control, frozen, dehydration and anoxia treatment 
Figure 3.5: Relative nuclear GAPDH expression level in liver of Rana sylvatica from control, frozen, dehydration and anoxia frogs

Figure S1: Whole image of ECL-detected membrane using the control, dehydration and anoxia liver GDH samples probed with anti-phosphoserine antibody

Figure S2: Whole image of ECL-detected membrane using the control and dehydration liver GAPDH samples probed with anti-phosphoserine antibody

Figure S3: Whole image of ECL-detected membrane using the control and frozen liver samples probed with anti-GAPDH antibody

Figure S4: Whole image of ECL-detected membrane using the control and frozen liver nuclear samples probed with anti-GAPDH antibody

Figure S5: Whole image of ECL-detected membrane using the control and dehydration liver samples probed with anti-GAPDH antibody

Figure S6: Whole image of ECL-detected membrane using the control and dehydration nuclear liver nuclear samples probed with anti-GAPDH antibody

Figure S7: Whole image of ECL-detected membrane using the control and anoxia liver samples probed with anti-GAPDH antibody

Figure S8: Whole image of ECL-detected membrane using the control and anoxia liver nuclear samples probed with anti-GAPDH antibody

Figure S9: The identification of proteins bands excised from 10\% resolving SDS-PAGE for mass spectroscopy analysis

Figure S10: Mass spectroscopy analysis for GAPDH that was excised from $10 \%$ resolving SDS-

PAGE 
Chapter 1

\section{General Introduction}




\subsection{Survival strategies and metabolic rate depression}

Organisms that live in the wild must deal with unpleasant environmental conditions. Many animals have developed numerous coping strategies to survive harsh seasonal changes in their environments. For instance, some animals migrate to escape harsh environmental changes (Canada geese), while others must endure month-long periods of stress, such as seasonal freezing or dehydration during extreme cold or dry seasons. Those animals that can't escape unforgiving conditions developed adaptations to cope with seasonal changes (cold or dry) and drastic decreases in resources (food, water or level of oxygen) that allow them to survive for a long period of time [1]. To survive under these conditions, many animals transition into a hypometabolic state to sustain general metabolic functioning over a long period of time through the slow use of endogenous fuels reserves [1].These animals have the ability to lower their metabolic rate below the typical resting rate to extend their survival period. This is necessary because normal metabolic rate would likely burn through fuel reserves in a short period of time which would then make their survival impossible. This mechanism is found throughout the animal kingdom including both vertebrates and invertebrates [1,2]. For example, some small mammals and reptiles drop their metabolic rate to $1-20 \%$ of their resting rate [1]. Similarly, hibernating amphibians are capable of decreasing their metabolic rate up to $75 \%$ to survive hypoxic conditions [3]. Therefore, the ability to transition into a hypometabolic state and reduce metabolic rate are essential for stress survival.

Metabolic rate depression (MRD) requires major behavioural, physiological and biochemical changes. The typical behavioural and physiological responses include cessation of feeding, digestion, movement, as well as substantial decreases in breathing and slowing of cardiac activity [4]. Moreover, other vital organs like kidney display reduced filtration and the 
brain can undergo alternation in neurological organization [4]. It is believed that at least half of the energy savings are due to major alternations in cellular biochemistry [4]. The biochemical changes are established by reaching a balance between ATP-consuming and ATP-producing processes. This is accomplished by reduction in the activity of cellular processes, but the reductions are not the same throughout all tissues and they are dependent on the animals and corresponding stress that they encounter. Protein synthesis is an energy expensive process which was found to be suppressed to a varying degree in ground squirrel organs during torpor $[5,6]$. However, in the brown adipose tissue protein synthesis stays fully functional throughout torpor but it is strongly supressed in the brain and kidney $[5,6]$. Although the majority of metabolic processes are shutdown during hypometabolic state, some processes need to be enhanced to aid the survival of the organisms. For example, cellular protection (antioxidant, anti-apoptotic and chaperone proteins) in the wood frog are enhanced during hypometabolism [7-9]. Another example is urea synthesis that is suppressed by $70 \%$ during anaerobiosis in freshwater turtles but it is significantly increased during land snail estivation $[10,11]$. These examples indicate that MRD is selective and depends on the metabolic adjustments needed by individual species for survival during hypometabolism.

The selective regulation that is needed to enter a hypometabolic state is achieved by several mechanisms at the transcriptional level which have been shown to be essential mediators of MRD [4]. During hypometabolic states, certain transcription factors are differentially modified which alters gene expression. Additionally, the control of MRD also happens posttranscriptionally by the action of microRNA [12-16] that have the ability to target mature mRNA transcripts for either degradation or silencing $[17,18]$. These microRNAs can act quickly and provide an inexpensive method of suppressing costly protein synthesis while providing the 
possibility of storing mRNA in stress granules until conditions improve [19,20]. Moreover, at the post-translational level, proteins/enzymes are regulated through modification. One method known for regulating proteins is post translational modifications (PTMs) such as phosphorylation, acetylation, nitrosylation, methylation, ADP ribosylation and many other more. These PTMs are energetically inexpensive compared to protein synthesis and degradation and can be easily reversed by appropriate kinases or phosphatases, making this a useful mode of metabolic regulation under rapidly changing conditions that often accompany MRD [21-25].

\subsection{The wood frog, Rana sylvatica, as a model for adaptation to extreme environments}

The wood frog, Rana sylvatica, is not only one of the most well-studied freeze-tolerant vertebrates, but also demonstrates a robust ability to endure dehydration, anoxia and hyperglycemia [26]. They are widely distributed across the boreal forests of North America ranging from northern Georgia to Alaska [27]. They spend the winter months frozen under leaf litter, and although air temperature can reach $-30{ }^{\circ} \mathrm{C}$, the temperature under leaf cover rarely drops below $-5^{\circ} \mathrm{C}[27]$. Wood frogs begin to freeze at high sub-zero temperatures $\left(-0.5^{\circ} \mathrm{C}\right)$ that gives them enough time to initiate freeze tolerance strategies. Ice nucleation typically initiated upon epithelial contact with environmental ice [28,29]. This facilitation of ice nucleation is guided by ice nucleators such as bacteria on the skin or gut or by the production of ice nucleating proteins (INPs) [28,29]. The action of these INPs helps ice formation to occur at a slow rate and thereby avoid extensive supercooling [28,29]. It has been shown that wood frog blood plasma contains ice nucleating proteins which upon activation mediate the formation of ice crystals within the vasculature [30]. Due to the permeable skin of the wood frogs, ice formed on the skin surface allow it to penetrate through the internal body fluids and initiate an internal ice nucleation cascade [31,32]. Wood frogs confine ice growth within the extra-organ space, such as 
the abdominal cavity, bladder, and/or between skeletal muscle and the skin in order to limit cellular damage to capillaries and tissues [33]. The wood frog freezes up to $65-70 \%$ of its total body water as extracellular ice causing a reduction in cell volume and ultimately cellular dehydration [26,31,34]. Previous experimental studies have shown that it takes $12-24 \mathrm{~h}$ for the wood frog to achieve maximum ice content of 60-70\% [31]. In addition, all physiological activities such as breathing, muscle movement, cardiac and neurological functions cease [26]. The freezing of blood plasma interrupts oxygen delivery to organs which results in anoxic conditions throughout the body.

Wood frogs also show well-developed dehydration tolerance (an ability to endure the loss of approximately $60 \%$ of total body water) and anoxia resistance (at least $48 \mathrm{~h}$ exposure to N2 gas at $5{ }^{\circ} \mathrm{C}$ ) independent of freezing $[26,35,36]$. Indeed, pre-existing abilities to deal with low oxygen or wide variation in body water content, likely supported the development of freeze tolerance in selected northern frog species. Therefore, the wood frogs have developed multiple adaptive mechanisms to effectively combat freezing, cellular dehydration and anoxia. One beneficial mechanism added by wood frogs to support freezing tolerance is the accumulation of high amounts of glucose to be used as a cryoprotectant. Glucose act as a cryoprotectant by retaining enough water inside the cell and also by aiding in stabilization of macromolecules [37]. During the late summer and autumn, the wood frog accumulates extensive level of glycogen ( $\sim 180 \mathrm{mg} / \mathrm{g}$ wet weight) in the liver $[31,38]$. Upon ice nucleation (within the first 2-5 minutes), the liver starts to mobilize large quantities of glycogen (via glycogenolysis) to form glucose which is then exported via the blood to other organs [39]. Glucose levels in the frozen wood frogs can increase to $250-300 \mathrm{mM}$ from a normal concentration of around $\sim 5 \mathrm{mM}[34,40]$. Glucose production in the liver is maintained during the freezing period and continues until the 
beginning of the thawing period [34]. Similarly, glycogenolysis was activated to produce glucose in dehydrated wood frogs [36]. This was proven by the increase in liver glucose-6-phosphate (G6P) and glucose in frogs that only lost $10 \%$ of total body water [36]. The importance of glucose as a cryo- or osmo-protectant in wood frogs has been well understood, however, more recent research has begun to elucidate the relevance of urea in the wood frog for survival purposes [25,41-43]. In general, amphibians are prone to water loss due to the highly permeable nature of their skin and many species are thought to use urea as an osmoprotectant during dehydration [42]. The accumulation of urea is one of the strategies to prevent excessive water loss. For example, Rana sylvatica, can accumulate up to $90 \mathrm{mM}$ urea under dry conditions or freezing [41]. Urea has been demonstrated to function as both an osmo-protectant and cryoprotectant in wood frogs. Urea functions as cryoprotectant has been shown on several level where it significantly reduce damage to organs such as heart and muscle during freezing [42]. A previous study demonstrated that a $48 \mathrm{~h}$ freezing of wood frogs from Ohio led to a $40 \%$ increase in liver urea level compared to a control from the same population whereas Alaskan wood frogs displayed an $80 \%$ increase in urea compared to the unfrozen liver group [44]. This suggest that urea may play a role in the wood frog freeze survival since the Alaskan population are known to be resistant to lower temperatures than the Ohioan population. Therefore, glucose and urea both play critical roles in aiding the wood frog survival during the winter season.

The accumulation of glucose and urea are only found in wood frogs under freezing and dehydration however, there is no known accumulation of cryoprotective agents in wood frogs under anoxia treatment only [26]. Under anoxia conditions, the wood frog need to transition from oxidative phosphorylation to anaerobic glycolysis as a source of ATP. This transition is also seen in the wood frogs during freezing due to oxygen deprivation and during dehydration when water 
loss reaches a high level that impairs blood circulation. Under normoxic conditions, the catabolism of glucose via glycolysis + the tricarboxylic acid cycle can produce up to 38 moles of ATP per one mole of glucose whereas during anoxic conditions, breakdown of glucose to lactate and $\mathrm{H}^{+}$yield only 2 moles of ATP for each mole of glucose [45]. This means that the amount of ATP produced anaerobically is far less than the amount of ATP produced under aerobic conditions. As a consequence, many species have developed metabolic rate depression to sustain life until conditions are better. This is accomplished through switching into a hypometabolic state during the period of stress which is globally coordinated. MRD has been well studied in the wood frog. However, metabolic rates during dehydration and anoxia have not been measured in wood frogs but studies in other organisms that undergo these stresses showed suppression of overall metabolic rates [1]. A previous study on isolated mitochondria from the skeletal muscle of the frog, Rana temporaria, under hypoxia revealed a reduction in metabolic rate as oxygen levels were limited. In another example, the spadefoot toad that employs aestivation as a survival strategy to withstand extended periods of dry conditions was documented to lower its metabolic rate to just $20 \%-30 \%$ of its normal resting rate [46]. Other anoxia-tolerant vertebrates, such as freshwater turtles can reduce overall metabolic rate to just $10 \%-20 \%$ of the normal aerobic level $[1,47]$. These examples support the suppression of metabolic rate in the wood frog in response to dehydration and anoxia.

MRD is centrally controlled and coordinated by mechanisms that help to reduce most ATP-expensive or harmful cellular processes while maintaining the limited energy available only for pro-survival pathways $[7-9,35,48,49]$. This is accomplished at various cellular levels including: transcription (epigenetic modification such as changes in histone phosphorylation, acetylation \& methylation, DNA methylation \& acetylation, etc.), post-transcription (microRNA 
and stress granules), and post-translational (post-translational modifications such as reversible protein phosphorylation, acetylation \& methylation, etc.) $[15,26,50]$. Some of the important prosurvival pathways are processes that are needed for cellular protections such as dealing with the production of reactive oxygen species (ROS). Given that the ETC is reduced during anoxia, it becomes more susceptible to producing large quantities of ROS upon re-oxygenation which can cause serious damage to cells. Therefore, the wood frog selectively modulates the level and activities of specific antioxidant enzymes. For example, wood frogs showed up-regulation of superoxide dismutase, catalase, glutathione S-transferase, glutathione reductase and total Sedependent glutathione peroxidase in most of the tissues in response to anoxia [31,51]. There are many energy intensive cellular pathways such as gene expression or protein synthesis which require a great amount of ATP to power DNA replication, or the cell cycle [9]. Therefore, transcription and subsequent translation are suppressed during hypometabolic states [50]. One important mechanism used as an inhibitory control during MRD is reversible protein phosphorylation of targets involved in energetically demanding processes in the wood frogs $[23,25]$. It has been shown that metabolic enzymes are heavily regulated to balance suppression of all aspects of metabolism in the wood frog. For example, many glycolytic enzymes in the wood frog undergo reversible protein phosphorylation [22,26,52]. Taken all together, the wood frog provides a tight regulation of energy utilization through the modification of enzymes.

\subsection{Post-translation modification}

The readjustment of energy demand is one of the key strategies employed to support long-term stress survival in a hypometabolic state. This requires tight control over metabolic pathways which is often accomplished by altering PTMs in response to stress. Covalent modification can alter the degree of activity and/or the conformation of its target depending on 
which group is added and to which amino acid residue [53]. The significance of PTMs as a regulatory mechanism lies in the fact that they can often be reversibly added or removed and doing so is less energetically costly than the synthesis of proteins [53]. Therefore, controlling enzyme function by PTMs are an attractive option to modulate their activity and metabolic processes during a hypometabolic state [54].

Protein phosphorylation is the most commonly reported modification in regulating enzymatic activity. The addition of phosphate groups to a protein is accomplished by enzymes called protein kinases whereas phosphate groups are removed by protein phosphatases. Protein phosphorylation constitutes a potent effector in stress-responsive regulation of metabolic enzymes [23]. Several studies have highlighted the importance of reversible phosphorylation in animals that undergo hypometabolic state such as estivation, hibernation and anoxia [24,55-58]. Recently, other PTMs have been discovered that may act independently or in conjugation with phosphorylation [59]. For example, protein acetylation has been recently been demonstrated to be a common modification in enzymes and plays an important role in regulating metabolism $[60,61]$. Protein acetylation has been found for most enzymes of glycolysis and gluconeogenesis, in the TCA cycle through the activation of malate dehydrogenase, in the urea cycle via the inhibition of argininosuccinate lyase, glycogen metabolism and fatty acid metabolism in human liver tissue with the acetylation status depending on the concentration of the metabolic fuels [62]. Glycogen phosphorylase was revealed to be acetylated on Lys 470 which enhances its interaction with the protein phosphatase 1 targeting subunit to favour glycogen phosphorylase dephosphorylation and inactivation [63]. Studies from our lab have highlighted the role of PTMs in regulating enzymatic activity during undesirable conditions. Lactate dehydrogenase (LDH) from red-eared slider displayed modification of the acetylation state of LDH with corresponding 
changes in enzyme properties [64]. Another study showed that glutamate dehydrogenase (GDH) may be regulated by acetylation and ADP-ribosylation in the freeze tolerant wood frog. That study showed a decrease in $\mathrm{K}_{\mathrm{m}}$ for substrates in both directions of the reaction concurrent with a reduction in GDH acetylation and ADP-ribosylation suggesting that GDH is more active during freezing in order to facilitate the production of urea [65]. These examples imply the importance of PTMs in modifying enzymes to suit physiological needs of the animals.

PTMs have been found to play a critical role in helping to regulate the metabolic pathways of the wood frog. For example, in response to dehydration a reduction in acetylation of LDH was seen that agreed with the altered kinetic parameters of the enzyme [23]. Studies of the regulation of glycogen metabolism in wood frogs also demonstrated that glycogen synthase kinase 3 (GSK3) is strongly regulated by phosphorylation in multiple tissues leading to glycogen synthase being phosphorylated and inactivated and thus reducing the level of glycogen synthesis and facilitating the breakdown of glycogen by glycogen synthase in order to accelerate the production of the cryoprotectant glucose $[31,66]$. Results from a recent phosphoproteomic study on wood frog liver in response to freezing, dehydration or anoxia showed differential phosphorylation patterns in glycolytic, glycogenolysis and urea cycle enzymes [25]. This study revealed the importance of reversible protein phosphorylation in regulating key metabolic enzymes in the wood frog. Additionally, antioxidant enzymes in the wood frog (superoxide dismutase, glutathione reductase and catalase) have been also shown to be regulated by reversible protein phosphorylation to overcome oxidative stress encountered over freeze-thaw cycles $[67,68]$. Protein kinase $\mathrm{C}(\mathrm{PKC})$ is known to be involved in targeting other proteins for phosphorylation at serine and threonine residues and it was shown to be less phosphorylated (less active) in the liver and kidney of wood frogs in response to full body freezing [69]. This suggests 
that reversible protein phosphorylation may act as a general regulatory response for making modification to enzymes or pathways during freezing. Taken together, PTMs, particularly reversible protein phosphorylation may serve as a common regulatory response for controlling metabolic and pathways in the wood frog. Therefore, alterations in PTMs are key players in contributing to the changes needed for entry into MRD in wood frogs upon encountering a stress.

\subsection{Metabolic pathway}

Tight control of metabolic rate is coordinated with a specific subset of regulatory enzymes whose activity is modulated to control cellular processes [31]. Thus, it is unsurprising that MRD strategies are regulated by key metabolic enzymes in response to harsh environmental conditions. Previous studies have shown that glycolysis in wood frogs is controlled through the regulation of key glycolytic enzymes [36,70-72]. The wood frog produces a huge quantity of glucose that is needed to serve as a cryoprotectant in cells, and therefore, wood frogs need to suppress the activity of key glycolytic enzymes to prevent the use of cryoprotectant glucose as a source of fuel [72]. Hexokinase (HK) is the first main control point in glycolysis and catalyzes the first reaction of this pathway. This enzyme was found to be modified (reversible protein phosphorylation) in the wood frog during freezing in order to help conserve a high level of cryoprotectant glucose and to reduce the consumption of glucose [22]. Phosphofructokinase (PFK) is another key regulatory enzyme of glycolysis that converts fructose-6-phosphate (F6P) to fructose 1,6-bisphosphate. This enzyme has also been shown to be highly regulated in wood frogs. It was reported that level of F6P and glucose-6-phosphate (G6P) significantly increased in the liver of the wood frog [70]. Additionally, levels of fructose-2,6-bisphosphate $(\mathrm{F} 2,6 \mathrm{P} 2) \mathrm{a}$ potent activator of PFK were significantly decreased during freezing in wood frog liver [73,74]. These results suggest an inhibitory block of glycolysis at the PFK step during freezing of wood 
frogs. Similarly, glycolysis was also reported to be inhibited at the PFK locus in wood frogs in response to dehydration [36]. The regulation of PFK has also been seen in other species that experience extreme environmental conditions. For example, PFK in the anoxia tolerant snail Littorina littorea was found to be less active and displayed lower substrate affinity under anoxia conditions which was consistent with regulation through reversible protein phosphorylation [75]. Moreover, PFK enzymatic activity was also reduced in hepatopancreas of another snail, Otala lactea, in response to anoxia [76]. Generally, it was reported that levels of F2,6P2 decreased in response to anoxia/ischemia in different animals in the liver, demonstrating strong glycolytic control, during oxygen deprivation $[77,78]$. The third main control point of glycolysis is pyruvate kinase (PK) that catalyze the last step in glycolysis. PK was shown to decrease in enzymatic activity due to increases in total serine phosphorylation during freezing [71]. The regulation of PK through phosphorylation was suggested to contribute to energy conservation and overall MRD as well, maintaining cryoprotectant levels during freezing [71]. Suppression of PK was also seen in other animals that that experience harsh environmental conditions such as Littorina littorea, spadefoot toads and marine oysters [79-81]. This suggests that PK is a regulatory target in animals that undergo MRD and its inactivation supports the overall MRD. Taken all together, glycolysis is highly regulated pathway during hypometabolism.

Lately, the role of urea had gained a lot of attention in wood frog responding to freezing or dehydration. It has been noted that urea plays a role as an osmoprotectant and cryoprotectant along with glucose to help reduce freezing and/ or dehydration stress as well as to protect cells from freeze/thaw injury. Therefore, the urea cycle is likely to be highly regulated in order to facilitate urea production in wood frog liver to aid its survival. Carbamoyl phosphate synthetase I (CPSI) is a rate limiting step of urea synthesis that mediate the entrance of nitrogen in the form 
of free ammonia into organic compounds. A previous study showed that purified liver CPS1 from frozen wood frogs had increased affinity for ATP and a lower $\mathrm{K}_{\mathrm{a}}$ for $\mathrm{N}$-acetylglutamate (NAG; an allosteric activator of CPSI) when exposed to $400 \mathrm{mM}$ glucose, a physiological level in frozen frogs [82]. These results suggested that CPSI activity increases in response to freezing in order to produce urea even as ATP levels decrease in the liver of frozen frogs [34]. Additionally, it has been noted that the wood frog can maintain levels of CPSI activity during freezing regardless of a reduction in overall metabolic rate [83]. Another study from our lab showed that ornithine transcarbamylase (OTC) had increased phosphorylation on serine residues and increased affinity for ornithine in response to freezing [84]. This study suggested that OTC could be regulated through phosphorylation to increase the affinity for ornithine in order to encourage flux through the urea cycle and reduce the access of ornithine to competitive pathways [84]. The African clawed frog, Xenopus laevis, displayed an increase in activity of multiple urea cycle related enzymes including argininosuccinate lyase, CPSI and OTC in response to elevated salinity [85]. These studies indicate the importance of regulating urea cycle enzymes in the wood frogs in order to mediate urea production to serve as a cryoprotectant or osmoprotectant.

Altogether, the above studies demonstrated the strict control over selected metabolic enzymes in response to stress in efforts to meet metabolic demand and contribute to the reorganization of metabolism. The current research focuses on two key enzymes, glutamate dehydrogenase (GDH) and glyceraldehyde-3-phosphate dehydrogenase (GAPDH), both of which play pivotal roles in regulating core metabolic processes. Therefore, the aim of this project to determine whether or not GDH and GAPDH are regulated in response to environmental stress and if they contribute to the overall suppression of metabolic rate. 


\subsection{Objective}

The wood frog is an excellent model for studying MRD and adaptations to extreme environmental conditions since it can survive multiple stresses that are deadly to most animals including, winter freezing, dehydration and anoxia. The wood frog demonstrates remarkable adaptations to cope with these stresses including production of cryoprotectants (glucose and urea) and suppression of metabolic rate to survive when tissues are oxygen starved. The wood frog must undergo metabolic rate depression to ensure that stored carbohydrate supplies are sufficient for the animal to survive during bouts of freezing. This is mediated through the coordinated regulation of metabolic pathways and their enzymes often through the action of altered PTMs. This thesis seeks to understand metabolic regulation in the liver of the wood frog in response to extreme environmental stresses with regard to the functions of key enzymes associated with carbohydrate and nitrogen metabolism: GAPDH and GDH. Wood frog liver GAPDH and GDH are characterized kinetically, structurally and post-translationally in response to freezing, dehydration and anoxia stresses in order to fully to understand their role in energy metabolism.

\subsection{Hypotheses and Prediction}

Based on the importance of regulating central metabolism in the wood frog during hypometabolic states the following hypotheses are proposed about the regulation of GDH and GAPDH in the liver of the wood frog,

\section{Chapter 1: Glutamate dehydrogenase.}

I hypothesized that the activity of GDH in the glutamate-oxidizing direction is enhanced to provide another source of energy other than glycolysis as well as providing the ammonium 
needed to contribute to the production of urea (a key molecule for maintaining osmotic balance in amphibian dehydration) during dehydration exposure in the wood frog. Due to the overall suppression of oxygen-based metabolism, I hypothesize that liver GDH is suppressed in the glutamate-oxidizing direction during anoxia in the wood frog. Finally, I hypothesize that PTMs are involved in the regulation of GDH in response to anoxia and dehydration.

\section{Chapter 2: Glyceraldehyde-3-phosphate dehydrogenase}

This chapter investigates the regulation of GAPDH in the liver of the wood frog in response to freezing, dehydration and anoxia treatment. Given that glycolysis is inhibited at the PFK level in liver of the wood frog in response to freezing and dehydration, I hypothesize that liver GAPDH is also suppressed in the liver of the wood frog during freeze and dehydration exposure in order to enhance and support the overall decrease in glycolysis. In addition, glycolysis was also inhibited at the PFK level in liver of anoxia-tolerant animals leading to hypothesize that liver GAPDH from anoxic wood frogs is also actively suppressed. In order to achieve the regulations predicted above, I hypothesize that PTMs would play a part in GAPDH regulation during freezing, dehydration and anoxia. 


\section{References (chapter 1)}

[1] K.B. Storey, J.M. Storey, Metabolic rate depression and biochemical adaptation in anaerobiosis, hibernation and estivation, 65 (1990) 145-174. doi:10.1086/416717.

[2] K.B. Storey, J.M. Storey, Putting life on "pause" - Molecular regulation of hypometabolism, J. Exp. Biol. 210 (2007) 1700-1714. doi:10.1242/jeb.02716.

[3] P.H. Donohoe, R.G. Boutilier, The protective effects of metabolic rate depression in hypoxic cold submerged frogs, Respir. Physiol. 111 (1998) 325-336. doi:10.1016/S00345687(97)00125-4.

[4] K.B. Storey, J.M. Storey, Metabolic rate depression in animals: Transcriptional and translational controls, Biol. Rev. Camb. Philos. Soc. 79 (2004) 207-233. doi:10.1017/S1464793103006195.

[5] D. Hittel, K.B. Storey, The translation state of differentially expressed mRNAs in the hibernating 13-lined ground squirrel (Spermophilus tridecemlineatus), Arch. Biochem. Biophys. 401 (2002) 244-254. doi:10.1016/S0003-9861(02)00048-6.

[6] S. Branch, S.N. Branch, W. State, Suppression of protein synthesis in brain during hibernation, Proc. Natl. Acad. Sci. 95 (1998) 14511-14516.

[7] R. Roufayel, K.K. Biggar, K.B. Storey, Regulation of cell cycle components during exposure to anoxia or dehydration stress in the wood frog, Rana sylvatica, J. Exp. Zool. Part A Ecol. Genet. Physiol. 315 A (2011) 487-494. doi:10.1002/jez.696.

[8] V.E.M. Gerber, S. Wijenayake, K.B. Storey, Anti-apoptotic response during anoxia and recovery in a freeze-tolerant wood frog (Rana sylvatica), PeerJ. 2016 (2016) 1-21. doi:10.7717/peerj.1834.

[9] J. Zhang, K.B. Storey, Cell cycle regulation in the freeze-tolerant wood frog, Rana sylvatica, Cell Cycle. 11 (2012) 1727-1742. doi:10.4161/cc.19880.

[10] P.W. Hochachka, L.T. Buck, C.J. Doll, S.C. Land, Unifying theory of hypoxia tolerance: Molecular/metabolic defense and rescue mechanisms for surviving oxygen lack, Proc. Natl. Acad. Sci. U. S. A. 93 (1996) 9493-9498. doi:10.1073/pnas.93.18.9493.

[11] C.H. Kum, M.L. Ai, F.C. Shit, K.I. Yuen, Increases in urea synthesis and the ornithineurea cycle capacity in the giant African snail, Achatina fulica, during fasting or aestivation, or after the injection with ammonium chloride, J. Exp. Zool. Part A Comp. Exp. Biol. 303 (2005) 1040-1053. doi:10.1002/jez.a.238.

[12] S. Bansal, B.E. Luu, K.B. Storey, MicroRNA regulation in heart and skeletal muscle over the freeze-thaw cycle in the freeze tolerant wood frog, J. Comp. Physiol. B Biochem. Syst. Environ. Physiol. 186 (2016) 229-241. doi:10.1007/s00360-015-0951-3.

[13] K.K. Biggar, K.B. Storey, Evidence for cell cycle suppression and microRNA regulation of cyclin D1 during anoxia exposure in turtles, Cell Cycle. 11 (2012) 1705-1713. doi: $10.4161 /$ cc. 19790.

[14] S.F. Kornfeld, K.K. Biggar, K.B. Storey, Differential expression of mature MicroRNAs involved in muscle maintenance of hibernating little brown bats, Myotis lucifugus: A model of muscle atrophy resistance, genomics, proteomics bioinforma. 10 (2012) 295- 
301. doi:10.1016/j.gpb.2012.09.001.

[15] K.K. Biggar, K.B. Storey, The emerging roles of microRNAs in the molecular responses of metabolic rate depression, J. Mol. Cell Biol. 3 (2011) 167-175.

doi:10.1093/jmcb/mjq045.

[16] C.W. Wu, K.K. Biggar, K.B. Storey, Dehydration mediated microRNA response in the African clawed frog Xenopus laevis, Gene. 529 (2013) 269-275. doi:10.1016/j.gene.2013.07.064.

[17] D.P. Bartel, MicroRNAs: Genomics, biogenesis, mechanism, and function, Cell. 116 (2004) 281-297. doi:10.1016/S0092-8674(04)00045-5.

[18] W. Filipowicz, S.N. Bhattacharyya, N. Sonenberg, Mechanisms of post-transcriptional regulation by microRNAs: Are the answers in sight?, Nat. Rev. Genet. 9 (2008) 102-114. doi:10.1038/nrg2290.

[19] N. Bley, M. Lederer, B. Pfalz, C. Reinke, T. Fuchs, M. Glaß, B. Möller, S. Hüttelmaier, Stress granules are dispensable for mRNA stabilization during cellular stress, Nucleic Acids Res. 43 (2015). doi:10.1093/nar/gku1275.

[20] A. Eulalio, I. Behm-Ansmant, E. Izaurralde, P bodies: At the crossroads of posttranscriptional pathways, Nat. Rev. Mol. Cell Biol. 8 (2007) 9-22. doi:10.1038/nrm2080.

[21] C.A. Dieni, K.B. Storey, Creatine kinase regulation by reversible phosphorylation in frog muscle, Comp. Biochem. Physiol. - B Biochem. Mol. Biol. 152 (2009) 405-412. doi:10.1016/j.cbpb.2009.01.012.

[22] C.A. Dieni, K.B. Storey, Regulation of hexokinase by reversible phosphorylation in skeletal muscle of a freeze-tolerant frog, Comp. Biochem. Physiol. - B Biochem. Mol. Biol. 159 (2011) 236-243. doi:10.1016/j.cbpb.2011.05.003.

[23] J. Abboud, K.B. Storey, Novel control of lactate dehydrogenase from the freeze tolerant wood frog: Role of posttranslational modifications, PeerJ. 2013 (2013) 1-23. doi:10.7717/peerj.12.

[24] S.R. Green, K.B. Storey, Regulation of crayfish, Orconectes virilis, tail muscle lactate dehydrogenase $(\mathrm{LDH})$ in response to anoxic conditions is associated with alterations in phosphorylation patterns, Comp. Biochem. Physiol. Part - B Biochem. Mol. Biol. 202 (2016) 67-74. doi:10.1016/j.cbpb.2016.08.004.

[25] L.J. Hawkins, M. Wang, B. Zhang, Q. Xiao, H. Wang, K.B. Storey, Glucose and urea metabolic enzymes are differentially phosphorylated during freezing, anoxia, and dehydration exposures in a freeze tolerant frog, Comp. Biochem. Physiol. - Part D Genomics Proteomics. 30 (2019) 1-13. doi:10.1016/j.cbd.2019.01.009.

[26] K.B. Storey, J.M. Storey, Molecular physiology of freeze tolerance in vertebrates, Physiol. Rev. 97 (2017) 623-665. doi:10.1152/physrev.00016.2016.

[27] R.E. Lee, J.P. Costanzo, E.C. Davidson, J.R. Layne, Dynamics of body water during freezing and thawing in a freeze-tolerant frog (Rana sylvatica), J. Therm. Biol. 17 (1992) 263-266. doi:10.1016/0306-4565(92)90064-M.

[28] R.E. Lee, J.P. Costanzo, Biological ice nucleation and ice distribution in cold-hardy ectothermic animals, Annu. Rev. Physiol. 60 (1998) 55-72. 
doi:10.1146/annurev.physiol.60.1.55.

[29] K.E. Zachariassen, E. Kristiansen, Ice nucleation and antinucleation in nature, Cryobiology. 41 (2000) 257-279. doi:10.1006/cryo.2000.2289.

[30] K.B. Storey, J.M. Storey, Freeze tolerance in animals, Physiol. Rev. 68 (1988) 27-84. doi:10.1152/physrev.1988.68.1.27.

[31] K.B. Storey, Life in a frozen state: Adaptive strategies for natural freeze tolerance in amphibians and reptiles, Am. J. Physiol. - Regul. Integr. Comp. Physiol. 258 (1990) 559568. doi:10.1152/ajpregu.1990.258.3.r559.

[32] J.M. Storey, K.B. Storey, Cold hardiness and freeze tolerance, in: Funct. Metab. Regul. Adapt., Hoboken, New Jersey: John Wiley and Sons Inc, n.d.: pp. 473-503. doi:10.1002/047167558x.ch17.

[33] K.B. Storey, Living in the cold: Freeze-induced gene responses in freese-tolerant vertebrates, Clin. Exp. Pharmacol. Physiol. 26(1) (1999) 57-63.

[34] K.B. Storey, J.M. Storey, Biochemical adaption for freezing tolerance in the wood frog, Rana sylvatica, J. Comp. Physiol. B. 155 (1984) 29-36. doi:10.1007/BF00688788.

[35] C.P. Holden, K.B. Storey, Second messenger and cAMP-dependent protein kinase responses to dehydration and anoxia stresses in frogs, J. Comp. Physiol. - B Biochem. Syst. Environ. Physiol. 167 (1997) 305-312. doi:10.1007/s003600050078.

[36] T.A. Churchill, K.B. Storey, Metabolic responses to dehydration by liver of the wood frog, Rana sylvatica, Can. J. Zool. 72 (1994) 1420-1425. doi:10.1139/z94-188.

[37] K.B. Storey, Organic solutes in freezing tolerance, Comp. Biochem. Physiol. - A Physiol. 117 (1997) 319-326. doi:10.1016/S0300-9629(96)00270-8.

[38] K. Storey, Natural freeze tolerance in ectothermic vertebrates, Annu. Rev. Physiol. 54 (1992) 619-637. doi:10.1146/annurev.physiol.54.1.619.

[39] J.P. Costanzo, R.E. Lee, P.H. Lortz, Glucose concentration regulates freeze tolerance in the wood frog Rana sylvatica., J. Exp. Biol. 181 (1993) 245-255.

[40] K.B. Storey, J.M. Storey, Freeze tolerant frogs: cryoprotectants and tissue metabolism during freeze-thaw cycles, Can. J. Zool. 64 (1986) 49-56. doi:10.1139/z86-008.

[41] J.P. Costanzo, Cryoprotection by urea in a terrestrially hibernating frog, J. Exp. Biol. 208 (2005) 4079-4089. doi:10.1242/jeb.01859.

[42] J.P. Costanzo, R.E. Lee, Urea loading enhances freezing survival and postfreeze recovery in a terrestrially hibernating frog, J. Exp. Biol. 211 (2008) 2969-2975. doi:10.1242/jeb.019695.

[43] J.P. Costanzo, A.M. Reynolds, M. Clara, F. Do Amaral, A.J. Rosendale, R.E. Lee, Cryoprotectants and extreme freeze tolerance in a subarctic population of the wood frog, PLoS One. 10 (2015) 1-23. doi:10.1371/journal.pone.0117234.

[44] J.P. Costanzo, M.C.F. Do Amaral, A.J. Rosendale, R.E. Lee, Hibernation physiology, freezing adaptation and extreme freeze tolerance in a northern population of the wood frog, J. Exp. Biol. 216 (2013) 3461-3473. doi:10.1242/jeb.089342.

[45] J.M. Storey, K.B. Storey, Oxygen limitation and metabolic rate depression, in: Funct. 
Metab. Regul. Adapt., Hoboken, New Jersey: John Wiley and Sons Inc, n.d.: pp. 415-442.

[46] K.J. Cowan, J.A. MacDonald, J.M. Storey, K.B. Storey, Metabolic reorganization and signal transduction during estivation in the spadefoot toad, Exp. Biol. Online. 5 (2000) 125. doi:10.1007/s00898-000-0001-8.

[47] P.W. Hochachka, P.L. Lutz, Mechanism, origin, and evolution of anoxia tolerance in animals, Comp. Biochem. Physiol. - B Biochem. Mol. Biol. 130 (2001) 435-459. doi:10.1016/S1096-4959(01)00408-0.

[48] A. Gupta, K.B. Storey, Regulation of antioxidant systems in response to anoxia and reoxygenation in Rana sylvatica, Comp. Biochem. Physiol. Part B. 243-244 (2020) 110436. doi:10.1016/j.cbpb.2020.110436.

[49] J.M. Storey, K.B. Storey, In defense of proteins: Chaperones respond to freezing, anoxia, or dehydration stress in tissues of freeze tolerant wood frogs, J. Exp. Zool. Part A Ecol. Integr. Physiol. 331 (2019) 392-402. doi:10.1002/jez.2306.

[50] K.B. Storey, Regulation of hypometabolism: Insights into epigenetic controls, J. Exp. Biol. 218 (2015) 150-159. doi:10.1242/jeb.106369.

[51] D.R. Joanisse, K.B. Storey, Oxidative damage and antioxidants in Rana sylvatica, the freeze-tolerant wood frog, Am. J. Physiol. - Regul. Integr. Comp. Physiol. 271 (1996). doi:10.1152/ajpregu.1996.271.3.r545.

[52] C.A. Dieni, K.B. Storey, Regulation of glucose-6-phosphate dehydrogenase by reversible phosphorylation in liver of a freeze tolerant frog, J. Comp. Physiol. B Biochem. Syst. Environ. Physiol. 180 (2010) 1133-1142. doi:10.1007/s00360-010-0487-5.

[53] D.G. Knorre, N. V Kudryashova, T.S. Godovikova, Chemical and functional aspects of posttranslational modification of proteins, Acta Naturae. 1 (2009) 29-51. doi:10.32607/actanaturae.10755.

[54] B. Lant, K.B. Storey, An overview of stress response and hypometabolic strategies in Caenorhabditis elegans: Conserved and contrasting signals with the mammalian system, Int. J. Biol. Sci. 6 (2010) 9-50. doi:10.7150/ijbs.6.9.

[55] K.B. Storey, Regulation of liver metabolism by enzyme phosphorylation during mammalian hibernation., J. Biol. Chem. 262 (1987) 1670-1673.

[56] C.L. Childers, K.B. Storey, Post-translational regulation of hexokinase function and protein stability in the aestivating frog Xenopus laevis, Protein J. 35 (2016) 61-71. doi:10.1007/s10930-016-9647-0.

[57] S.P.J. Brooks, K.B. Storey, De novo protein synthesis and protein phosphorylation during anoxia and recovery in the red-eared turtle, Am. J. Physiol. - Regul. Integr. Comp. Physiol. 265 (1993). doi:10.1152/ajpregu.1993.265.6.r1380.

[58] M. Aivaliotis, B. Macek, F. Gnad, P. Reichelt, M. Mann, D. Oesterhelt, Ser/Thr/Tyr protein phosphorylation in the archaeon Halobacterium salinarum - A representative of the third domain of life, PLoS One. 4 (2009). doi:10.1371/journal.pone.0004777.

[59] T.M. Karve, A.K. Cheema, Small changes huge impact: The role of protein posttranslational modifications in cellular homeostasis and disease, J. Amino Acids. 2011 (2011) 1-13. doi:10.4061/2011/207691. 
[60] Q. Wang, Y. Zhang, C. Yang, H. Xiong, Y. Lin, Acetylation of metabolic enzymes and metabolic Flux, Science (80-. ). 327 (2010) 1004-1007. doi:10.1126/science.1179687.

[61] K.L. Guan, Y. Xiong, Regulation of intermediary metabolism by protein acetylation, Trends Biochem. Sci. 36 (2011) 108-116. doi:10.1016/j.tibs.2010.09.003.

[62] S. Zhao, W. Xu, W. Jiang, W. Yu, Y. Lin, T. Zhang, J. Yao, L. Zhou, Y. Zeng, H. Li, Y. Li, J. Shi, W. An, S.M. Hancock, F. He, L. Qin, J. Chin, P. Yang, X. Chen, Q. Lei, K.-L. Guan, Regulation of cellular metabolism by protein lysine acetylation, (2010) 1000-1005. doi:DOI 10.1126/science.1179689.

[63] T. Zhang, S. Wang, Y. Lin, W. Xu, D. Ye, Y. Xiong, S. Zhao, K.L. Guan, Acetylation negatively regulates glycogen phosphorylase by recruiting protein phosphatase 1 , Cell Metab. 15 (2012) 75-87. doi:10.1016/j.cmet.2011.12.005.

[64] Z.J. Xiong, K.B. Storey, Regulation of liver lactate dehydrogenase by reversible phosphorylation in response to anoxia in a freshwater turtle, Comp. Biochem. Physiol. - B Biochem. Mol. Biol. 163 (2012) 221-228. doi:10.1016/j.cbpb.2012.06.001.

[65] S.R. Green, K.B. Storey, Regulation of glutamate dehydrogenase (GDH) in response to whole body freezing in wood frog liver linked to differential acetylation and ADPribosylation, Arch. Biochem. Biophys. 636 (2017) 90-99. doi:10.1016/j.abb.2017.10.010.

[66] C.A. Dieni, M.C. Bouffard, K.B. Storey, Glycogen synthase kinase-3: Cryoprotection and glycogen metabolism in the freeze-tolerant wood frog, J. Exp. Biol. 215 (2012) 543-551. doi:10.1242/jeb.065961.

[67] N.J. Dawson, B.A. Katzenback, K.B. Storey, Free-radical first responders: The characterization of $\mathrm{CuZnSOD}$ and MnSOD regulation during freezing of the freezetolerant North American wood frog, Rana sylvatica, Biochim. Biophys. Acta - Gen. Subj. 1850 (2015) 97-106. doi:10.1016/j.bbagen.2014.10.003.

[68] N.J. Dawson, K.B. Storey, A hydrogen peroxide safety valve: The reversible phosphorylation of catalase from the freeze-tolerant North American wood frog, Rana sylvatica, Biochim. Biophys. Acta - Gen. Subj. 1860 (2016) 476-485. doi:10.1016/j.bbagen.2015.12.007.

[69] C.A. Dieni, K.B. Storey, Protein kinase C in the wood frog, Rana sylvatica: Reassessing the tissue-specific regulation of PKC isozymes during freezing, PeerJ. 2014 (2014). doi: $10.7717 /$ peerj.558.

[70] K.B. Storey, Glycolysis and the regulation of cryoprotectant synthesis in liver of the freeze tolerant wood frog, (1987) 373-380. doi:10.1007/BF00693364.

[71] M.B. Smolinski, J.J.L. Mattice, K.B. Storey, Regulation of pyruvate kinase in skeletal muscle of the freeze tolerant wood frog, Rana sylvatica, Cryobiology. 77 (2017) 25-33. doi:10.1016/j.cryobiol.2017.06.002.

[72] K.J. Cowan, K.B. Storey, Freeze-thaw effects on metabolic enzymes in wood frog organs, Cryobiology. 43 (2001) 32-45. doi:10.1006/cryo.2001.2338.

[73] K.B. Storey, Organ-specific metabolism during freezing and thawing in a freeze-tolerant frog, Am. J. Physiol. - Regul. Integr. Comp. Physiol. 253 (1987) 292-297.

doi:10.1152/ajpregu.1987.253.2.r292. 
[74] M.D. Vazquez Illanes, K.B. Storey, 6-Phosphofructo-2-kinase and control of cryoprotectant synthesis in freeze tolerant frogs, BBA - Gen. Subj. 1158 (1993) 29-32. doi:10.1016/0304-4165(93)90092-M.

[75] S.C. Greenway, K.B. Storey, Effects of seasonal change and prolonged anoxia on metabolic enzymes of Littorina littorea, Can. J. Zool. 79 (2001) 907-915. doi:10.1139/cjz-79-5-907.

[76] R. Whitwam, K. Storey, Regulation of phosphofructokinase during estivation and anoxia in the land snail, Otala lactea, Comp. Biol. (1991).

[77] B. Storey, Fructose 2,6-bisphosphate and anaerobic metabolism in marine molluscs, 181 (1985) 245-248.

[78] L. Hue, M.H. Rider, Role of fructose 2,6-bisphosphate in the control of glycolysis in mammalian tissues, 245 (1987) 313-324.

[79] M.B. Smolinski, Regulation of pyruvate kinase in hypometabolic states, Carleton University, 2016.

[80] K.J. Cowan, K.B. Storey, Reversible phosphorylation control of skeletal muscle pyruvate kinase and phosphofructokinase during estivation in the spadefoot toad, Scaphiopus couchii, Mol. Cell. Biochem. 195 (1999) 173-181. doi:10.1023/A:1006932221288.

[81] S.C. Greenway, K.B. Storey, Seasonal change and prolonged anoxia affect the kinetic properties of phosphofructokinase and pyruvate kinase in oysters, J. Comp. Physiol. - B Biochem. Syst. Environ. Physiol. 170 (2000) 285-293. doi:10.1007/s003600000098.

[82] S.R. Green, K.B. Storey, Purification of carbamoyl phosphate synthetase 1 (CPS1) from wood frog (Rana sylvatica) liver and its regulation in response to ice-nucleation and subsequent whole-body freezing, Mol. Cell. Biochem. 455 (2019) 29-39. doi:10.1007/s11010-018-3468-8.

[83] T.M. Schiller, J.P. Costanzo, R.E. Lee, Urea production capacity in the wood frog (Rana sylvatica) varies with season and experimentally induced hyperuremia, J. Exp. Zool. Part A Ecol. Genet. Physiol. 309 (2008) 484-493. doi:10.1002/jez.479.

[84] S.R. Green, Regulation of urea cycle related enzymes in response to freezing in the wood Frog, Rana sylvatica, Carleton University, 2017.

[85] A.R. Lee, M. Silove, U. Katz, J.B. Balinsky, Urea cycle enzymes and glutamate dehydrogenase in Xenopus laevis and Bufo viridis adapted to high salinity, J. Exp. Zool. 221 (1982) 169-172. doi:10.1002/jez.1402210207. 


\section{Chapter 2}

\section{Glutamate dehydrogenase}




\title{
Insight into the regulation of liver glutamate dehydrogenase during dehydration and anoxia exposure
}

\author{
Ranim Saleem and Kenneth B. Storey*
}

Institute of Biochemistry \& Department of Biology, Carleton University, 1125 Colonel By Drive, Ottawa, K1S 5B6 Ontario, Canada 


\begin{abstract}
Glutamate dehydrogenase (GDH) plays a crucial role in metabolism by linking amino acid and carbohydrate metabolism in cells and mediating the production of ammonium ion for urea biosynthesis. The present study analyzed the regulation of GDH from liver of wood frogs, Rana sylvatica, a species that employs freeze tolerance as a winter survival strategy. During freezing, wood frogs experience cellular dehydration due to water withdrawn into extracellular ice formation, as well as anoxia due to interruption in blood flow. GDH was purified from control $\left(5^{\circ} \mathrm{C}\right), 40 \%$ dehydrated, and $24 \mathrm{~h}$ anoxia-exposed male wood frogs. Purification involved a two-step column chromatography procedure using a Cibacron blue affinity column and a GTPagarose affinity column. Analysis of kinetic properties revealed significant stress-responsive changes in $\mathrm{K}_{\mathrm{m}}$ values for glutamate and $\mathrm{NAD}^{+}$, alpha-ketoglutaric acid and ammonium ion, $\mathrm{V}_{\max }$ values, $\mathrm{K}_{\mathrm{a}}$ values for ADP (a GDH activator), and inhibition by urea between control and stressed conditions. Thermal denaturation of GDH was assessed by differential scanning fluorimetry and revealed that GDH from dehydrated frogs was significantly less stable than controls. However, the effect of additives such as urea significantly stabilized the enzyme in that condition. Immunoblot analysis of posttranslational modifications to GDH showed differential modifications of liver GDH in response to dehydration (serine phosphorylation, acetylation and ADP-ribosylation) and anoxia (serine phosphorylation) that could adapt enzyme responses under these diverse stresses. These results indicate that GDH plays a key role in energy metabolism to aid the survival of wood frogs under stress.

Key words: Glutamate dehydrogenase, carbohydrate metabolism, Rana sylvatica, posttranslational modifications, Dehydration, Anoxia
\end{abstract}




\subsection{Introduction}

Many animals must find a way to survive harsh conditions like major changes in environmental parameters (temperature or salinity) or drastic decrease in resources available (food, water, and sufficient amount of oxygen). To survive under these conditions, animals have developed a range of physiological and biochemical adaptations. For example, the wood frogs employ freeze tolerance as a survival strategy to withstand harsh winter conditions [1,2]. Freeze tolerance is an extreme winter survival strategy that has been extensively investigated in multiple species including insects, nematodes, some molluscs, reptiles (turtles \& snakes) and amphibians (frogs \& salamanders) [1]. One of the most beneficial adaptations that aid freeze tolerant animals is metabolic rate depression (MRD), a strategy that lowers cell ATP demand by reducing the activity of most ATP-expensive or harmful cellular processes (cell cycle, proliferation, apoptosis,) and allocating limited fuel/energy supplies only for pro-survival pathways [3-5]. Such processes include antioxidant defenses, anti-apoptosis, and chaperone proteins $[1,2,4,6]$.

The best-studied freeze-tolerant amphibian is the North American wood frog, Rana sylvatica. These frogs display one of the highest freeze tolerance capacities in the animal kingdom by enduring the freezing of $65-70 \%$ of their total body water as extracellular and extraorgan ice masses $[1,7,8]$. Freezing is associated with the reduction of various vital physiological functions such as breathing, heartbeat, muscle movement and brain activity [1,7]. As one consequence of freezing, the cells of wood frogs also need to cope with severe dehydration due to the loss of water from cells, and prolonged periods of anoxia due to the freezing of blood plasma which would interrupt oxygen delivery to organs $[1,2,9,10]$. Indeed, in the absence of freezing, wood frogs can endure dehydration up to $\sim 60 \%$ of total body water lost, and survive anoxia exposures of at least $48 \mathrm{H}$ under a $\mathrm{N}_{2}$ gas atmosphere at $5^{\circ} \mathrm{C}[1,10]$. Freezing and 
dehydration also impose mechanical challenges to cell membrane that could lead to membrane rupture or breakdown of the lipid bilayer. As such, wood frogs have developed several adaptations to deal with these challenges, including the production of high amounts of glucose to be used as a protectant during freezing or dehydration [1,11-13]. For example, liver glucose content increases 3.8-fold in response to dehydration, and blood glucose levels can rise from 5 $\mathrm{mM}$ to $300 \mathrm{mM}$ in response to freezing [1,9]. In addition, urea has been experimentally shown to be an important metabolite that contributes to cryoprotection in Rana sylvatica to help protect cells from freeze/thaw or dehydration injury [13-18]. Anoxic exposure is not environmentally relevant to the wood frogs, but since its one of the stressors that is associated with freezing, it is important to investigated whether wood frogs also regulate their metabolism under anoxia in a similar manner as during dehydration or freezing. Anoxic frogs do not experience interruption of blood flow show no significant accumulation of cryoprotective agents [1]. As cells become anoxic, they switch from aerobic metabolism via the tricarboxylic acid cycle (TCA) and the electron transport chain (ETC) to anaerobic metabolism with a heavy reliance on anaerobic glycolysis [1]. Under these conditions, ATP production decreases, thereby forcing cells to enter a hypometabolic state [1]. Therefore, suppression of energy expensive processes while prioritizing available ATP for pro- survival processes is necessary for enduring long periods of anoxia.

Glutamate dehydrogenase (GDH; E.C. 1.4.1.3) is a key enzyme that contributes to multiple metabolic processes. It is present in the mitochondrial matrix that and catalyzes the reversible conversion of L-glutamate to $\alpha$-ketoglutaric acid ( $\alpha-\mathrm{KG})$ and ammonium ion while reducing $\mathrm{NAD}^{+}$or $\mathrm{NADP}^{+}[19]$. In the oxidative deamination direction (denoted as the forward reaction), GDH is the entry point for carbon skeletons derived from the catabolism of from the various amino acids (glutamate, glutamine, arginine, histidine and proline) into the Krebs cycle, 
contributing into the increase in energy production and the generation of mitochondrial ammonium ions needed for the synthesis of urea through the urea cycle [20]. In the opposite direction, GDH produces L-glutamate, that is subsequently a key substrate for transamination reactions to synthesize other amino acids [20]. Thus, the role of GDH in many cellular processes indicates the need for its strict regulation. It is well known that GDH is regulated by multiple allosteric modifiers including nucleotides (ATP, ADP, AMP, GTP), where ADP is an allosteric activator and ATP/GTP act as inhibitors to reduce the flux into the Krebs cycle [21-23]. Posttranslational modification (PTM) represents an energy inexpensive mechanism by which enzymes can be regulated based on environmental conditions. This enzyme modification controls their form and function in the presence of denaturants or other stressors and modulates their substrate binding capacity under such conditions [24]. GDH has shown to be modified by posttranslational modifications in multiple different organism ranging from bacteria and yeast, to snails, turtles, and ground squirrels, among others [25-29]. It was recently shown that GDH can be regulated by acetylation and ADP-ribosylation in the liver of freeze tolerant wood frogs responding to $24 \mathrm{~h}$ freeze exposure [30]. Given the importance of GDH in carbohydrate and nitrogen metabolism as well as in amino acid catabolism, this raised our interest to see how this multifunctional enzyme is regulated in response to anoxia and dehydration exposures.

A readjustment of energy use is one of the key strategies employed to support the survival of the wood frog in response of severe dehydration and anoxia. This led us to investigate the regulation of liver GDH, an enzyme that is pivotal to carbohydrate, amino acid and nitrogen metabolism. It was hypothesized that GDH from liver of dehydrated frogs may contribute to the overall suppression of metabolic rates and to the reorganization energy metabolism to promote glutamate oxidization as another substrate for cellular energy metabolism besides glycolysis. In 
addition, GDH would also provide the ammonium ion needed for the production of urea, which is a key osmolyte aiding cell water retention under dehydrating or freezing conditions $[15,17]$. However, the inhibition of aerobic metabolism (TCA cycle and ETC) under anoxia led us to hypothesize that there is a suppression in liver GDH activity in anoxic wood frogs. A previous study of GDH from wood frog liver showed a reduction of $\mathrm{K}_{\mathrm{m}}$ values for substrates in both directions as well as a reduction in acetylation and ADP-ribosylation in response to whole body

freezing [30]. This suggested that GDH in liver of frozen frogs was regulated by acetylation and ADP-ribosylation in order to favour glutamate catabolism to support urea synthesis. The present study revealed that GDH isolated from liver of control, dehydrated and anoxic wood frogs had significantly different properties that were potentially caused by differences in the covalent modification of the enzyme, including protein acetylation, ADP-ribosylation and phosphorylation.

\subsection{Methods}

\subsubsection{Animals and experimental procedures}

Adult male wood frogs were captured from spring breeding ponds in the Ottawa area. Prior to experimentation, all frogs were washed in a tetracycline bath and then placed in plastic containers lined with a damp sphagnum moss for two weeks at $5{ }^{\circ} \mathrm{C}$ to acclimate. The control group was randomly selected and sampled from this condition.

The dehydration exposure experiments were conducted as previously published [9]. Briefly, acclimated frogs were individually weighed and then placed in open plastic containers on ice ( 4 frogs per container). Containers were then placed in incubators set at $5^{\circ} \mathrm{C}$, where animals were allowed to lose body water via evaporation. Frogs were weighed at intervals to monitor dehydration. The amount of body water lost was calculated using the following equation 
$\left(\mathrm{M}_{\mathrm{i}}-\mathrm{M}_{\mathrm{d}}\right) /\left(\mathrm{M}_{\mathrm{i}} \mathrm{x} \% \mathrm{H}_{2} \mathrm{O}\right)$, where $\mathrm{M}_{\mathrm{i}}$ is the initial mass of the animal, $\mathrm{M}_{\mathrm{d}}$ is the mass at a given weighing and $\% \mathrm{H}_{2} \mathrm{O}$ is the percentage of total body mass of hydrated control frogs that is water $(80.8+1.2 \%)$. Experimental dehydration was continued until frogs reached $40 \%$ of total body water lost when animals were sampled.

Anoxia exposure experiments followed a previously established protocol [31]. Frogs were placed in plastic chambers that were fitted with a single layer of damp paper towel on the bottom (previously wetted with water that had been bubbled with $100 \% \mathrm{~N}_{2}$ gas for $\sim 15 \mathrm{~min}$ ) in order to prevent dehydration. The chambers had two ports in the lid, one allowing nitrogen gas to enter and the other one to vent the gas out. The containers were flushed with nitrogen gas for $\sim 20$ min and then frogs (4-5 animals) were quickly added to the jars and lids were closed and sealed with parafilm. Nitrogen gas was flushed for another $\sim 30 \mathrm{~min}$ and then ports were closed, and chambers were placed back in the $5^{\circ} \mathrm{C}$ incubator for $24 \mathrm{~h}$. After this time, containers were reconnected to the nitrogen gas lines while held on ice and anoxic frogs were quickly sampled.

In all cases, frogs were euthanized via pithing and tissues were rapidly dissected, flash frozen in liquid nitrogen and transferred to an ultralow freezer for storage. All animal procedures had the prior approval of the Carleton University Animal Care Committee (protocol \#106935) in accordance with guidance set out by the Canadian Council on Animal Care.

\subsubsection{Preparation of Liver Extracts}

Frozen liver samples from control, anoxic or dehydrated conditions were quickly weighed and homogenized in 1:5 w:v in ice-cold buffer A (25 mM HEPES buffer pH 7.5, 10 $\mathrm{mM} \beta$-mercaptoethanol, 10\% v:v glycerol, $25 \mathrm{mM} \beta$-glycerophosphate (Sigma, Cat. No. G9422), 1 mM EDTA (Sigma, Cat. No. 2854), 2 mM EGTA (Sigma, Cat. No. 324626)) and a few crystals of phenylmethylsulfonyl fluoride (PMSF) (Bioshop, Cat. No. PMS444). Samples 
were then centrifuged in an Eppendorf 5810R for $30 \mathrm{~min}$ at $13,500 \mathrm{x}$ g at $4{ }^{\circ} \mathrm{C}$. The supernatant was removed and held on ice until purification columns were prepared.

\subsubsection{Enzyme Assay}

Standard conditions for the forward reaction of GDH (glutamate-oxidizing direction) were $50 \mathrm{mM}$ HEPES buffer at $\mathrm{pH} 8.0$ with $40 \mathrm{mM}$ glutamate and $4 \mathrm{mM} \mathrm{NAD}{ }^{+}$. These conditions were experimentally determined to be sufficient to obtain maximal velocity of the enzymatic reaction. The reverse reaction ( $\alpha$-KG-reducing direction) was assayed using $50 \mathrm{mM}$ HEPES buffer at pH 7.2 in the presence of $0.2 \mathrm{mM}$ NADH, $0.8 \mathrm{mM} \alpha-\mathrm{KG}$, and $240 \mathrm{mM}$ ammonium chloride $\left(\mathrm{NH}_{4} \mathrm{Cl}\right)$. Assays were performed at $22^{\circ} \mathrm{C}$. The absorbance of individual wells was read every 21 seconds for 40 times at $340 \mathrm{~nm}$ using a Thermo Scientific Multiskan Spectrum microplate reader.

\subsubsection{Enzyme Purification}

A Cibacron Blue affinity column was prepared (Bioworld, Cat. No. 20181096-1) and equilibrated with $15 \mathrm{~mL}$ of buffer $\mathrm{A}$ at $\mathrm{pH}$ 7.5. Crude extract was loaded onto the column and washed with $25 \mathrm{~mL}$ buffer A in order to elute any unbound proteins. GDH was then eluted with $30 \mathrm{~mL}$ of linear salt gradient of $0-2 \mathrm{M}$ potassium chloride $(\mathrm{KCl})$ prepared in buffer $\mathrm{A}$. The activity of GDH was measured in the glutamate-oxidizing direction and the top 6 fractions containing GDH activity were pooled and desalted using an Amicon Ultra-4 centrifugal filter 10K (Sigma-Aldrich, 10,000 MWCO). The sample was then centrifuged in a Sorvall RC-58 for $15 \mathrm{~min}$ at $8,000 \mathrm{xg}$ at $4^{\circ} \mathrm{C}$. The volume was recorded and brought back to its original volume by addition of buffer $\mathrm{A}$. 
A GTP-agarose affinity column (Sigma Chemical Co.) was prepared and equilibrated by running through $15 \mathrm{~mL}$ of buffer $\mathrm{A}$ at $\mathrm{pH}$ 7.5. The enzyme sample was then loaded onto the column, followed by a $25 \mathrm{~mL}$ wash with buffer A to remove unbound proteins. GDH was eluted from the column using $30 \mathrm{~mL}$ of a linear salt gradient of $0-2 \mathrm{M} \mathrm{KCl}$ prepared in buffer $\mathrm{A}$. The top 3 fractions containing GDH activity were collected.

Protein concentrations of samples were determined using the Bradford method with the BioRad prepared reagent (Cat. No. 50000006) with bovine serum albumin as the protein standard. Sample absorbance was read at $595 \mathrm{~nm}$ using a BioTek microplate reader.

\subsubsection{Gel electrophoresis and staining}

GDH purity was assessed via SDS-PAGE (sodium dodecyl sulfate-polyacrylamide gel electrophoresis). Enzyme samples were mixed 1:1 v:v with SDS loading buffer (100 mM Tris buffer, pH 6.8, 4\% w:v SDS, 20\% v:v glycerol, $0.2 \% \mathrm{w}: \mathrm{v}$ bromophenol blue, and 10\% v:v $\beta$ mercaptoethanol) and were boiled for 5 min before being stored at $-20{ }^{\circ} \mathrm{C}$ until use. Purified GDH samples were loaded onto gels (10\% resolving gel, 5\% stacking gel) and run at $180 \mathrm{~V}$ for $55 \mathrm{~min}$ in running buffer ( $25 \mathrm{mM}$ Tris-base, $250 \mathrm{mM}$ glycine, and $0.1 \% \mathrm{SDS}$ ). A protein molecular weight ladder (Froggabio, Cat. No. PM005-0500) and a commercially purified sample of bovine liver GDH (Sigma, Cat. No. G2626) were also run on the gel along with the samples. Once appropriate separation was reached, gels were stained with Coomassie Brilliant Blue (0.25\% w:v Coomassie brilliant blue, $7.5 \% \mathrm{v}: \mathrm{v}$ acetic acid, $50 \%$ methanol) for $30 \mathrm{~min}$ and then destained using Coomassie destain solution (10\% acetic acid, $15 \%$ methanol). Gels were visualized under light and images were captured using the ChemiGenius BioImaging system (Syngene, Frederick, MD). 


\subsubsection{Kinetic parameters}

The $\mathrm{K}_{\mathrm{m}}$ values for different substrates were determined by varying the substrate concentration while keeping co-substrate concentration(s) constant at optimal levels. $\mathrm{K}_{\mathrm{m}}$ values for forward glutamate, $\left.\mathrm{NAD}^{+}\right)$and reverse $\left(\alpha-\mathrm{KG}\right.$ and $\left.\mathrm{NH}_{4}^{+}\right)$directions were determined at 22 ${ }^{\circ} \mathrm{C}$. The inhibitor concentration for urea that reduced enzyme activity by $50 \%$ ( $\mathrm{I}_{50}$ values) were determined by increasing urea concentrations under optimal substrate conditions in the forward direction at $22{ }^{\circ} \mathrm{C}$. The activator constant $\left(\mathrm{K}_{\mathrm{a}}\right)$ values for ADP was determined by varying ADP concentrations under optimal substrate conditions in the forward direction at $22{ }^{\circ} \mathrm{C}$. The maximal rate $\left(\mathrm{V}_{\max }\right)$ of GDH is presented as units/mg of soluble purified protein. The $\mathrm{V}_{\max }$ was determined in both directions by measuring the activity at optimal substrate concentration as well as in the presence of $0.5 \mathrm{mM}$ ADP. The effects of ADP, urea and glucose on enzyme affinity for glutamate, $\mathrm{NAD}^{+}, \alpha-\mathrm{KG}$ and $\mathrm{NH}_{4}{ }^{+}$were analyzed at a constant concentration of the metabolites (0.5 mM ADP, $100 \mathrm{mM}$ urea and $400 \mathrm{mM}$ glucose) while varying substrate concentrations. Data were processed using an enzyme kinetic analysis program, Kinetics v.3.5.1 [32].

\subsubsection{Western blots analysis of post-translational modifications}

In order to assess the putative control of GDH via PTMs, western blot analysis using purified GDH was used with antibodies that detected different PTMs. Samples of purified GDH were prepared as described for gel electrophoresis and staining. All samples of purified liver GDH used for western blots were standardized to a constant protein concentration. The western blotting procedure was as described previously [33]. Purified samples were loaded on 10\% polyacrylamide gels at $180 \mathrm{~V}$ for $55 \mathrm{~min}$. Following electrophoresis, protein was transferred to polyvinylidene fluoride (PVDF) membranes at $160 \mathrm{~mA}$ for $90 \mathrm{~min}$ using transfer buffer (25 mM Tris, $\mathrm{pH} 8.5,192 \mathrm{mM}$ glycine and 10\% v/v methanol). Membranes were then blocked with $2.5 \%$ 
non-fat dried milk in Tris-buffered saline containing Tween-20 (TBST: $20 \mathrm{mM}$ Tris base, $\mathrm{pH}$ 7.6, $140 \mathrm{mM} \mathrm{NaCl}, 0.05 \% \mathrm{v} / \mathrm{v}$ Tween-20) for $20 \mathrm{~min}$ and then washed $3 \mathrm{x}$ for $5 \mathrm{~min}$ with TBST. Membranes were incubated overnight at $4{ }^{\circ} \mathrm{C}$ with different primary antibodies. The primary antibodies used in this study were anti-rabbit except for phospho-tyrosine which was anti-mouse. Antibodies were diluted 1:1,000 (v:v) in TBST and were as follows: anti-phosphorylated tyrosine (Cell signaling, \# 9441), anti-phosphorylated serine (Abcam, \# ab9332), antiphosphorylated threonine (Invitrogen, \#718200), anti tri-methylated lysine (StressMarq, \# SPC158), anti nitrosylated cysteine (Abcam, \# ab50185), anti- pan acetylated (Santa Cruz Biotechnology, \# SC-8663), and anti-glutamate dehydrogenase (GeneTex, GTX105765). In addition, ADP-ribose binding reagent conjugated to the Fc portion of rabbit IgG (EMD Millipore, MABE1016) was used to probe the protein for mono- and poly-ADP ribosylation in the same manner as for a primary antibody.

After incubation, unbound primary antibody was removed and membranes were washed $3 \mathrm{x}$ for $5 \mathrm{~min}$ with TBST before being incubated with secondary antibody, either horseradish peroxidase conjugated anti-rabbit IgG or anti-mouse IgG (BioShop, diluted 1:8,000 v:v in TBST) for $30 \mathrm{~min}$ at room temperature with gentle rocking. To remove unbound secondary antibody, membranes were washed with TBST for $3 \times 5 \mathrm{~min}$. An enhanced chemiluminescence protocol was used to visualize PTM signal strength where the luminol and oxidizing reagent (hydrogen peroxide) were mixed in 1:1 v:v and the enhanced chemiluminescence (ECL) signal was detected via a ChemiGenius Bioimaging system (Syngene, Frederick, MD). Blots were then stained with Coomassie blue and GDH bands were reimaged. PTM and GDH immuno-band intensities from the enhanced chemiluminescent membranes were then standardized again, the Coomassie-stained band intensity of the same membrane being used to correct for any minor 
discrepancy in sample loading. GeneTools software was used to determine the relative signal intensities and data are reported relative to controls which set to 1 .

\subsubsection{Differential scanning fluorometry}

Differential scanning fluorimetry (DSF) is a method used to monitor the thermal unfolding of proteins in the presence of a fluorescent dye (SYPRO orange) [34]. The technique uses a real-time PCR machine in order to measure the melting point of a protein [35]. Purified GDH was mixed with the fluorescent dye resulting in a fluorescence signal when bound to an exposed hydrophobic residue of a denatured protein [35]. Changes in fluorescence are monitored as the sample is heated at a constant rate from $22{ }^{\circ} \mathrm{C}$ to $95^{\circ} \mathrm{C}$. The protocol was followed as previously published [36]. Purified GDH $(0.06 \mathrm{mg} / \mathrm{mL})$, DSF buffer $(100 \mathrm{mM}$ potassium phosphate, $\mathrm{pH} 7.0,150 \mathrm{mM} \mathrm{NaCl}$ ) and 40X SYPRO orange dye with a final concentration of $5 \mathrm{X}$ per well were mixed in a $20 \mu \mathrm{L}$ final volume in the microplate wells. The plates were sealed and placed in a Bio-Rad CFX Connect ${ }^{\mathrm{TM}}$ Real-Time PCR Detection System (Bio-Rad, Cat. No. 1855201) and SYPRO orange fluorescence was measured at excitation $490 \pm 20 \mathrm{~nm}$ and emission of $625 \pm 30 \mathrm{~nm}$ wavelengths. The thermal stability of GDH was also examined by the addition of $100 \mathrm{mM}$ urea (prepared in DSF buffer) in order to test the effect of urea on enzyme thermal stability. The increase in fluorescence was modeled by using Boltzmann distribution curve via OriginPro 8.5 .

\subsubsection{Data and Statistical Analysis}

Enzyme activities were analysed using a Microplate Analysis (MPA) program, and kinetic parameters were determined using a nonlinear least square regression program, Kinetics v.3.5.1, modelled to the Hill equation $(h>0)$ to determine $\mathrm{K}_{\mathrm{m}}$ and $\mathrm{I}_{50}$ values [32]. Standardization 
of protein concentrations for western blots was accomplished by quantifying the GDH band from the purified protein samples using Coomassie stain on PVDF membrane after transfer from an SDS-PAGE gel. The data are expressed as mean \pm SEM from independent determinations on separate enzyme preparations $(n \geq 4)$. Graphing and statistical testing used RBioplot with twotailed Student's t-tests accounting for unequal variance $(p<0.05)$ [37]. The difference between

the $\mathrm{K}_{\mathrm{m}}$ determined in the presence of either $0.5 \mathrm{mM}$ ADP, $100 \mathrm{mM}$ urea or $400 \mathrm{mM}$ glucose and respective standard assay conditions for one of the animal treatments determined by one-way ANOVA followed by Dunnett's post hoc test $(p<0.05)$, while the difference between the control and its corresponding treatment in the stress group were analyzed using a two-tailed Student's ttests accounting for unequal variance $(p<0.05)$ [37].

\subsection{Results}

\subsubsection{Enzyme purification}

GDH from wood frog liver was purified to homogeneity using a two-step chromatographic process. The typical scheme for the purification is summarised in Table 2.1. The first step in the purification was affinity chromatography on Cibacron blue where GDH was eluted with a gradient of 0-2 $\mathrm{M} \mathrm{KCl}$. This gradient was effective at removing impurities and resulted in a 5.3-fold purification with $84.7 \%$ recovered activity. The fractions containing GDH activity were pooled and desalted by centrifugation using an Amicon Ultra-4 filter centrifugal filter $10 \mathrm{~K}$. The second column step depended on the binding of GDH to GTP agarose where the enzyme was eluted with a $0-2 \mathrm{M} \mathrm{KCl}$ gradient, a range that was very effective in removing the rest of the impurities. The second step resulted in a 12.0-fold purification with approximately $95.0 \%$ activity retained. The full procedure yielded $81.4 \%$ of the enzymatic activity and a 64.3 fold purification with a final specific activity at $1.93 \mathrm{U} / \mathrm{mg}$ protein. GDH from liver of anoxic 
and dehydrated wood frogs was purified with the same scheme (supplementary information; Table S1). SDS-PAGE analysis was used to determine the purity of the samples followed by Coomassie brilliant blue staining. The GDH band from all conditions was found at $\sim 62 \mathrm{KDa}$ based on electrophoretic mobility compared to a commercial GDH standard (Fig.2.1)

\subsubsection{Enzyme kinetics}

The purified GDH from control, dehydrated and anoxic frogs was used to analyze enzymatic parameters in the forward and reverse directions (Table 2.2). Under standard assay conditions at $22{ }^{\circ} \mathrm{C}$, the $\mathrm{K}_{\mathrm{m}}$ of glutamate in the dehydrated group $(1.26 \mathrm{mM})$ was significantly lower than for controls $(2.06 \mathrm{mM}) . \mathrm{K}_{\mathrm{m}}$ glutamate $(2.65 \mathrm{mM})$ for the enzyme from anoxic frogs did not change significantly compared with controls but an increase in the $\mathrm{K}_{\mathrm{m}}$ of $\mathrm{NAD}^{+}(2.91$ $\mathrm{mM}$ ) under anoxia was significantly different compared to controls (2.06 mM) (Table 2.2). The $\alpha-K G$ consuming direction also showed some differences between control and the dehydration or anoxia treatments. The affinity for ammonium ion for GDH from control and dehydrated conditions was significantly different with the dehydrated group showing a lower $\mathrm{K}_{\mathrm{m}}$ than the control group (10.8 $\mathrm{mM}$ versus $16.3 \mathrm{mM})$. The affinity for ammonium ion of anoxic GDH was significantly lower with a $\mathrm{K}_{\mathrm{m}}$ of $35.2 \mathrm{mM}$ compared with control $(16.3 \mathrm{mM})$.

In the forward direction the maximal activity was measured with GDH from liver of dehydrated frogs showing a significantly greater value than the control $(9.69 \mathrm{U} / \mathrm{mg}$ compared to $3.53 \mathrm{U} / \mathrm{mg}$ for control) (Table 2.2). However, enzyme activity from anoxic frogs was significantly lower than the control at $1.60 \mathrm{U} / \mathrm{mg}$ (Table 2.2). In the reverse reaction, the activity of the anoxic enzyme increased compared to control, with the anoxic GDH being $9.22 \mathrm{U} / \mathrm{mg}$ compared to the control value of $6.57 \mathrm{U} / \mathrm{mg}$ (Table 2.2). ADP is known to be an activator for GDH activity and so the maximal activity was also measured in the presence of $0.5 \mathrm{mM}$ ADP in 
both directions (Table 2.2). There was similar trend for maximal activity in the forward reaction where dehydrated GDH (14.9 U/mg) increased and anoxic GDH (1.45 U/mg) decreased compares to control $(5.86 \mathrm{U} / \mathrm{mg})$. Furthermore, the maximal activity for control and dehydrated enzyme was significantly higher in the presence of ADP compared to control or the dehydrated enzyme without ADP (Table 2.2; denoted by ${ }^{a}$ ). The reverse reaction demonstrated a significant decrease in dehydrated GDH maximal activity compared to control in the presence of $0.5 \mathrm{mM}$ ADP (Table 2.2). In addition, dehydrated GDH maximal activity increase significantly in the presence of ADP where, GDH activity in presence of ADP was $6.68 \mathrm{U} / \mathrm{mg}$ and dehydrated GDH without ADP was $5.38 \mathrm{U} / \mathrm{mg}$ (Table 2.2; denoted by ${ }^{a}$ ).

The $\mathrm{K}_{\mathrm{a}}$ is the concentration of activator that causes a half maximal increase in enzymatic activity. In this study, the $\mathrm{K}_{\mathrm{a}}$ value for $\mathrm{ADP}$ was examined in the forward direction to assess the strength of the activator on GDH. There was no significant different between the control and dehydrated GDH for $\mathrm{K}_{\mathrm{a}} \mathrm{ADP}$ (Table 2.2). However, the $\mathrm{K}_{\mathrm{a}}$ value for ADP from anoxia treatment $(0.29 \mathrm{mM})$ was significantly higher than the control group (0.11 mM; Table 2.2$)$.

The effect of ADP on GDH affinity for glutamate, $\mathrm{NAD}^{+}, \alpha-\mathrm{KG}$ and $\mathrm{NH}_{4}{ }^{+}$were also investigated in response to dehydration (Fig. 2.2) and anoxia treatments (Fig. 2.3). For the dehydration treatment, there was no significant change in the $\mathrm{K}_{\mathrm{m}}$ for glutamate (Fig. 2.2A), $\mathrm{K}_{\mathrm{m}}$ for $\mathrm{NAD}^{+}$(Fig. 2.2B), $\mathrm{K}_{\mathrm{m}}$ for alpha-ketoglutarate (Fig. 2.2C) or $\mathrm{Km}_{\text {for }} \mathrm{NH}_{4}^{+}$(Fig. 2.2D) in comparison to control group in the presence of ADP. The addition of ADP increased the glutamate $\mathrm{K}_{\mathrm{m}}$ for dehydration group compared to the standard condition (2.39 $\mathrm{mM}$ compared to $1.26 \mathrm{mM}$; Fig. 2.2A) but decreased the $\mathrm{K}_{\mathrm{m}}$ for $\mathrm{NAD}^{+}$compared to the standard condition ( 0.38 $\mathrm{mM}$ versus $0.83 \mathrm{mM}$; Fig. 2.2B). For anoxia treatment, $\mathrm{K}_{\mathrm{m}}$ for $\mathrm{NAD}^{+}(0.40 \mathrm{mM})$ was significantly lower compared to the standard value $(2.91 \mathrm{mM})$ and no significant change was 
noted compared to the control (Fig. 2.3B). However, the addition of $0.5 \mathrm{mM}$ ADP increased alpha-ketoglutarate $\mathrm{K}_{\mathrm{m}}$ for the anoxia GDH by 1.10-fold relative to the standard condition $(0.21$ $\mathrm{mM}$ compared to $0.19 \mathrm{mM}$; Fig. 2.3C). Finally, the control and anoxia group displayed lower $\mathrm{K}_{\mathrm{m}}$ for $\mathrm{NH}_{4}{ }^{+}$compared to the standard values for both control and anoxia group (Fig. 2.3D).

The effects of urea on the affinity of GDH for its substrate were also examined (Fig. 2.2\&2.3). The results showed a significant increase in the $\mathrm{K}_{\mathrm{m}}$ for glutamate for the dehydration group compared to the control group (Fig. 2.2A). However, the addition of urea lowered the $\mathrm{K}_{\mathrm{m}}$ for glutamate for the control GDH ( $0.87 \mathrm{mM}$ versus $2.06 \mathrm{mM}$ under standard conditions), but not for the dehydration group (Fig. 2.2A). Both forms of GDH (control and dehydration) appeared to have higher $\mathrm{K}_{\mathrm{m}}$ values for $\mathrm{NAD}^{+}$in the presence of $100 \mathrm{mM}$ urea relative to their standard conditions as well; $\mathrm{K}_{\mathrm{m}}$ for $\mathrm{NAD}^{+}$for dehydration group displayed a significant increase compared to control group (Fig. 2.2B). Anoxic GDH had higher $\mathrm{K}_{\mathrm{m}}$ values for glutamate compared to control, with the anoxia value being $2.54 \mathrm{mM}$ compared to the control value of 0.87 $\mathrm{mM}$ (Fig. 2.3A). Similar trends were shown for the $\mathrm{K}_{\mathrm{m}}$ for $\mathrm{NAD}^{+}$whereas the anoxic $\mathrm{K}_{\mathrm{m}}$ value was $3.49 \mathrm{mM}$ and the control $\mathrm{K}_{\mathrm{m}}$ value was $2.39 \mathrm{mM}$ (Fig. 2.3B). In the forward direction, urea lowered the $\mathrm{I}_{50}$ values for dehydrated and anoxia treated groups compare to control, with the control value being $0.73 \mathrm{M}$, dehydrated being $0.66 \mathrm{M}$ and anoxia $0.62 \mathrm{M}$ (Table 2.2). The effect of urea was also investigated in the reverse direction of the reaction. The $\mathrm{K}_{\mathrm{m}}$ alpha-ketoglutarate for dehydration $(0.25 \mathrm{mM})$ increased relative to standard condition $(0.17 \mathrm{mM}$; Fig.2C), but decreased for anoxia $(0.16 \mathrm{mM})$ compared to standard condition ( $0.19 \mathrm{mM}$; Fig. $2.3 \mathrm{C})$. The control and anoxic form of GDH displayed a lower $\mathrm{K}_{\mathrm{m}}$ value for $\mathrm{NH}_{4}{ }^{+}$compared to the standard values for both control and anoxia groups, with the control parameter being $10.5 \mathrm{mM}$ with urea 
and $16.3 \mathrm{mM}$ without urea and anoxia parameter being $10.7 \mathrm{mM}$ with urea compared to the anoxia standard condition value of $35.2 \mathrm{mM}$ (Fig. 2.3D).

Lastly, the effect of $400 \mathrm{mM}$ glucose on the affinity of GDH for each substrate was investigated. In the forward direction, the $\mathrm{K}_{\mathrm{m}}$ value for glutamate in response to dehydration $(0.77 \mathrm{mM})$ increased significantly compared to control $(0.32 \mathrm{mM})$. The control and dehydrated GDH displayed a higher $\mathrm{K}_{\mathrm{m}}$ for $\mathrm{NAD}^{+}$in the presence of $400 \mathrm{mM}$ glucose compared to their standard condition (Fig. 2.2B). The $\mathrm{K}_{\mathrm{m}}$ for glutamate and $\mathrm{NAD}^{+}$of the anoxia-exposed enzyme was significantly higher than the control (Fig. 2.3A \& 2.3B). In the reverse direction, glucose greatly increased the $\mathrm{K}_{\mathrm{m}}$ of the control and dehydrated $\mathrm{GDH}$ for alpha-ketoglutarate relative to their standard value (Fig. 2.2C) while the $\mathrm{K}_{\mathrm{m}}$ for anoxic GDH significantly decreased relative to the standard value (Fig. 2.3C). In addition, the $\mathrm{K}_{\mathrm{m}}$ for alpha-ketoglutarate was found to be significantly lower in anoxia treatment than in the control (Fig. 2.3C). The presence of $400 \mathrm{mM}$ glucose resulted in a significant increase in the $\mathrm{K}_{\mathrm{m}}$ of $\mathrm{NH}_{4}{ }^{+}$under both control and dehydration conditions relative to their standard values (Fig. 2.2D). It also displayed a significant increase compare to the control, with GDH from dehydrated frogs being $44.4 \mathrm{mM}$ compared to the control value of $26.8 \mathrm{mM}$ (Fig. 2.2D).

\subsubsection{Structural stability of GDH}

DSF was used to determine the thermal stability of purified GDH from control, dehydrated and anoxic frogs in the presence and absence of urea (Figure 2.4). The $\mathrm{T}_{\mathrm{m}}$ value is defined as the temperature at which 50\% maximal fluorescence is achieved during the unfolding of the protein. The $\mathrm{T}_{\mathrm{m}}$ value for GDH from dehydrated frogs was significantly lower $\left(52.2{ }^{\circ} \mathrm{C}\right)$ by $5{ }^{\circ} \mathrm{C}$ compared to control GDH $\left(57.2^{\circ} \mathrm{C}\right)$ (Fig. $\left.2.4 \mathrm{~A}\right)$. Due to the high concentration of urea accumulated by the dehydrated frogs, a concentration of $100 \mathrm{mM}$ urea was used to evaluate the 
effect of urea on $\mathrm{T}_{\mathrm{m}}$ for GDH. The $\mathrm{T}_{\mathrm{m}}$ significantly increased $\left(56.6^{\circ} \mathrm{C}\right)$ by $4.4{ }^{\circ} \mathrm{C}$ in the presence of $100 \mathrm{mM}$ urea compared to GDH from dehydration treated frogs $\left(52.2^{\circ} \mathrm{C}\right)$ in the absence of urea (Fig. 2.4A). In contrast, anoxic GDH did not display any significant differences with/without urea treatment compared to controls (Fig. 2.4B).

\subsubsection{Western blots for posttranslational modification}

Western blot analysis was used to determine whether purified GDH is post-translationally modified in vivo in response to dehydration or anoxia treatments. Phosphorylation on serine residues of the dehydrated form of GDH was calculated to be 1.40-fold greater than control (Fig. 2.5). In contrast, dehydrated GDH showed a significant decrease in acetylation and ADPribosylation by $\sim 17 \%$ and $\sim 41 \%$ compared to control, respectively (Fig. 2.5 ). Interestingly, the level of phosphorylation on serine residues in response to anoxia treatment showed a decrease by $\sim 16 \%$ relative to the control (Fig. 2.5 ).

\subsection{Discussion}

Extreme environmental conditions such as temperature fluctuation, limited food availability, water loss and fluctuations in environmental oxygen level can inflict distress to organisms living in the wild. These animals must adjust at both the biochemical and physiological levels to survive theses stresses. One example of environmental stress adaptation is employed by North American wood frogs; they tolerate freezing of their whole body where 65$75 \%$ of their body water is converted into extracellular ice $[1,8]$. Along with ice formation throughout their body, wood frogs need to also deal with severe dehydration due to the loss of water and anoxia since breathing, heart rate and blood circulation are stopped while frozen [1]. To survive all of these stresses, wood frogs have developed adaptations such as the accumulation of glucose and osmolytes (urea) as a cryoprotectants in order to prevent intracellular ice 
formation and minimize cell shrinkage due to water loss to join extracellular ice crystals $[15,38,39]$. Moreover, MRD is a core component for surviving long term freezing and its associated stresses in wood frogs [1,2]. MRD is aided by several control mechanisms such as regulation of key metabolic enzymes to conserve energy. Glutamate dehydrogenase is a mitochondrial enzyme with a significant role in carbohydrate, amino acid and nitrogen metabolism [20]. The present study revealed that purified liver GDH from control, dehydrated and anoxic frogs had significantly different kinetic properties, response to cellular metabolites and thermal stability compared to controls. It also demonstrated regulation by post-translational modifications.

Wood frog GDH was functionally purified using a combination of affinity chromatography techniques (Fig. 2.1). For the control GDH this resulted in 64.3-fold purification with activity yield of $81 \%$ (Table 2.1). The GDH from dehydrated and anoxia- exposed frogs revealed a similar yield (supplementary information, Table S1). The purification schemes presented in this study are comparable to those used in other studies in different animals, thereby demonstrating a reproducible and effective way of isolating GDH from tissues [27-30].

Analysis of kinetic parameters of purified GDH revealed differences between dehydrated wood frogs compared with control GDH. In the glutamate oxidizing direction, GDH from dehydrated frogs was more active since it displayed higher affinity for its substrate in addition to demonstrating an increase in $\mathrm{V}_{\max }$ (Table 2.2). Conversely, dehydrated GDH in the reverse direction was less active than the control (Table 2.2). The dehydrated GDH displayed a significant lower $\mathrm{K}_{\mathrm{m}}$ for $\mathrm{NH}_{4}^{+}$compared to controls (Table 2.2). However, the $\mathrm{K}_{\mathrm{m}}$ for ammonium ion was much higher compared to the $\mathrm{K}_{\mathrm{m}}$ value of other substrates, meaning that the activity of reverse direction (producing glutamate) is likely low in the wood frog as seen in 
mammals [19]. The increase in substrate affinity in the forward direction is likely to increase the flux in the glutamate consuming direction in response to dehydration (Table 2.2). The higher affinity for glutamate in the dehydration state could be important since glutamate levels increase in the liver of estivated spadefoot toads, which can contribute to more ammonium ion being produced to feed into the urea cycle [40]. Therefore, the increase in the affinity of glutamate could contribute to more $\alpha-\mathrm{KG}$ being produced, which can be used to fuel the Krebs cycle as another source of energy, and to producing more ammonium ion to feed into the urea cycle. This is needed as it would provide the ammonium ion to carbamoyl phosphate synthetase I (CPSI) to catalyze the first step of the urea cycle [41]. The significant increase in maximal activity of GDH in the glutamate consuming direction also suggests that wood frogs may be breaking down proteins at an increased rate to provide a source of energy in addition to glycolysis during dehydration [42]. ADP is a well-known activator for GDH, as it cause a conformational change in the enzyme, leading to an increase in its reaction rate [21]. The maximal activity of GDH in the forward direction increased significantly in the presence of $0.5 \mathrm{mM}$ ADP compared to controls and increased by 1.54-fold compared to dehydrated GDH without ADP (Table 2.2). This further suggests that dehydrated GDH is likely more responsive to changes in the energy state of the cell, and it may function in the liver to promote catabolism of glutamate during dehydration. Kinetic studies were also assessed for purified GDH from anoxic frogs, and results revealed a lower affinity for all the substrates in both directions. The decrease of substrate affinity in both directions suggests a substantial decrease in GDH activity in response to anoxia. In addition, the maximal activity of anoxic GDH decreased for the forward reaction (Table 2.2), which could indicate that GDH is suppressed in this condition. The anoxic GDH had lower affinity for $\mathrm{NH}_{4}{ }^{+}$and there were no significant changes for the other substrates (glutamate, 
$\mathrm{NAD}^{+}$and $\alpha-\mathrm{KG}$ ) in the presence of $0.5 \mathrm{mM}$ ADP compared to the control group (Fig. 2.3). This further suggests that GDH activity is likely suppressed during anoxia since it is less sensitive to activation by ADP. Taken together, a reduction in liver GDH activity during anoxia correlates with the metabolic changes that occur in this condition in the wood frog. In response to anoxia, aerobic metabolism is inhibited; therefore, the breakdown of glutamate to $\alpha-K G$ for as an energy substrate would be unnecessary. This coincides with another study that showed a decreased GDH enzymatic activity during anoxia, which is an indicative of reduced TCA cycle activity [28].

As previously discussed, accumulation of urea and glucose as osmolytes serves as an effective way to help maintain cellular integrity and reduce the amount of intracellular dehydration. The concentration of glucose has been shown to increase in the liver of the wood frog in response to dehydration $[43,44]$. Under dry conditions, the levels of urea can raise up to $90 \mathrm{mM}$ in wood frogs [15]. In addition, urea accumulation was suggested to play a key role in the induction of metabolic rate depression in wood frogs [45]. The affinity of GDH for its substrates were measured in the presence of glucose and urea to mimic intracellular conditions when they experience dehydration. Interestingly, dehydrated GDH's affinity for its substrate in the forward direction in the presence of $100 \mathrm{mM}$ urea decreased relative to the control (Fig. 2.2). This may suggest that urea acts as a feedback regulator to inhibit over production of $\mathrm{NH}_{4}{ }^{+}$during dehydration. This coincides with the another study that showed decreased glutamate and NAD ${ }^{+}$ affinities in the presence of $100 \mathrm{mM}$ urea in response to whole-body freezing of the wood frog liver [30]. In addition, it can be hypothesized that urea could act as a regulator of GDH during dehydration and contribute to MRD. These results support findings from a previous study which showed that urea-treated liver from wood frogs had significantly depressed metabolic rates ( $\sim 15 \%)$ compared to control liver [45]. Therefore, the effects of urea on GDH could be a 
physiological mechanism to regulate the activity of the enzyme during stress in order to contribute to the overall MRD. Urea did not result in any significant changes in the reverse direction for dehydrated GDH compared to the control group (Fig. 2.2C\&D).

It was also noted that the presence of $400 \mathrm{mM}$ glucose significantly increased the $\mathrm{K}_{\mathrm{m}}$ value for ammonium ion for dehydrated GDH (Fig. 2.2D). Glucose may alter the affinity of dehydrated GDH for ammonium ion to limit the formation of glutamate. This was seen in wood frog liver where ammonium ion increased up to $\sim 7.5 \mu \mathrm{mol} / \mathrm{g}$ wet weight in response to freezing [11]. The presence of $100 \mathrm{mM}$ urea and $400 \mathrm{mM}$ glucose were also examined on the anoxic GDH (Fig. 2.3). It was revealed that both urea and glucose decreased the affinity of GDH in response to anoxia for its substrates in the forward direction compared to the control group (Fig. 2.3A\&B). This suggests that urea and glucose may alter the affinity of the anoxia-exposed GDH to lower the production of the TCA cycle intermediates $(\alpha-\mathrm{KG})$, that are generated from glutamate. This would further support the idea that GDH activity is being suppressed to limit the production of unnecessary metabolites such as $\alpha-K G$ since it will not be necessary for energy production under anoxia conditions.

The changes in kinetic parameters are an indication of potential structural differences to the enzymes. DSF was used to see if the differences in kinetic parameters are related to the change in the overall structure of the enzymes [46]. GDH from dehydrated liver had significantly lower melting temperature compared to the control enzyme without urea treatment (Fig. 2.4A). The effect of urea on the thermal stability of GDH was also investigated since dehydration in amphibians raises the concentration of urea in their body to limit water loss [16]. Levels of urea can rise up to $90 \mathrm{mM}$ in wood frogs under dry conditions [15]. The addition of physiological levels of urea $(100 \mathrm{mM})$ significantly increased the thermal stability of GDH isolated from 
dehydrated frogs (Fig. 2.4A). This indicates that urea exhibits a stabilizing effect on protein structure and prevents protein unfolding. As such urea enhances the thermal stability of GDH in response to dehydration. Urea is a chaotropic agent that at high concentrations can result in protein denaturation. The concentration required to reduce the activity of GDH by half was less for GDH from dehydrated frogs compared to controls as seen by the DSF results (Table 2.2). Additionally, the $\mathrm{I}_{50}$ values for anoxia exposed GDH were less than those of the control (Table 2.2), further indicating that there are stability and structural differences between enzymes from different treatment conditions.

Enzymatic regulation is of great interest especially when biochemical adaptations are required to survive various unfavorable conditions. One way that this regulation is achieved, is through altering amino acid residues of an enzyme by reversible PTMs, a common method used by cells to regulate metabolic pathways [47]. It is suggested that changes in enzyme kinetics and stability are regulated via changes in PTMs which alter the functionality of the enzyme in order to survive environmental stress. Western blot analysis revealed that for most PTMs examined in this study there were not responsive to anoxia or dehydration treatments (Fig. 2.5). However, current results show that GDH from dehydrated frogs had significantly more (1.40-fold greater) phosphorylated serine residues than GDH from control frogs (Fig. 2.5), suggesting that perhaps the increase in activity seen here could be due to this PTM. GDH regulation via phosphorylation may play an essential role for animals that enter hypometabolic states and its regulation may depend on the environmental stress encountered by the organism. For example, a mammalian hibernator (Richardson's ground squirrels) showed a reduction in liver GDH phosphorylation during hibernation, which suggests that GDH is regulated in order to promote amino acid oxidation to contribute to energy production during hibernation [27]. The regulation of GDH was 
also examined in foot muscle from estivating snails (land snail) and results revealed an increase in phosphorylation in GDH in response to estivation [29]. Indeed, this increase could play a role in promoting urea synthesis under this condition, a response that may be necessary to maintain cellular viability during stress. In comparison, GDH from anoxic frogs was found to have significantly lower level of phosphorylated serine residues compared to GDH from control frogs (Fig. 2.5). The reduction of phosphorylation at serine residues as it transitions into an anoxic state correlates with the reduction of enzymic activity and lower affinity for its substrate seen in this study (Table 2.2). This suggests that GDH from anoxic frogs might be modified through phosphorylation in order to decrease its activity to prevent build-up of TCA cycle intermediates $(\alpha-K G)$ and inhibit the synthesis of amino acids in anoxic conditions. This was also seen in the anoxia-tolerant freshwater turtles which revealed that GDH from anoxic liver was significantly less phosphorylated than control GDH [28]. This further supports the suppression of GDH during anoxia-exposure and agrees with the overall shutdown of aerobic metabolism. In addition, dehydrated GDH had significantly lower acetylated amino acids residues compared to control GDH (Fig. 2.5). It was shown that deacetylation of GDH in vitro and in vivo via Sirtuin 3 (Sirt3) increases GDH activity, thereby indicating that acetylation has an inhibitory role on GDH [4850]. Dehydrated GDH was also shown to have significantly lower ADP-ribosylation residues (lysine and arginine) relative to controls GDH (Fig. 2.5). An increase in mono-ADP-ribosylation plays a major role in the regulating GDH activity, which can result in substantial inhibition of its catalytic activity [51]. A previous study showed that Sirtuin 4 (NAD ${ }^{+}$-dependent enzymes; Sirt4) can interact with GDH and modify GDH by ADP- ribosylation to suppress its activity [52]. Therefore, the decrease in ADP-ribosylation may be due to the inhibition of Sirt 4 activity, which in turn could promote GDH activity. Previous studies from our lab showed that GDH from 
frozen wood frogs is regulated by acetylation and ADP-ribosylation, suggesting that dehydrated and frozen frogs experience similar physiological responses whereby GDH is regulated by a reduction in acetylation and ADP-ribosylation to increase its activity [30]. However, GDH from anoxia-exposed frogs experiences different regulation than frozen or dehydrated frogs. With entry into the anoxic state, GDH undergoes a reduction in phosphorylated serine residues, and this correlates with the reduction of enzymatic activity and affinity for its substrates, thereby suggesting the suppression of GDH activity during anoxia.

\subsection{Conclusion}

The data presented above indicates that liver GDH experiences different physiological responses to stress. GDH from dehydrated frogs is regulated by acetylation, ADP-ribosylation and phosphorylation, likely to increase the flux into the TCA cycle and facilitate the production of ammonium species during dehydration. This was supported by the increase in GDH maximal activity and higher affinity of GDH for glutamate and $\mathrm{NAD}^{+}$. The regulation of GDH from dehydrated frogs may play a key role in providing another source of cellular energy in sustaining high level of urea, since it was seen in this study that urea significantly increases GDH stability during dehydration. In contrast, kinetic analyses of GDH from anoxic frogs indicated that a stable suppression of the enzyme may due to a reduction in GDH serine phosphorylation during anoxia. This suppression of enzymatic activity is beneficial to the anoxic wood frog which could prevent wasteful accumulation of TCA cycle intermediates. Therefore, the overall suppression of GDH activity agrees with the overall MRD and suppression of all aerobic metabolism during anoxia condition. Taken together, these results support that GDH play a key role in carbohydrate and nitrogen metabolism when these animals encounter undesirable environmental conditions. 
Tables

Table 2.1: Purification scheme for wood frog GDH in liver. Two steps were used to achieve the purification: (a) Cibacron Blue column chromatography where the enzyme was eluted using a salt gradient 0-2 M KCl, and (b) GTP agarose affinity chromatography where the enzyme was eluted using 0-2 $\mathrm{M} \mathrm{KCl}$. Activities were measured in the glutamate oxidizing direction at $22{ }^{\circ} \mathrm{C}$. This step was repeated $\mathrm{n} \geq 5$.

\begin{tabular}{lccccc}
\hline Steps & $\begin{array}{c}\text { Total } \\
\text { protein (mg) }\end{array}$ & $\begin{array}{c}\text { Total } \\
\text { Activity (U) }\end{array}$ & \% Yield & $\begin{array}{c}\text { Specific } \\
\text { Activity } \\
\text { (U/mg) }\end{array}$ & $\begin{array}{c}\text { Fold } \\
\text { purification }\end{array}$ \\
\hline Crude & 21.1 & 0.72 & - & 0.03 & \\
\hline $\begin{array}{l}\text { Cibacron } \\
\text { Blue }\end{array}$ & 3.90 & 0.61 & 84.7 & 0.16 & 5.3 \\
\hline GTP-agarose & 0.30 & 0.58 & 81.4 & 1.93 & 64.3 \\
\hline
\end{tabular}


Table 2.2: Comparison of purified liver GDH kinetic parameters from control, dehydrated and anoxic exposed wood frog in the glutamate-consuming direction at $\mathrm{pH} 8.0$ and $\alpha-\mathrm{KG}$ consuming direction at $\mathrm{pH}$ 7.2. Assay were conducted at $22{ }^{\circ} \mathrm{C}$ and data are expressed as mean $\pm \mathrm{SEM}, \mathrm{n} \geq$ 4 independent purified enzyme preparations. The $\mathrm{K}_{\mathrm{m}}$ values were determined at optimal cosubstrate concentrations; the assay conditions were as described in the Method section

\begin{tabular}{|c|c|c|c|}
\hline & Control & Dehydration & Anoxia \\
\hline \multicolumn{4}{|c|}{ Forward reaction } \\
\hline $\begin{array}{l}K_{m} \text { Glutamate } \\
(\mathrm{mM})\end{array}$ & $2.06 \pm 0.21$ & $1.26 \pm 0.14^{*}$ & $2.65 \pm 0.55$ \\
\hline $\mathrm{K}_{\mathrm{m}} \mathrm{NAD}^{+}(\mathrm{mM})$ & $1.03 \pm 0.08$ & $0.83 \pm 0.04$ & $2.91 \pm 0.46^{*}$ \\
\hline$V_{\max }(\mathrm{U} / \mathbf{m g})$ & $3.53 \pm 0.04$ & $9.69 \pm 0.03 *$ & $1.60 \pm 0.06^{*}$ \\
\hline $\begin{array}{l}V_{\max }(\mathrm{U} / \mathrm{mg}) \text { with } \\
0.5 \mathrm{mM} \text { ADP }\end{array}$ & $5.86 \pm 0.02^{a}$ & $14.9 \pm 0.65^{* a}$ & $1.45 \pm 0.062 *$ \\
\hline $\begin{array}{l}{\left[\mathrm{V}_{\max } 0.5 \mathrm{mM} \mathrm{ADP} /\right.} \\
\left.\mathrm{V}_{\max } \text { non activated }\right] \\
(\mathrm{U} / \mathrm{mg})\end{array}$ & $1.65 \pm 0.02$ & $1.54 \pm 0.07$ & $0.91 \pm 0.04 *$ \\
\hline$K_{\mathbf{a}} \mathrm{ADP}(\mathbf{m M})$ & $0.11 \pm 0.01$ & $0.11 \pm 0.01$ & $0.29 \pm 0.04 *$ \\
\hline I50 urea $(M)$ & $0.73 \pm 0.006$ & $0.66 \pm 0.008^{*}$ & $0.62 \pm 0.004 *$ \\
\hline \multicolumn{4}{|c|}{ Reverse reaction } \\
\hline$K_{m} \alpha-K G(m M)$ & $0.22 \pm 0.01$ & $0.17 \pm 0.01$ & $0.19 \pm 0.01$ \\
\hline $\mathrm{Km}_{\mathrm{m}} \mathrm{NH}_{4}^{+}(\mathrm{mM})$ & $16.3 \pm 0.83$ & $10.8 \pm 0.62 *$ & $35.2 \pm 0.31 *$ \\
\hline$V_{\max }(\mathrm{U} / \mathbf{m g})$ & $6.57 \pm 0.64$ & $5.38 \pm 0.15$ & $9.22 \pm 0.59^{*}$ \\
\hline $\begin{array}{l}V_{\max }(\mathrm{U} / \mathrm{mg}) \text { with } \\
0.5 \mathrm{mM} \text { ADP }\end{array}$ & $8.13 \pm 0.23$ & $6.68 \pm 0.06^{* a}$ & $8.52 \pm 0.57$ \\
\hline $\begin{array}{l}{\left[\mathrm{V}_{\max } 0.5 \mathrm{mM} \mathrm{ADP} /\right.} \\
\mathrm{V}_{\max } \text { non activated] } \\
(\mathrm{U} / \mathrm{mg})\end{array}$ & $1.27 \pm 0.13$ & $1.25 \pm 0.03$ & $0.93 \pm 0.05$ \\
\hline
\end{tabular}

*Significantly different from control values using the Student's $t$-test, $P<0.05$. $\left({ }^{a}\right)$ indicates the parameter is significantly different from the corresponding parameter in the presence of ADP, (Student's t-test $p<0.05)$. Data means $\pm S E M, n=4$ independent trials. 


\section{Figures}

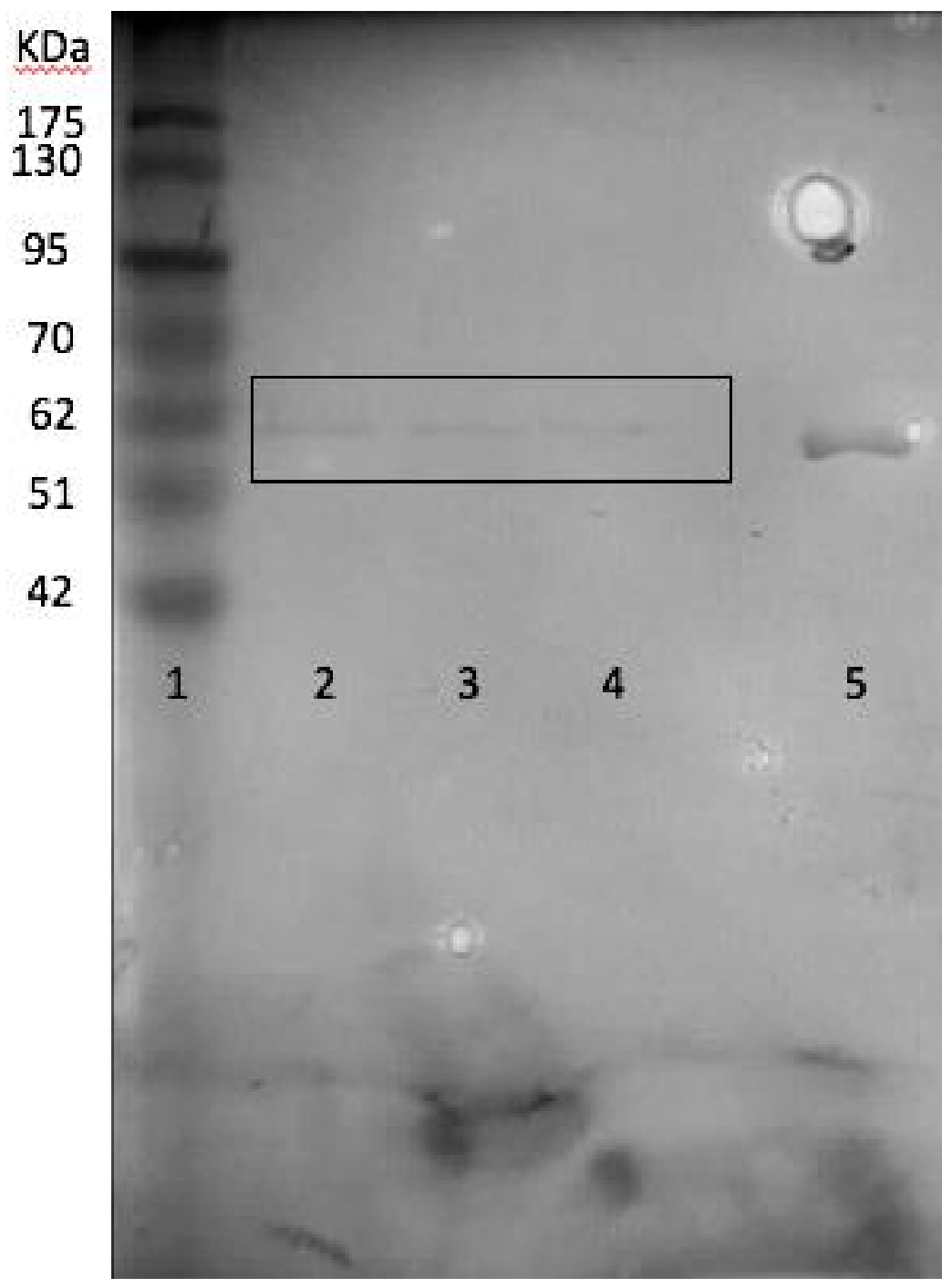

Figure 2.1: Representation of purified control, dehydrated and anoxic Rana sylvatica GDH from liver. The Coomassie blue stained gel displays the follo `wing lane 1: piNK Plus Pre-stained Protein Ladder 10-175KDa, 2: purified control GDH, 3: purified dehydrated GDH, 4: purified anoxic GDH, 5: bovine liver GDH (Sigma) 


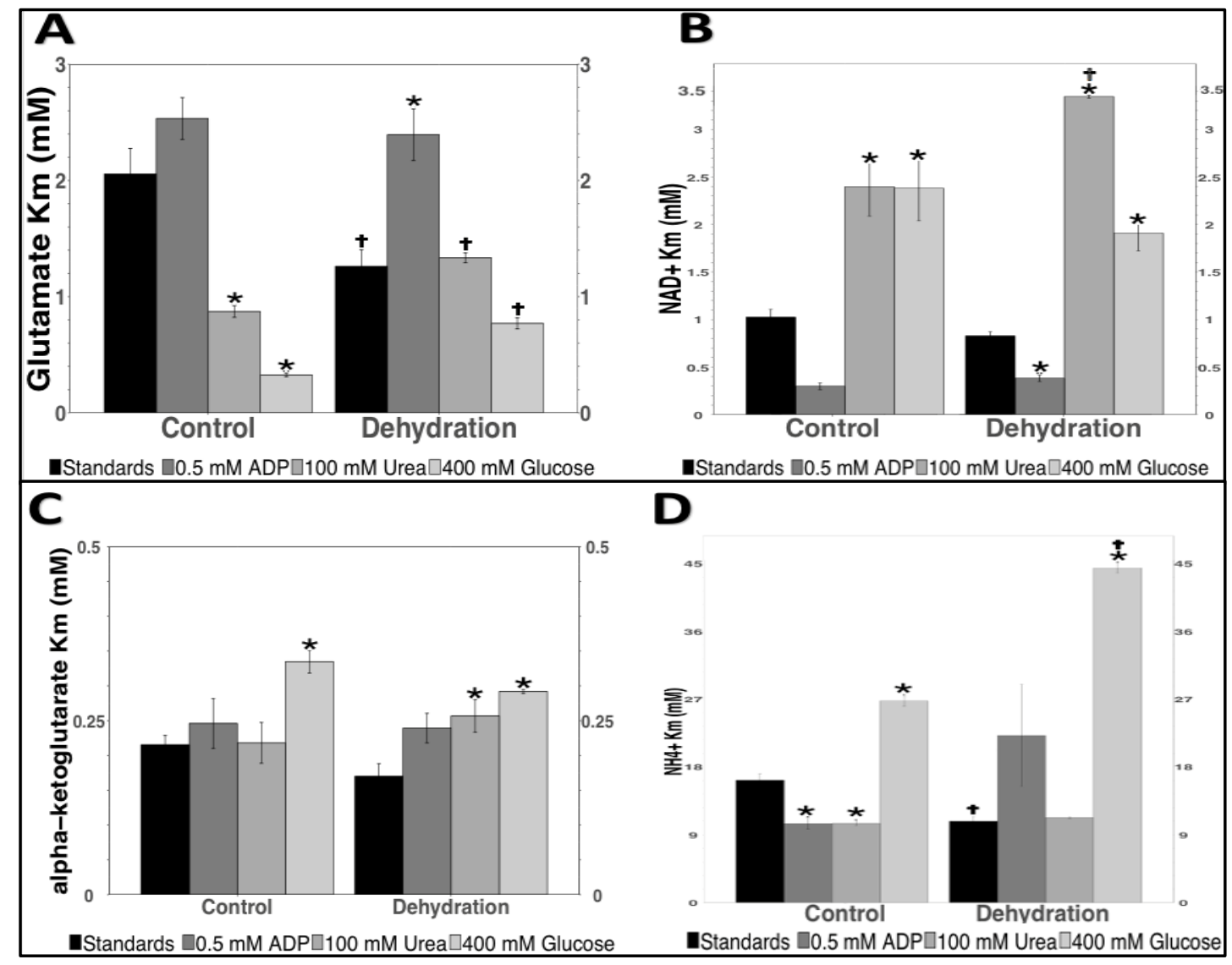

Figure 2.2: The effect of metabolites ( $0.5 \mathrm{mM}$ ADP, $100 \mathrm{mM}$ urea and $400 \mathrm{mM}$ glucose) on purified GDH from Rana sylvatica liver control and dehydrated GDH affinities for (A) glutamate $\mathrm{K}_{\mathrm{m}}$, (B) NAD ${ }^{+} \mathrm{K}_{\mathrm{m}}$, (C) alpha-ketoglutarate $\mathrm{K}_{\mathrm{m}}$, and (D) $\mathrm{NH}_{4}{ }^{+} \mathrm{K}_{\mathrm{m}}$. The assays were performed in $50 \mathrm{mM}$ HEPES buffer at $\mathrm{pH} 8.0$ (forward direction) and $50 \mathrm{mM}$ HEPES buffer at $\mathrm{pH}$ 7.2(reverse direction) at $22{ }^{\circ} \mathrm{C}$. Data are means \pm SEM, $\mathrm{n}=4$ with $\mathrm{K}_{\mathrm{m}}$ expressed in $\mathrm{mM}$. Statistical analysis used ANOVAs and Dunnett's post-hoc test for each condition of GDH to compare the effects of different metabolites on the $\mathrm{K}_{\mathrm{m}}$, data were considered significantly different when $p<0.05$ which represented by '*', ' $\mathbf{t}$ ' denotes a difference between the control and dehydrated parameters determined by two-tailed Student's t-test $p<0.05$. 


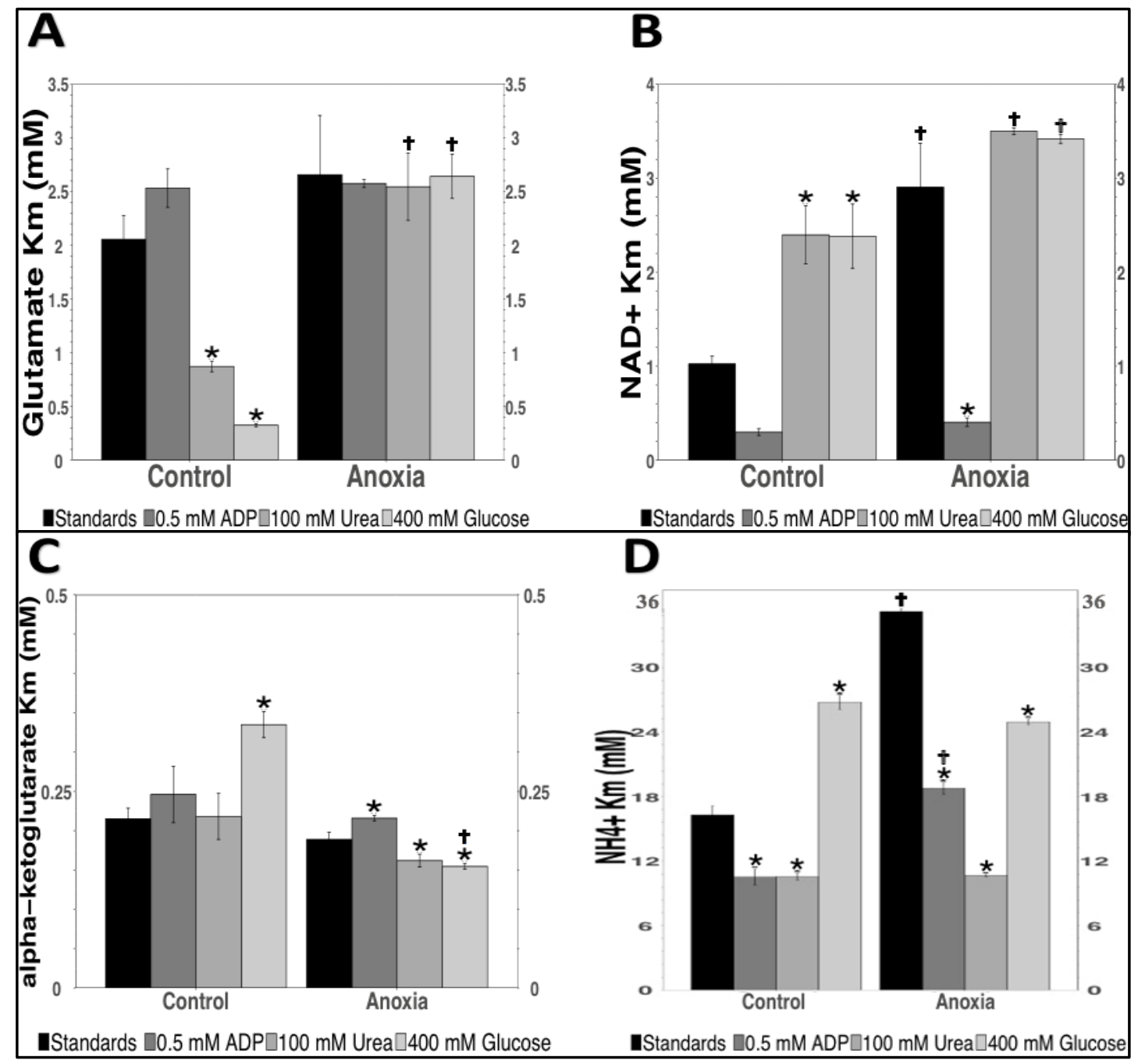

Figure 2.3: The effect of metabolites (0.5 mM ADP, $100 \mathrm{mM}$ urea and $400 \mathrm{mM}$ glucose) on the Rana sylvatica liver control and anoxic GDH affinities for (A) glutamate $\mathrm{K}_{\mathrm{m}}$, (B) $\mathrm{NAD}^{+} \mathrm{K}_{\mathrm{m}}$, (C) alpha-ketoglutarate $\mathrm{K}_{\mathrm{m}}$, and (D) $\mathrm{NH}_{4}{ }^{+}$. Other information as in Fig. 2.2. 


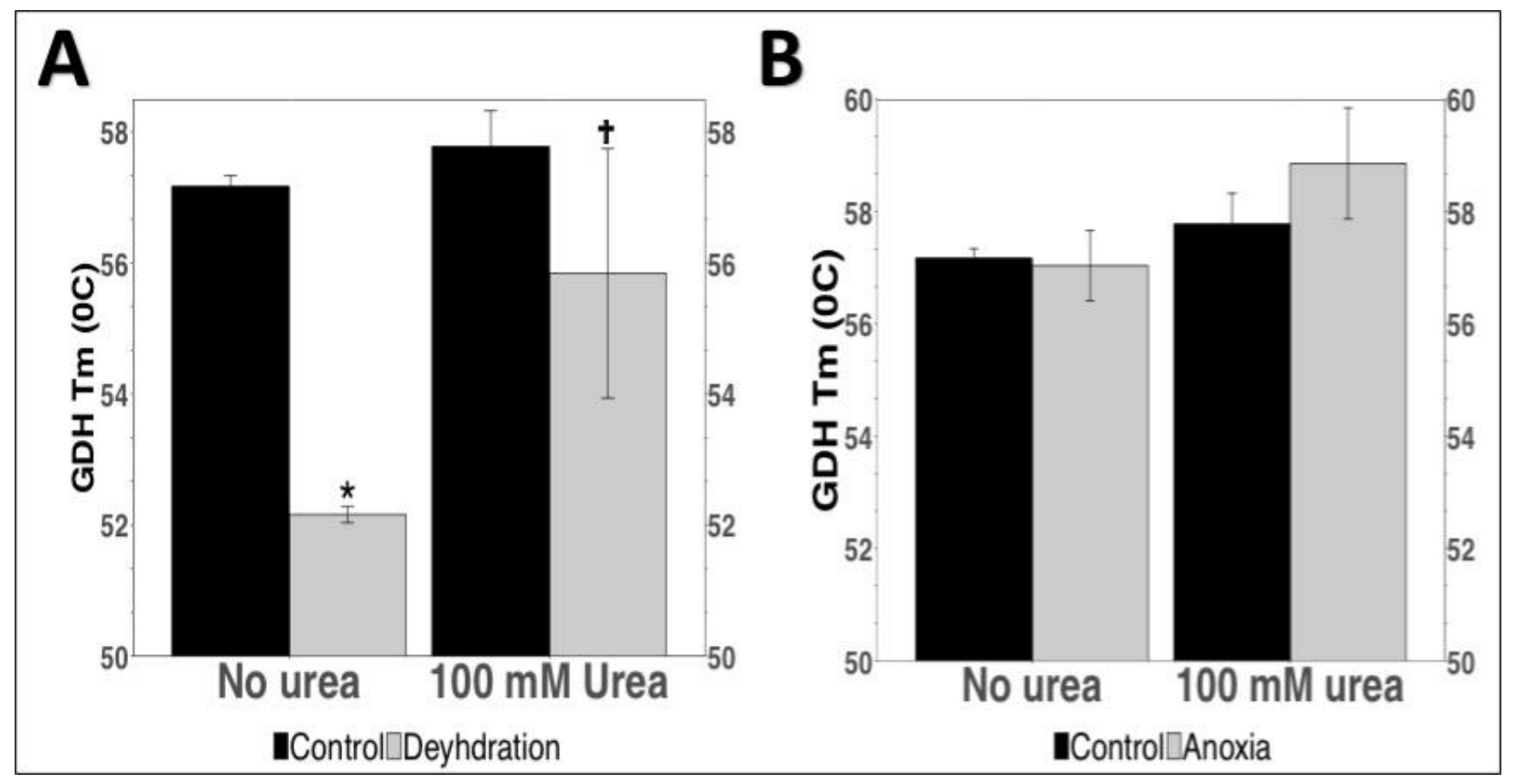

Figure 2.4: The melting temperature $\left(\mathrm{T}_{\mathrm{m}}\right)$ for purified GDH from control, dehydrated $(\mathrm{A})$ and $(\mathrm{B})$ anoxic Rana sylvatica in presence and absence of $100 \mathrm{mM}$ urea at $\mathrm{pH} 7.4$ using DSF. The enzyme concentration used in this experiment was $0.06 \mathrm{mg} / \mathrm{mL}$ of purified GDH per assay well. '*' represent a significant different between $\mathrm{T}_{\mathrm{m}}$ of the control and the corresponding stress condition $\left(p<0.05\right.$, student's t-test). ' $t$ ' indicate that the $\mathrm{T}_{\mathrm{m}}$ in the presence of $100 \mathrm{mM}$ urea was significantly different from the same parameter without urea $(p<0.05$, student's t-test). Data represent mean $\pm S E M, n \geq 3$ 


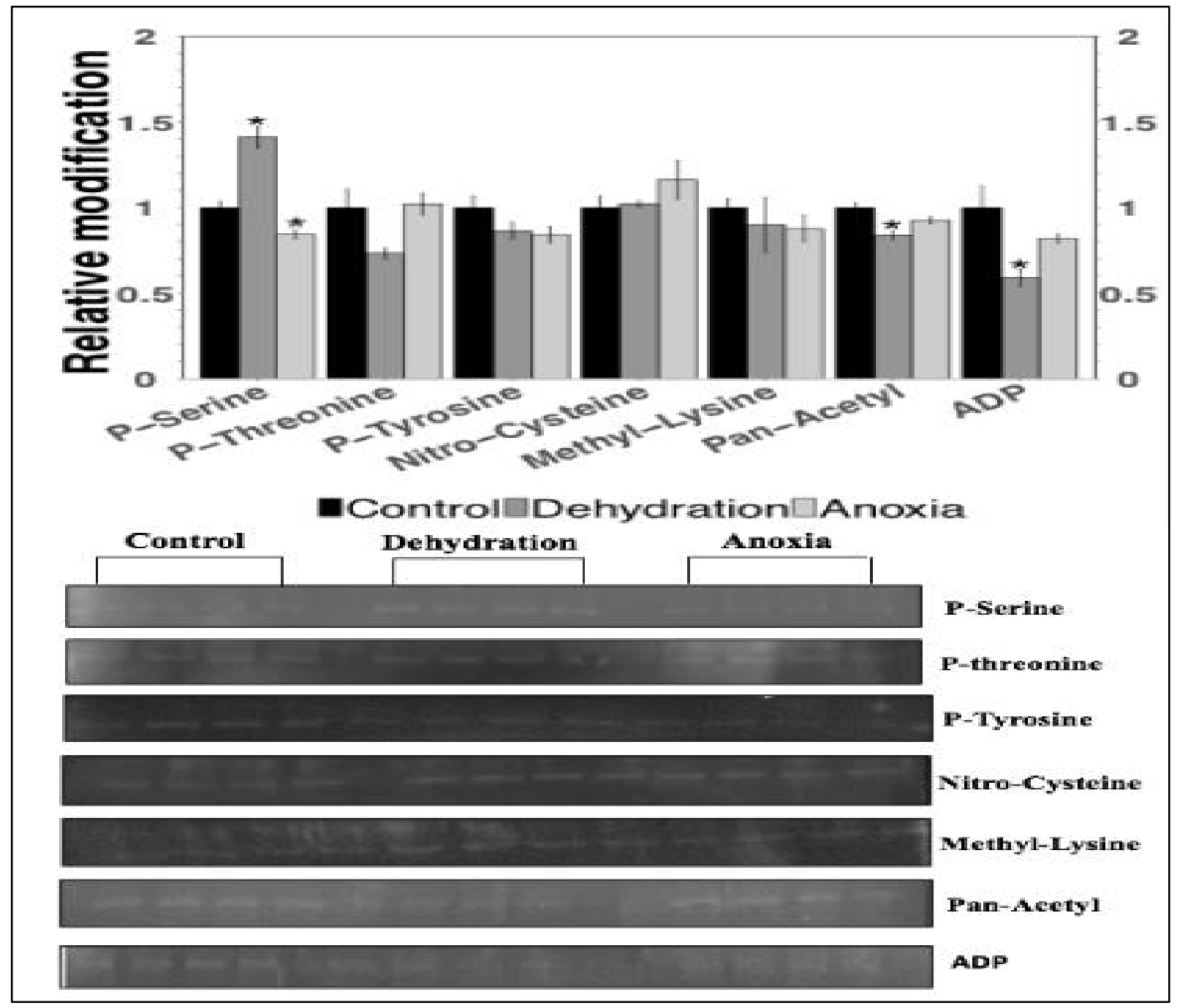

Figure 2.5: Analysis of posttranslational modification of liver GDH from control, dehydrated and anoxic wood frog via western blot analysis. Data are mean \pm SEM, $n=4$ independent purified enzyme preparations. The relative band intensity refers to the intensity of the chemiluminescent signal standardized to band intensity from the same membrane stained with Coomassie brilliant blue. $(*)$ indicates that values are significantly different from the corresponding control $(p<0.05$, student's t-test) 


\section{Supplementary information}

Table S1: Purification scheme for dehydrated and anoxic wood frog GDH in liver. Two steps were used to achieve the purification: (a) Cibacorn Blue column chromatography and (b) GTP agarose affinity chromatography. The activities were measured in the glutamate oxidizing direction at $22^{\circ} \mathrm{C}$. This step was repeated $\mathrm{n} \geq 5$ for each stress.

\begin{tabular}{|c|c|c|c|c|c|}
\hline $\begin{array}{l}\text { Purification } \\
\text { Step }\end{array}$ & $\begin{array}{c}\text { Total } \\
\text { protein }(\mathrm{mg})\end{array}$ & $\begin{array}{c}\text { Total } \\
\text { Activity (U) }\end{array}$ & $\%$ Yield & $\begin{array}{l}\text { Specific } \\
\text { Activity } \\
\text { (U/mg) }\end{array}$ & $\begin{array}{c}\text { Fold } \\
\text { purification }\end{array}$ \\
\hline \multicolumn{6}{|l|}{ Dehydration } \\
\hline Crude & 41.4 & 0.87 & - & 0.02 & - \\
\hline $\begin{array}{l}\text { Cibacron } \\
\text { Blue }\end{array}$ & 5.53 & 0.72 & 82.8 & 0.13 & 6.20 \\
\hline GTP-agarose & 0.22 & 0.52 & 59.5 & 2.37 & 112 \\
\hline \multicolumn{6}{|l|}{ Anoxia } \\
\hline Crude & 30.1 & 0.75 & - & 0.02 & - \\
\hline $\begin{array}{l}\text { Cibacron } \\
\text { Blue }\end{array}$ & 3.68 & 0.61 & 81.3 & 0.16 & 6.66 \\
\hline GTP-agarose & 0.24 & 0.47 & 62.6 & 1.94 & 78.1 \\
\hline
\end{tabular}




\section{References (chapter 2)}

[1] K.B. Storey, J.M. Storey, Molecular physiology of freeze tolerance in vertebrates, Physiol. Rev. 97 (2017) 623-665. doi:10.1152/physrev.00016.2016.

[2] K.B. Storey, J.M. Storey, Molecular biology of freezing tolerance, Compr. Physiol. 3 (2013) 1283-1308. doi:10.1002/cphy.c130007.

[3] R. Roufayel, K.K. Biggar, K.B. Storey, Regulation of cell cycle components during exposure to anoxia or dehydration stress in the wood frog, Rana sylvatica, J. Exp. Zool. Part A Ecol. Genet. Physiol. 315 A (2011) 487-494. doi:10.1002/jez.696.

[4] V.E.M. Gerber, S. Wijenayake, K.B. Storey, Anti-apoptotic response during anoxia and recovery in a freeze-tolerant wood frog (Rana sylvatica), PeerJ. 2016 (2016) 1-21. doi:10.7717/peerj.1834.

[5] J. Zhang, K.B. Storey, Cell cycle regulation in the freeze-tolerant wood frog, Rana sylvatica, Cell Cycle. 11 (2012) 1727-1742. doi:10.4161/cc.19880.

[6] N.J. Dawson, Front line antioxidant defenses in the freeze tolerant wood frog, Rana sylvatica : an in-depth analysis of mechanisms of enzyme regulation., D Phil Thesis. (2014).

[7] K.B. Storey, J.M. Storey, Natural freezing survival in animals, Annu. Rev. Ecol. Syst. 27 (1996) 365-386. doi:10.1146/annurev.ecolsys.27.1.365.

[8] D.J. Larson, L. Middle, H. Vu, W. Zhang, A.S. Serianni, J. Duman, B.M. Barnes, Wood frog adaptations to overwintering in Alaska: New limits to freezing tolerance, J. Exp. Biol. 217 (2014) 2193-2200. doi:10.1242/jeb.101931.

[9] T.A. Churchill, K.B. Storey, Metabolic responses to dehydration by liver of the wood frog, Rana sylvatica , Can. J. Zool. 72 (2008) 1420-1425. doi:10.1139/z94-188.

[10] C.P. Holden, K.B. Storey, Second messenger and cAMP-dependent protein kinase responses to dehydration and anoxia stresses in frogs, J. Comp. Physiol. - B Biochem. Syst. Environ. Physiol. 167 (1997) 305-312. doi:10.1007/s003600050078.

[11] K.B. Storey, J.M. Storey, Freeze tolerant frogs: cryoprotectants and tissue metabolism during freeze-thaw cycles, Can. J. Zool. 64 (1986) 49-56. doi:10.1139/z86-008.

[12] K.B. Storey, J.M. Storey, Biochemical adaption for freezing tolerance in the wood frog, Rana sylvatica, J. Comp. Physiol. B. 155 (1984) 29-36. doi:10.1007/BF00688788.

[13] J.P. Costanzo, A.M. Reynolds, M. Clara, F. Do Amaral, A.J. Rosendale, R.E. Lee, Cryoprotectants and extreme freeze tolerance in a subarctic population of the wood frog, PLoS One. 10 (2015) 1-23. doi:10.1371/journal.pone.0117234.

[14] A.J. Rosendale, J.P. Costanzo, R.E. Lee, Seasonal variation and response to osmotic challenge in urea transporter expression in the dehydration and freeze-tolerant wood frog, Rana sylvatica, J. Exp. Zool. Part A Ecol. Genet. Physiol. 317 (2012) 401-409. doi:10.1002/jez.1733.

[15] J.P. Costanzo, Cryoprotection by urea in a terrestrially hibernating frog, J. Exp. Biol. 208 (2005) 4079-4089. doi:10.1242/jeb.01859.

[16] T.J. Muir, J.P. Costanzo, R.E. Lee, Osmotic and metabolic responses to dehydration and urea-loading in a dormant, terrestrially hibernating frog, J. Comp. Physiol. B Biochem. Syst. Environ. Physiol. 177 (2007) 917-926. doi:10.1007/s00360-007-0190-3.

[17] J.P. Costanzo, R.E. Lee, Urea loading enhances freezing survival and postfreeze recovery in a terrestrially hibernating frog, J. Exp. Biol. 211 (2008) 2969-2975. doi:10.1242/jeb.019695. 
[18] H.A. Sampson, S.H. Sicherer, Urea and amphibian water economy, Immunol. Allergy Clin. North Am. 19 (1999) 495-517. doi:10.1016/S0889-8561(05)70104-1.

[19] and T.J.S. Ming Li, Christopher J. Smith, Matthew T. Walker, Novel inhibitors complexed with glutamate dehydrogenase, PLoS One. 10 (2019) 1-23. doi: $10.1242 /$ jeb.01859.

[20] V. Bunik, A. Artiukhov, V. Aleshin, G. Mkrtchyan, Multiple forms of glutamate dehydrogenase in animals: Structural determinants and physiological implications, Biology (Basel). 5 (2016). doi:10.3390/biology5040053.

[21] T.J. Smith, C.A. Stanley, Untangling the glutamate dehydrogenase allosteric nightmare, Trends Biochem. Sci. 33 (2008) 557-564. doi:10.1016/j.tibs.2008.07.007.

[22] T.J. Smith, T. Schmidt, J. Fang, J. Wu, G. Siuzdak, C.A. Stanley, The structure of apo human glutamate dehydrogenase details subunit communication and allostery, J. Mol. Biol. 318 (2002) 765-777. doi:10.1016/S0022-2836(02)00161-4.

[23] M. Li, C.J. Smith, M.T. Walker, T.J. Smith, Novel inhibitors complexed with glutamate dehydrogenase, J. Biol. Chem. 284 (2009) 22988-23000. doi:10.1074/jbc.m109.020222.

[24] S.J. Humphrey, D.E. James, M. Mann, Protein phosphorylation: A major switch mechanism for metabolic regulation, Trends Endocrinol. Metab. 26 (2015) 676-687. doi:10.1016/j.tem.2015.09.013.

[25] H.P.P. Lin, H.C. Reeves, In vivo phosphorylation of $\mathrm{NADP}^{+}$glutamate dehydrogenase in Escherichia coli, Curr. Microbiol. 28 (1994) 63-65. doi:10.1007/BF01569047.

[26] H. Brian, Reactivation of the phospho form of the NAD-dependent glutamate dehydrogenase by a yeast protein phosphatase, Eur. J. Biochem. 116 (1981) 47-50. doi:10.1111/j.1432-1033.1981.tb05298.x.

[27] R.A.V. Bell, K.B. Storey, Regulation of liver glutamate dehydrogenase by reversible phosphorylation in a hibernating mammal, Comp. Biochem. Physiol. - B Biochem. Mol. Biol. 157 (2010) 310-316. doi:10.1016/j.cbpb.2010.07.005.

[28] R.A.. Bell, K.B. Storey, Regulation of liver glutamate dehydrogenase from an anoxiatolerant freshwater turtle, HOAJ Biol. 1 (2012) 3. doi:10.7243/2050-0874-1-3.

[29] R.A. V. Bell, N.J. Dawson, K.B. Storey, Insights into the In Vivo regulation of glutamate dehydrogenase from the foot muscle of an estivating land snail, Enzyme Res. 2012 (2012) 1-10. doi:10.1155/2012/317314.

[30] S.R. Green, K.B. Storey, Regulation of glutamate dehydrogenase (GDH) in response to whole body freezing in wood frog liver linked to differential acetylation and ADPribosylation, Arch. Biochem. Biophys. 636 (2017) 90-99. doi:10.1016/j.abb.2017.10.010.

[31] R. Al-Attar, K.B. Storey, Effects of anoxic exposure on the nuclear factor of activated T cell (NFAT) transcription factors in the stress-tolerant wood frog, Cell Biochem. Funct. 36 (2018) 420-430. doi:10.1002/cbf.3362.

[32] S.P.J. Brooks, A simple computer program with statistical tests for the analysis of enzyme kinetics, Biotechniques. 13 (1992) 906-911. https://www.ncbi.nlm.nih.gov/pubmed/1476744 (sccessed April 19, 2020).

[33] M.B. Smolinski, J.J.L. Mattice, K.B. Storey, Regulation of pyruvate kinase in skeletal muscle of the freeze tolerant wood frog, Rana sylvatica, Cryobiology. 77 (2017) 25-33. doi:10.1016/j.cryobiol.2017.06.002.

[34] F.H. Niesen, H. Berglund, M. Vedadi, The use of differential scanning fluorimetry to detect ligand interactions that promote protein stability, Nat. Protoc. 2 (2007) 2212-2221. doi:10.1038/nprot.2007.321. 
[35] K.K. Biggar, N.J. Dawson, K.B. Storey, Real-time protein unfolding: A method for determining the kinetics of native protein denaturation using a quantitative real-time thermocycler, Biotechniques. 53 (2012) 231-238. doi:10.2144/0000113922.

[36] S.R. Green, K.B. Storey, Regulation of crayfish, Orconectes virilis, tail muscle lactate dehydrogenase $(\mathrm{LDH})$ in response to anoxic conditions is associated with alterations in phosphorylation patterns, Comp. Biochem. Physiol. Part - B Biochem. Mol. Biol. 202 (2016) 67-74. doi:10.1016/j.cbpb.2016.08.004.

[37] J. Zhang, K.B. Storey, RBioplot: an easy-to-use R pipeline for automated statistical analysis and data visualization in molecular biology and biochemistry., PeerJ. 4 (2016) e2436. doi:10.7717/peerj.2436.

[38] J.M. Storey, K.B. Storey, Triggering of cryoprotectant synthesis by the initiation of ice nucleation in the freeze tolerant frog, Rana sylvatica, J. Comp. Physiol. B. 156 (1985) 191-195. doi:10.1007/BF00695773.

[39] D.J. Larson, B.M. Barnes, Cryoprotectant production in freeze-tolerant wood frogs is augmented by multiple freeze-thaw cycles, Physiol. Biochem. Zool. 89 (2016) 340-346. doi:10.1086/687305.

[40] K.J. Cowan, J.A. MacDonald, J.M. Storey, K.B. Storey, Metabolic reorganization and signal transduction during estivation in the spadefoot toad, Exp. Biol. Online. 5 (2000) 125. doi:10.1007/s00898-000-0001-8.

[41] S.R. Green, K.B. Storey, Purification of carbamoyl phosphate synthetase 1 (CPS1) from wood frog (Rana sylvatica) liver and its regulation in response to ice-nucleation and subsequent whole-body freezing, Mol. Cell. Biochem. 455 (2019) 29-39. doi:10.1007/s11010-018-3468-8.

[42] J.B. Balinsky, E.L. Choritz, C.G.L. Coe, G.S. van der Schans, Amino acid metabolism and urea synthesis in naturally aestivating Xenopus laevis, Comp. Biochem. Physiol. 22 (1967) 59-68. doi:10.1016/0010-406X(67)90166-1.

[43] T.A. Churchill, K.B. Storey, Metabolic responses to dehydration by liver of the wood frog, Rana sylvatica, Can. J. Zool. 72 (1994) 1420-1425. doi:10.1139/z94-188.

[44] T.A. Churchill, K.B. Storey, Dehydration tolerance in wood frogs: A new perspective on development of amphibian freeze tolerance, Am. J. Physiol. - Regul. Integr. Comp. Physiol. 265 (1993). doi:10.1152/ajpregu.1993.265.6.r1324.

[45] T.J. Muir, J.P. Costanzo, R.E. Lee, Metabolic depression induced by urea in organs of the wood frog, Rana sylvatica: Effects of season and temperature, J. Exp. Zool. Part A Ecol. Genet. Physiol. 309 (2008) 111-116. doi:10.1002/jez.436.

[46] R.A.V. Bell, J.C. Smith, K.B. Storey, Purification and properties of glyceraldehyde-3phosphate dehydrogenase fromthe skeletalmuscle of the hibernating ground squirrel, ictidomys tridecemlineatus, PeerJ. 2014 (2014) 1-20. doi:10.7717/peerj.634.

[47] K.B. Storey, J.M. Storey, Metabolic rate depression in animals: Transcriptional and translational controls, Biol. Rev. Camb. Philos. Soc. 79 (2004) 207-233. doi:10.1017/S1464793103006195.

[48] C. Schlicker, M. Gertz, P. Papatheodorou, B. Kachholz, C.F.W. Becker, C. Steegborn, Substrates and regulation mechanisms for the human mitochondrial Sirtuins Sirt3 and Sirt5, J. Mol. Biol. 382 (2008) 790-801. doi:10.1016/j.jmb.2008.07.048.

[49] D.B. Lombard, F.W. Alt, H.-L. Cheng, J. Bunkenborg, R.S. Streeper, R. Mostoslavsky, J. Kim, G. Yancopoulos, D. Valenzuela, A. Murphy, Y. Yang, Y. Chen, M.D. Hirschey, R.T. Bronson, M. Haigis, L.P. Guarente, R. V. Farese, S. Weissman, E. Verdin, B. 
Schwer, Mammalian Sir2 Homolog SIRT3 regulates global mitochondrial lysine acetylation, Mol. Cell. Biol. 27 (2007) 8807-8814. doi:10.1128/mcb.01636-07.

[50] K.L. Guan, Y. Xiong, Regulation of intermediary metabolism by protein acetylation, Trends Biochem. Sci. 36 (2011) 108-116. doi:10.1016/j.tibs.2010.09.003.

[51] A. Herrero-Yraola, S.M.A. Bakhit, P. Franke, C. Weise, M. Schweiger, D. Jorcke, M. Ziegler, Regulation of glutamate dehydrogenase by reversible ADP-ribosylation in mitochondria, EMBO J. 20 (2001) 2404-2412. doi:10.1093/emboj/20.10.2404.

[52] M.C. Haigis, R. Mostoslavsky, K.M. Haigis, K. Fahie, D.C. Christodoulou, A.J.J. Murphy, D.M. Valenzuela, G.D. Yancopoulos, M. Karow, G. Blander, C. Wolberger, T.A. Prolla, R. Weindruch, F.W. Alt, L. Guarente, SIRT4 inhibits glutamate dehydrogenase and opposes the effects of calorie restriction in pancreatic $\beta$ cells, Cell. 126 (2006) 941954. doi:10.1016/j.cell.2006.06.057. 


\section{Chapter 3}

\section{Glyceraldehyde-3-phosphate dehydrogenase}




\title{
Purification and regulation of glyceraldehyde-3-phosphate dehydrogenase (GAPDH) from freeze-tolerate Rana sylvatica liver in response to freezing, dehydration and anoxia
}

\author{
Ranim Saleem and Kenneth B. Storey*
}

Institute of Biochemistry \& Department of Biology, Carleton University, 1125 Colonel By Drive, Ottawa, K1S 5B6 Ontario, Canada 


\section{Abstract}

Wood frogs (Rana sylvatica) are one of the few species capable of full body freezing. In response to cold temperatures, these creatures convert up to $70 \%$ of their total body water to extracellular ice. Cellular dehydration and anoxia are two consequences of freezing and wood frogs can tolerate these stresses independently. Survival of these stresses requires a coordinated metabolic response, one of which is regulation of enzymatic activities. Glyceraldeyde-3phosphate dehydrogenase (GAPDH) is a key enzyme in the glycolytic and gluconeogenic pathway and it catalyzes the reversible conversion of D-glycerldeyhde-3-phosphate to generate 1,3-bisphosphateglycerate. GAPDH was purified from liver of wood frogs exposed to freezing, dehydration, or anoxia by a two-step column chromatography procedure using Cibacron blue affinity and phenyl Sepharose hydrophobic columns. Analysis of kinetic parameters of the purified GAPDH at room temperature versus $5{ }^{\circ} \mathrm{C}$ showed several notable differences between control and stresses in $\mathrm{K}_{\mathrm{m}}$ values for GAP, NAD ${ }^{+}$and 1,3BPG. The maximum GAPDH activity at $5{ }^{\circ} \mathrm{C}$ was lower for the enzyme isolated from the three stress conditions compared to the control in both directions. Thermal denaturation assessed by differential scanning fluorimetry revealed that purified GAPDH from frozen and dehydrated frogs was significantly more stable to thermal denaturation compared to control. Western blot analysis of common posttranslational modifications indicates an overall increase in phosphorylation at serine, threonine and tyrosine residues in response to freezing, dehydration and anoxia. Additionally, the nuclear distribution of GAPDH increased following dehydration and anoxic treatments. This suggests that GAPDH is translocated to the nucleus in order to aid cell survival during stressful condition. Overall, a reduction in GAPDH activity would likely contribute to the overall reduction of glycolytic flux 
as part of metabolic rate depression, and GAPDH phosphorylation may contribute to the regulation of non-glycolytic and gluconeogenic processes under these conditions.

Key words: Glyceraldeyde-3 phosphate dehydrogenase, Glycolytic \& gluconeogenic pathways, Rana sylvatica, differential scanning fluorimetry, Posttranslational modification, Phosphorylation

\subsection{Introduction}

The North American wood frog, Rana sylvatica, can survive the harsh winter months by employing a freeze tolerance strategy where it can endure the freezing of up to $65-70 \%$ of its total body water as extracellular ice [1,2]. During whole body freezing, all physiological activities such as breathing, movement, cardiac and neurological functions stop but resume to full function during springtime [1,2]. Furthermore, frozen frogs need to cope with a lack of oxygen delivery to different organs because heart beat and blood flow are interrupted [3]. Frogs also need to cope with the consequences of cellular dehydration due to the loss of much intracellular water to extracellular and extra-organ spaces to join ice crystals. This not only reduces cell volume, but also increase cellular osmolality and ionic strength $[3,4]$. Interestingly, wood frogs have also been shown to endure the loss of $\sim 60 \%$ of total body water and $48 \mathrm{~h}$ exposure to anoxia $\left(\mathrm{N}_{2}\right.$ atmosphere) at $5{ }^{\circ} \mathrm{C}$, independent of freezing, thereby allowing researchers to study the these stresses separately [5-7]. As a cryoprotective measure to freezing and dehydration, wood frogs produce large quantities of glucose as cryoprotectant [8-10]. Studies have shown that the onset of freezing triggers the mobilization of glucose from liver glycogen, thereby increasing blood glucose levels from $\sim 5 \mathrm{mM}$ to $\sim 300 \mathrm{mM}$ and saturating all organs with copious amounts of this cryoprotectant $[1,9,11]$. In order to survive whole body freezing, the wood frog would also need to rework its internal biochemical processes to reduce 
its metabolic expenditure [9]. Metabolic rate depression (MRD) is a useful adaption used by Rana sylvatica to aid with freezing, dehydration and anoxia survival, allowing most nonessential ATP-expensive cellular processes to be temporally reduced to allocate remaining limited fuel/energy only to pro-survival pathways [9]. Therefore, a regulated decrease of metabolism during freezing would be useful in order to conserve energy, and this can be achieved through strictly regulating metabolic enzymes.

The wood frog prepares itself for winter by increasing its liver glycogen storage in the fall and using that storage to generate cryoprotective glucose via glycogenolysis that is triggered within minutes after ice crystal formation on its skin. Glucose is then rapidly distributed to all organs in the body before extensive ice accumulation shuts down heartbeat and blood flow. During freezing the wood frog relies mainly on carbohydrate metabolism because the interruption in blood flow inhibits oxygen supply and leads to a switch to anaerobic glycolysis as the major internal means of ATP production [4,9]. Evidence showed an increase in phosphoenolpyruvate carboxykinase (PEPCK) activity in the liver, indicating that gluconeogenesis is occurring in early states of the freezing period [12]. Several studies showed a decrease in glycolytic flux in the liver of the wood frog during freezing $[1,9,13,14]$. It was shown within 5 min of freeze initiation, glucose-6-phopsphate (G6P) and fructose-6-phosphate (F6P) increased many fold in the liver and remained high over time as glucose was synthesized and exported, whereas fructose-1,6-bisphosphate $(\mathrm{F} 1,6 \mathrm{P} 2)$ and triose phosphate intermediates of glycolysis did not show significant changes during freeze exposure [14]. In addition, levels of fructose-2,6-bisphosphate $(\mathrm{F} 2,6 \mathrm{P} 2)$ a potent activator of phosphofructokinase (PFK) were significantly decreased during freezing in wood frog liver $[13,15]$. Indeed, these results indicate exposure to freezing inhibits glycolysis at the PFK step to block carbon flow into glycolysis and 
facilitate glycogenolysis and production of glucose $[13,14]$. Therefore, it is important to investigate into the regulation of metabolic enzyme in response to cellular stress.

One of the important enzymes involved in carbohydrate metabolism is glyceraldehyde-3phosphate dehydrogenase (GAPDH, EC 1.2.1.12), which make it an interesting enzyme to characterize in animals that experience extreme fluctuations in their fuel metabolism. GAPDH plays an important role in the glycolytic and gluconeogenic pathways, where it facilitates the conversion of D-glyceraldeyhde-3-phosphate (GAP) and $\mathrm{NAD}^{+}$to generate 1,3bisphosphoglycerate $(1,3 \mathrm{BPG})$ and $\mathrm{NADH}$ in the glycolytic direction or the reverse reaction in the gluconeogenic pathway [16]. GAPDH is a homotetramer composed of identical subunits with molecular weights of approximately $37 \mathrm{KDa}$ [16]. A previous study showed that GAPDH is regulated in a mammalian hibernator, thirteen-lined ground squirrels (Ictidomys tridecemlineatus) in skeletal muscle, to cope with hypometabolism [17]. The study showed a decrease in GAPDH activity with a reduction of GAPDH tyrosine phosphorylation during torpor, suggesting a stable suppression of GAPDH by reversible posttranslational modification, potentially to aid a reduction of carbohydrate metabolism during torpor [17]. It is well known that posttranslational modification (PTM) can be used to control cellular metabolism in response to environmental conditions, by promoting the stability or substrate binding specificity/affinity of enzymes [18]. The addition or removal of a small PTM is ATP-inexpensive and can be easily reversed by appropriate phosphatase or kinases and thereby regulation of enzyme function can be controlled by this mechanism when animals experience environmental stress and enter a hypometabolism state. Protein phosphorylation is the most commonly reported modification of enzymes in Rana sylvatica. For instance, protein phosphorylation mediates the activities of enzymes involved antioxidant defense (superoxide dismutase and catalase) as well, in glucose 
metabolism (hexokinase and glycogen phosphorylase) [19-23].Therefore, changes in phosphorylation state are indicative of regulatory changes contributing to global MRD.

Along with its conventional metabolic role in carbohydrate metabolism, GAPDH is also known to have multiple non-canonical roles in the cell such as membrane trafficking, apoptosis, oxidative stress response, autophagy, DNA repair and transcriptional activation depending on its posttranslational modifications [16,24]. Previous studies showed that serine/threonine protein kinase (Akt2) interacts with GAPDH to phosphorylate it at Thr-237, resulting in a decrease/inhibition of its nuclear translocation and its role in apoptosis [25]. Moreover, acetylation of GAPDH increases the glycolytic activity of GAPDH but inhibits its gluconeogenic functions [26,27]. In addition to its known function in glycolysis, cytoplasmic GAPDH is acetylated by acetyltransferase p300/CREB binding protein (PCAF), and this induces its nuclear translocation whereas it can participate and induce cell death $[27,28]$. Furthermore, GAPDH is modified by other posttranslational modification such as S-nitrosylation, ADP ribosylation, carbonylation, and S-glutathionylation, all of which regulate GAPDH association in apoptosis, nuclear translocation, autophagy, signal transduction and oxidative stress sensing [16,24,29-32]

Given the change in the flux of carbohydrate metabolism in response to freezing and its associated stress (dehydration and anoxia), it was hypothesized that liver GAPDH activity may be inhibited to contribute to the overall suppression of metabolic rate and the diversion of carbon flow into glucose output as a cryoprotectant. Therefore, the present study explored the regulation of GAPDH in freezing by investigating its different kinetic parameters and its physical and regulatory properties in response to freezing, dehydration and anoxia. The results revealed that purified liver GAPDH from control, frozen, dehydrated and anoxic frogs had significantly 
different kinetics properties, thermal stability and is regulated by changes in protein phosphorylation.

\subsection{Methods}

\subsubsection{Animals and experimental procedures}

Adult mature male wood frogs were collected from spring breeding ponds in the Ottawa area, Ontario, Canada in April. All frogs were washed in a tetracycline bath and held at $5{ }^{\circ} \mathrm{C}$ in plastic containers lined with damp sphagnum moss for two weeks for 1-2 weeks before the experiments. This allowed the wood frogs to acclimate before experimentation. Control animals were randomly sampled directly from this condition. Whole animal freezing was conducted as previously published [33]. Frogs were randomly selected and then placed in closed plastic containers lined with damp paper towels and placed in an incubator set at $-4{ }^{\circ} \mathrm{C}$ for $45 \mathrm{~min}$ in order to initiate ice nucleation. Following the initial $45 \mathrm{~min}$, the incubator temperature was raised to $-2.5^{\circ} \mathrm{C}$ for $24 \mathrm{~h}$ and then the frozen grogs were sampled.

Dehydration exposure was conducted as previously published [34]. Acclimated frogs were individually weighed and then placed in open dry container at $5{ }^{\circ} \mathrm{C}$. The frogs were weighed at different intervals to monitor the percentage of body waster lost by evaporation which was calculated using the following equation:

$$
\% \text { change }=\left[\left(\mathrm{M}_{\mathrm{i}}-\mathrm{M}_{\mathrm{d}}\right) /\left(\mathrm{M}_{\mathrm{i}} \mathrm{x} \% \mathrm{H}_{2} \mathrm{O}\right)\right] \mathrm{x} 100
$$

where $\mathrm{M}_{\mathrm{i}}$ is the initial body mass of the animal, $\mathrm{M}_{\mathrm{d}}$ is the mass at a given weighing and $\% \mathrm{H}_{2} \mathrm{O}$ percentage of body mass that is water which was determined to be $80.8+1.2 \%$ for control frogs. Frogs were sampled when they reached $40 \%$ dehydration. 
Anoxia experiments followed to a previously established protocol [35]. Large plastic jars were fitted with inlet and outlet ports to allow flushing with nitrogen gas. The containers were placed on ice and the bottom of the container was lined with a layer of damp paper towel that was previously wet in water bubbled with $100 \% \mathrm{~N}_{2}$ gas. Nitrogen gas was then flushed into the containers for 20 min prior to placing the frogs. Acclimated frogs were placed in the jar, the lid was tightened, and nitrogen gas was reintroduced for another 30 minutes to ensure that jars were $100 \%$ anoxic. Following exposure, containers were sealed with parafilm and transferred to a $5{ }^{\circ} \mathrm{C}$ incubator for $24 \mathrm{~h}$ prior to sampling. During sampling, the nitrogen gas line was reconnected in order to maintain an anoxic environment in the jar.

In all cases, frogs were euthanized via pithing and liver tissues were rapidly dissected, flash frozen in liquid nitrogen and transferred to $-80^{\circ} \mathrm{C}$ storage. All animal procedures were approved by Carleton University's Animal Care Committee (protocol \#13683) in accordance with guidance set out by the Canadian Council on Animal Care.

\subsubsection{Preparation of Liver Extracts}

Liver samples were weighed and homogenized in 1:5 w:v ratio in ice-cold buffer A containing $25 \mathrm{mM}$ imidazole buffer $\mathrm{pH}$ 7.0, $15 \mathrm{mM} \beta$-mercaptoethanol, 10\% v:v glycerol, and inhibitors of protein phosphatases (12.5 mM $\beta$-glycerophosphate; Sigma, Cat. No. G9422), protein kinases (1.25 mM EDTA and 1.25 mM EGTA) and proteases (a few crystals of phenylmethylsulfonyl fluoride; PMSF; Bioshop, Cat. No. PMS444) using a Polytron homogenizer. Samples were then centrifuged in an Eppendorf 5810R for $30 \mathrm{~min}$ at 13,500 x g at $4^{\circ} \mathrm{C}$. The supernatant was removed, and its volume measured; the pellet was discarded. 


\subsubsection{Enzyme Assays}

The optimal assay conditions were experimentally determined for the oxidation of Dglyceraldehyde-3-phosphate (GAP) and were 2.5 mM GAP (Chem Cruz, Cat. No. Sc.280680), 3 mM NAD ${ }^{+}, 30 \mathrm{mM}$ sodium arsenate $\left(\mathrm{Na}_{2} \mathrm{HAsO}_{4}\right)$, and $50 \mathrm{mM}$ sodium phosphate $\left(\mathrm{NaH}_{2} \mathrm{PO}_{4}\right), \mathrm{pH}$ 8.0 in a total volume of $100 \mu \mathrm{L}$ with $20 \mu \mathrm{L}$ of purified GAPDH protein. The optimal assay conditions for the reverse reaction were $2.5 \mathrm{mM}$ 3-phosphoglycerate (3PG), $2 \mathrm{mM} \mathrm{Mg-ATP}, 0.1$ mM NADH, 1 unit of phosphoglycerate kinase (Boehringer Mannheim), and $50 \mathrm{mM}$ Tris-HCl buffer, $\mathrm{pH}$ 8.0. The enzyme reaction for the reverse direction was initiated by addition of $20 \mu \mathrm{L}$ of purified GAPDH protein from wood frogs in a total volume of $200 \mu \mathrm{L}$. These conditions were determined to be sufficient to elicit maximal velocity of the enzyme reaction in both directions. All assays were performed at $22^{\circ} \mathrm{C}$ unless otherwise stated. The absorbance at $340 \mathrm{~nm}$ of each well was read using a Thermo Scientific Multiskan Spectrum microplate reader over a 15 minute period, at 21 second intervals for 40 times.

Protein concentrations of the obtained samples were determined using the Bio-Rad protein assay (BioRad, Cat. No. 50000006) using bovine serum albumin as a standard. Sample absorbance was read at $595 \mathrm{~nm}$ using a BioTek microplate reader.

\subsubsection{Enzyme Purification}

A Cibacron Blue affinity column (Bioworld, Cat. No. 20181096-1) was prepared and equilibrated with $15 \mathrm{~mL}$ of buffer $\mathrm{A}$ at $\mathrm{pH}$ 7.0. Crude enzyme homogenate was loaded onto the column and washed with $20 \mathrm{~mL}$ buffer A to elute any unbound protein. GAPDH was then eluted with a $60 \mathrm{~mL}$ linear salt gradient of $0-2 \mathrm{M}$ potassium chloride $(\mathrm{KCl})$ prepared in buffer $\mathrm{A}$. The activity of GAPDH was measured under optimal conditions for the oxidation of D- 
glyceraldehyde-3-phopshate as described and the top 6 fractions containing GAPDH activity were pooled and used for subsequent steps.

The phenyl-Sepharose column (Bioworld, Cat. No. 20181074-1) was prepared and equilibrated by running through $15 \mathrm{~mL}$ of buffer $\mathrm{B}$ (buffer A containing $1.5 \mathrm{M} \mathrm{KCl}$ ). The salt concentration of the samples was increased to $\sim 1.5 \mathrm{M} \mathrm{KCl}$ before loading on to the column. A volume of $20 \mathrm{~mL}$ of buffer B was used to remove any unbound proteins from the column. GAPDH was then eluted with a $100 \mathrm{~mL}$ linear $1.5-0 \mathrm{M} \mathrm{KCl}$ gradient (decreasing salt concentration). The top four fractions with the highest GAPDH activity were collected and held at $4{ }^{\circ} \mathrm{C}$ until use.

The purity of GAPDH was assessed via SDS-PAGE (sodium dodecyl sulfatepolyacrylamide gel electrophoresis). Enzyme samples were prepared by mixing them with 1:1 v:v of SDS loading buffer (100 mM Tris buffer, $\mathrm{pH} 6.8,4 \% \mathrm{w}$ :v SDS, 20\% v:v glycerol, $0.2 \%$ w:v bromophenol blue, and 10\% v:v $\beta$-mercaptoethanol) except for purified GAPDH obtained from the phenyl chromatography step that was mixed with 4:1 v:v SDS loading buffer. All samples were boiled for $5 \mathrm{~min}$, cooled on ice and stored at $-20{ }^{\circ} \mathrm{C}$ until use. Aliquots containing $\sim 10 \mu \mathrm{g}$ of protein, protein molecular weight ladder (Froggabio, Cat. No. PM005-0500) and a commercially purified rabbit muscle GAPDH (Kristal suspension) were loaded into wells of SDS-polyacrylamide gels (10\% resolving gel, $5 \%$ stacking gel). The gel was run at $180 \mathrm{~V}$ for 50 min in running buffer ( $25 \mathrm{mM}$ Tris-base, $250 \mathrm{mM}$ glycine, and $0.1 \% \mathrm{SDS}$ ). Once appropriate separation was reached, the gel was stained with Coomassie Brilliant Blue (25\% w:v Coomassie brilliant blue, $7.5 \%$ v:v acetic acid, 50\% methanol) for $30 \mathrm{~min}$ and then destained using Coomassie destain solution (10\% acetic acid, $15 \%$ methanol). The gel was visualized under light 
and images were captured using the ChemiGenius BioImaging system (Syngene, Frederick, MD).

\subsubsection{Determination of Kinetic Parameters}

The kinetic parameters of purified Rana sylvatica liver GAPDH were investigated to understand the properties of GAPDH under different conditions. The Michaelis-Menten constant $\left(\mathrm{K}_{\mathrm{m}}\right)$ values for different substrates were determined by varying the substrate concentration while keeping co-substrate concentration(s) constant at optimal levels, as listed above. $\mathrm{K}_{\mathrm{m}}$ values for GAP, NAD ${ }^{+}$and 1,3-bisphosphoglyceric acid were determined. The inhibitor concentration that reduced enzyme activity by $50 \%$ ( $\mathrm{I}_{50}$ values) were determined for urea, $\mathrm{KCl}$ and sodium chloride $(\mathrm{NaCl})$ by increasing their concentration and using optimal substrate conditions in the forward direction, as above. The $\mathrm{V}_{\max }$ was also determined in both directions by measuring the activity at optimal substrate concentrations and are expressed as units per milligram of purified protein. Data was processed using an enzyme kinetic analysis program, Kinetics v.3.5.1[36]

\subsubsection{Low Temperature Enzymes kinetics}

To assess the influence of temperature on the enzymatic activity of GAPDH, the assays were performed at low temperatures. The kinetics parameters $\left(\mathrm{K}_{\mathrm{m}}\right.$ and $\mathrm{V}_{\max }$ values $)$ for GAPDH in the forward and reverse direction were also assessed at $5^{\circ} \mathrm{C}$. To establish the low temperature condition, the Thermo Scientific Multiskan spectrophotometer was placed in a Precision 815 low temperature incubator (Thermo Scientific) set at $5{ }^{\circ} \mathrm{C}$. The microplate containing all assay components except for purified GAPDH (that was cooled separately) was pre-chilled at $5^{\circ} \mathrm{C}$. To ensure adequate cooling, the temperature of a blank well was measured using a thermistor before adding GAPDH. The Kinetics computer program was used to analyze the data [36]. 


\subsubsection{Total protein extraction}

Total protein extraction was performed as previously described [37]. Approximately 50 $\mathrm{mg}$ of frozen liver ( $\mathrm{n}=4$ independent biological replicates from different animals) from control, frozen, dehydrated and anoxia treatments were homogenized in 1:2 w/v homogenization buffer (20 mM HEPES, pH 7.5, $200 \mathrm{mM} \mathrm{NaCl}, 10 \mathrm{mM}$ sodium fluoride [NaF], $10 \mathrm{mM} \beta$ glycerophosphate, $0.1 \mathrm{mM}$ EDTA, $1 \mathrm{mM}$ sodium orthovanadate [ $\left.\mathrm{Na}_{3} \mathrm{VO}_{4}\right], 1 \mathrm{mM}$ PMSF, and 1 $\mu \mathrm{L} / \mathrm{mL}$ of protease inhibitor cocktail [BioShop, no.P1C00.1]) using a Polytron PT10 homogenizer for 20 seconds. Samples were then centrifuged at $10,000 \mathrm{rpm}$ for $10 \mathrm{~min}$ at $4^{\circ} \mathrm{C}$. The supernatant containing the soluble protein fractions were collected, their concentration was measured using the Bradford method (BioRad, no.5000006). All samples were then standardized to a constant protein concentration using the same homogenization buffer. Aliquots of total soluble protein extracts were mixed in 1:1 v: $\mathrm{v}$ with $2 \mathrm{X}$ loading buffer to give final concentration of $5 \mu \mathrm{g} / \mu \mathrm{L}$. All samples were boiled for $5 \mathrm{~min}$, and then stored at $-80{ }^{\circ} \mathrm{C}$ for future use.

\subsubsection{Cytoplasmic/nuclear extraction}

The procedure of the cytoplasmic and nuclear fractionation was followed as previously described [37]. Liver samples ( $\mathrm{n}=4$ ) from all treatment (control, frozen, dehydration and anoxia) were homogenized with 1:2 w/v buffer A containing $10 \mathrm{mM}$ HEPES, $\mathrm{pH}$ 7.9, $10 \mathrm{mM} \mathrm{KCl}, 10$ mM EDTA, $10 \mu \mathrm{L}$ of $100 \mathrm{mM}$ dithiothreitol (DTT) (Bioshop, Cat. No. DTT001.10) and $10 \mu \mathrm{L}$ of protease inhibitor cocktail per $1 \mathrm{~mL}$ of buffer using a Dounce homogenizer and then centrifuged at 10,000 rpm for $10 \mathrm{~min}$ at $4{ }^{\circ} \mathrm{C}$. The supernatant was collected and saved as the cytoplasmic fraction. The resulting pellets were resuspended in buffer B containing $10 \mathrm{mM}$ HEPES, pH 7.9, $400 \mathrm{mM} \mathrm{NaCl}, 1 \mathrm{mM}$ EDTA, 10\% v/v of glycerol, $10 \mu \mathrm{L}$ of $100 \mathrm{mM}$ DTT and $10 \mu \mathrm{L}$ of protease inhibitor cocktail per $1 \mathrm{~mL}$ per $1 \mathrm{~mL}$ of buffer. All samples were incubated on 
ice for 1 hour with a gentle vortexing every 10 minutes. Following incubation, samples were centrifuged as explained previously, and the supernatants were collected and stored as the corresponding nuclear fractions. The protein concentration of cytoplasmic and nuclear extracts were measured by using the Bradford assay. The fractions were prepared for western blotting analysis as explained under western blots analysis. Histone $\mathrm{H} 3$ (nuclear marker) or $\beta$-tubulin (cytoplasmic marker) were used to test the efficiency of the fractionation process.

\subsubsection{Western Blots Analysis}

Immunoblotting was used to investigate relative GAPDH expression, subcellular localization and PTMs. Semi-purified samples obtained from the first Cibacron blue chromatography step were used to determine relative level of GAPDH PTMs. The semi-purified samples were prepared by mixing them 1:1 v:v with SDS loading buffer. The amount of GAPDH used for western blots was adjusted by dilution such that equals amounts of GAPDH was loaded on each well of the gel. The procedure for western blots were followed as described previously [38].The semi-purified sample were loaded on $10 \%$ polyacrylamide gels with 5\% stacking gels

and then run for $50 \mathrm{~min}$ at $180 \mathrm{~V}$. For total GAPDH and nuclear GAPDH, equal amount of $15 \mu \mathrm{g}$ for all the conditions were loaded into wells of the gel and were run through $12 \%$ polyacrylamide gels with $5 \%$ stacking gels at $180 \mathrm{~V}$ for $70 \mathrm{~min}$. Following electrophoresis, proteins were transferred to a polyvinylidene fluoride (PVDF) membrane at $160 \mathrm{~mA}$ for $90 \mathrm{~min}$ using transfer buffer (25 mM Tris, $\mathrm{pH} 8.5,192 \mathrm{mM}$ glycine and 10\% v/v methanol).

Following transfer, membranes were probed with anti-GAPDH or PTM-specific primary antibodies and incubated overnight at $4{ }^{\circ} \mathrm{C}$ while rocking. For total GAPDH and nuclear GAPDH, the membrane was blocked with 5\% non-fat dried milk in Tris-buffered saline containing Tween-20 (TBST: $20 \mathrm{mM}$ Tris base, $\mathrm{pH}$ 7.6, $140 \mathrm{mM} \mathrm{NaCl}, 0.05 \%$ v/v Tween-20) 
for 30 min at room temperature while rocking, and then washed $3 \mathrm{x}$ for 5 minutes with TBST with the same conditions. The primary antibodies used in the experiments were diluted 1:1000 and weare as follows: anti-phosphorylated tyrosine (Cell signaling, \# 9441), 2: aAntiphosphorylated serine (Abcam, \# ab9332), 3: anti-phosphorylated threonine (Invitrogen, \#718200), 4: anti tri-methylated lysine (StressMarq, \# SPC-158), 5: anti nitrosylated cysteine (Abcam, \# ab50185), 6: anti- pan acetylated (Santa Cruz Biotechnology, \# SC-8663), and 7: antiGAPDH (GeneTex, GTX100118)

After incubation, unbound primary antibody was removed and membranes were washed five times for 5 min each with TBST before being incubated with either horseradish peroxidase conjugated anti-rabbit IgG or anti-mouse IgG antibodies (BioShop, diluted 1:8,000 v:v in TBST) for $30 \mathrm{~min}$ at room temperature while rocking. Following washing, equal volumes of chemiluminescence reagent and hydrogen peroxide were added to the membranes and imaged using the ChemiGenius Bioimaging system (Syngene, Frederick, MD). Following exposure, membranes were stained with Coomassie Brilliant-blue and imaged in the same manner. Band intensities from GAPDH expression, modification and subcellular localization were normalized against the same band on the Coomassie stained membrane using GeneTools software. Data for samples from stressed frogs are reported relative to controls which were set to 1.

\subsubsection{Differential scanning fluorimetry}

Differential scanning fluorimetry (DSF) is a fluorescent based (SYPRO orange) technique that monitors the thermal unfolding of proteins and measures the melting temperature ( $\left.\mathrm{T}_{\mathrm{m}}\right)$ using Bio-Rad CFX Connect ${ }^{\mathrm{TM}}$ Real-Time PCR Detection System (Bio-Rad, Cat. No. 1855201) [39]. SYPRO orange dye fluoresces when it is bound to the exposed hydrophobic residues of denatured proteins, and this can be measured as an indicator of protein folding [40]. 
Prior to DSF, purified GAPDH was spun on a G25 Sephadex column previously pre-equilibrated in DSF buffer (100 mM potassium phosphate, $\mathrm{pH} 7.0,150 \mathrm{mM} \mathrm{NaCl}$ ), at $2500 \mathrm{rpm}$ for $1 \mathrm{~min}$. Following equilibration, an Amicon Ultra-4 centrifugal filter 10K (Sigma-Aldrich, 10,000 MWCO) column was used to concentrate GAPDH. The column was centrifuged in a Sorvall RC58 for $15 \mathrm{~min}$ at $8,000 \mathrm{xg}$ and $4^{\circ} \mathrm{C}$. Purified GAPDH at final concentration of $0.08 \mathrm{mg} / \mathrm{mL}$, DSF buffer and 40X SYPRO orange dye (5X final concentration of the dye per well) were mixed in a $20 \mu L$ final volume in PCR microplates wells. The PCR plate was sealed and placed into the BioRad CFX Connect Real-Time System instrument customized for fluorescence detection of SYPRO orange (Invitrogen). The following wavelengths were used: excitation $490 \pm 20 \mathrm{~nm}$ and the emission filter $625 \pm 30 \mathrm{~nm}$. Measurement was taken as temperature rose from 20 to $95^{\circ} \mathrm{C}$ with a $0.5{ }^{\circ} \mathrm{C}$ increase per cycle. The protein $\mathrm{T}_{\mathrm{m}}$ was determined by analysis the fluorescence intensity with respect to temperature by using OriginPro 8.5 and the Boltzmann distribution curves [41].

\subsubsection{Data and Statistical Analysis}

All enzyme kinetic data were analyzed using a Microplate Analysis program (MPA) and Kinetics parameters ( $\mathrm{K}_{\mathrm{m}}$ and $\mathrm{I}_{50}$ values) were calculated using a nonlinear least regression computer program, Kinetics v.3.5.1 [36]. A Hill equation curve $(h>0)$ was used to fit the data points and determine the kinetic parameter. The standardization of protein concentration used for western blots was accomplished by quantifying the GAPDH band from the purified protein samples using Coomassie stain on a PVDF membrane after transfer from an SDS-PAGE gel. Data for all kinetics parameters, western blots and DSF compared between control and stresses were analyzed using two-tailed Student's $t$-test with accounting for unequal variance where a 
significant result was $p<0.05$. Graphing was performed using RBioplot statistical software with a two-tailed Student's $t$-test $(p<0.05)$ [42].

\subsection{Results}

\subsubsection{Enzyme Purification}

GAPDH from liver of the wood frog was purified to homogeneity in two-steps by using a Cibacron blue affinity column followed by a hydrophobic column of phenyl-Sepharose. The overall activity yield of GAPDH purification was $11 \%$ as measured from the total activity (units) from the final step divided by the total starting activity (crude), with a fold purification of 79 and a final specific activity of $15.3 \mathrm{U} / \mathrm{mg}$ (Table 3.1). The overall yield of GAPDH from liver of frozen frogs was $8 \%$ with a fold purification of 108 and a specific activity of $40 \mathrm{U} / \mathrm{mg}$ (Table 3.1). The full procedure for dehydrated GAPDH gave a $16 \%$ yield of enzymatic activity and a 57-fold purification with a final specific activity for GAPDH at $11.4 \mathrm{U} / \mathrm{mg}$ (Table 3.1). Finally, the overall yield for anoxic GAPDH was $13 \%$ with a 61 -fold purification and $7.3 \mathrm{U} / \mathrm{mg}$ specific

activity (Table 1). The purity of GAPDH was assessed by SDS-PAGE followed by staining with Coomassie brilliant blue (Fig.3.1). A standard of commercial rabbit muscle GAPDH was run alongside the frog GAPDH samples to act as a positive control. GAPDH from liver or control, frozen, dehydrated and anoxic wood frogs showed a consistent molecular weight of around 37 KDa based on electrophoretic mobility, as compared to the protein standard ladder (Fig. 3.1)

\subsubsection{Enzyme Kinetics}

Enzymatic parameters were investigated in the GAP oxidizing direction and 1,3BPGreducing direction using purified GAPDH from control, freeze-exposed, dehydrated-exposed and anoxia-exposed frogs at room temperature $\left(22^{\circ} \mathrm{C}\right)$ and at low temperature $\left(5^{\circ} \mathrm{C}\right)$. There were several significant differences in GAPDH kinetics parameters (Table 3.2). At $22^{\circ} \mathrm{C}$ in the GAP- 
oxidizing direction, the $\mathrm{K}_{\mathrm{m}}$ values for GAP isolated from dehydration and anoxic exposures were significantly lower than the control with the dehydrated parameter being $0.73 \mathrm{mM}$ and anoxia value of $0.81 \mathrm{mM}$ compared to control value of $1.28 \mathrm{mM}$. This trend also happened for $\mathrm{K}_{\mathrm{m}}$ of $\mathrm{NAD}^{+}$where frozen $(0.37 \mathrm{mM})$, dehydrated $(0.35 \mathrm{mM})$ and anoxic $(0.27 \mathrm{mM})$ forms of the enzyme showed a significant decrease as compared to the control (0.57 Mm; Table 3.2). In addition to the increase in substrate affinity in response to stress, the $V_{\max }$ was significantly increased under all stress conditions compared to the control (Table 3.2). The maximal activity of GAPDH under different conditions was as follows: freezing $19.6 \mathrm{U} / \mathrm{mg}$, dehydration 17.6 $\mathrm{U} / \mathrm{mg}$ and anoxia $11.9 \mathrm{U} / \mathrm{mg}$ compared to control which was $4.81 \mathrm{U} / \mathrm{mg}$. The enzymatic activity was also measured in the $1,3 \mathrm{BPG}$-reducing direction at $22{ }^{\circ} \mathrm{C}$, where the $\mathrm{K}_{\mathrm{m}}$ of $1,3 \mathrm{BPG}$ of the freeze-exposed enzyme $(0.22 \mathrm{mM})$ was significantly lower than the control $(0.32 \mathrm{mM})$. Values for GAPDH $V_{\max }$ in the 1,3BPG direction were significantly different between the purified samples, where frozen and anoxic GAPDH were $\sim 53 \%$ and $\sim 34 \%$ less compared to the control, respectively. The dehydration exposed GAPDH $(15.0 \mathrm{U} / \mathrm{mg})$ increased significantly when compared to the maximal activity of control GAPDH $(14.3 \mathrm{U} / \mathrm{mg})$.

Kinetic parameters were also assessed at $5{ }^{\circ} \mathrm{C}$ (Table 3.2). The frozen GAPDH showed a significant decrease in the affinity for $\mathrm{NAD}^{+}(0.41 \mathrm{mM})$ in comparison to the control $(0.19 \mathrm{mM})$ and there was a significant decrease in the maximal activity with the frozen form of the enzyme being $57 \%$ less than control (Table 3.2). The maximal activity in the reverse reaction also showed a significant decrease when compared to the control values, where the activity was $53 \%$ less in frozen, $15 \%$ less in dehydrated and $25 \%$ less in anoxia-expose tissue, compared with controls. The $\mathrm{K}_{\mathrm{m}}$ for 1,3BPG was significantly lower under dehydration compared to the control 
$(0.27 \mathrm{mM}$ versus $0.38 \mathrm{mM})$ and significantly higher under anoxic conditions than control $(0.54$ $\mathrm{mM}$ versus $0.38 \mathrm{mM}$ ).

The stability of GAPDH was evaluated using denaturants including urea, $\mathrm{KCl}$ and $\mathrm{NaCl}$ to calculating $\mathrm{I}_{50}$ values in response to increasing concentration of denaturants (Table 3.3). The $\mathrm{I}_{50}$ for urea for frozen GAPDH increased significantly by 1.23 -fold compared to the control. The $\mathrm{I}_{50}$ of urea value of the dehydrated form of GAPDH (3.09 M) and anoxic form of GAPDH (4.78 M) did not show a statistically significant changes compared to the control (Table 3.3). The $\mathrm{I}_{50}$ $\mathrm{KCl}$ values for the enzyme showed no significant differences between control and stress forms of GAPDH (Table 3.3). Finally, $\mathrm{I}_{50} \mathrm{NaCl}$ for GAPDH from dehydrated frogs increased by 1.34-fold compared to controls (Table 3.3). However, the $\mathrm{I}_{50} \mathrm{NaCl}$ for GAPDH from frozen and anoxic frogs did not show any significant differences as compared to the control value (Table 3.3).

\subsubsection{Differential scanning fluorimetry}

DSF is a high throughput method that determines the thermal stability of purified proteins in the presence of a fluorescent dye. The freeze-exposed enzyme displayed a significantly higher unfolding temperature $\left(\mathrm{T}_{\mathrm{m}}\right)$ of $78.2{ }^{\circ} \mathrm{C}$ compared to the control $51.2{ }^{\circ} \mathrm{C}$ (Fig. 3.2). As well, dehydration-exposed enzyme $\left(72.3{ }^{\circ} \mathrm{C}\right)$ showed a higher $\mathrm{T}_{\mathrm{m}}$ than control (Fig. 3.2$)$. The anoxia exposed enzyme did not change significantly compared to controls with a $\mathrm{T}_{\mathrm{m}}$ of $49.3{ }^{\circ} \mathrm{C}$ (Fig. 3.2).

\subsubsection{Analysis for posttranslational modifications}

Different posttranslational modifications of GAPDH were assessed through western blots. Overall, most PTMs were unresponsive to the different stresses with a few exceptions. Ptyrosine levels for frozen GAPDH were 1.19 times higher compared to controls (Fig. 3.3A). 
Similarly, levels of methyl-lysine were 1.43 times higher compared to the control (Fig. 3.3A). The dehydrated form of the enzyme demonstrated 4.08-fold higher P-serine levels compared to controls (Fig. 3.3B) and the anoxic GAPDH showed a significant increase in P-tyrosine content ( $\sim 1.40$ fold) but level of P-threonine on the anoxic variant decreased by $\sim 16 \%$ relative to controls (Fig. 3.3C).

\subsubsection{GAPDH subcellular localization}

The total and nuclear levels of GAPDH from control, frozen, dehydrated and anoxic samples were assessed to determine the overall expression and localization of GAPDH using western blotting. The total levels of GAPDH from freeze-exposed samples were $37 \%$ less compare to control GAPDH levels (Fig. 3.4A). In comparison, GAPDH from dehydrated frogs showed a slight but insignificant decrease in the total GAPDH level and anoxic GAPDH showed a slight insignificant increase in GAPDH levels (Fig. 3.4B\&C). Nuclear GAPDH levels for freezeexposed enzyme did not show any significant change when compared to controls (Fig. 3.5A). However, the dehydrated and anoxic conditions demonstrated 1.27 and 1.49 higher nuclear GAPDH levels compared to control, respectively (Fig. 3.5B\&C).

\subsection{Discussion}

Many animals deal with winter conditions differently: some migrate to warmer climates, some hide away in their hibernacula, and others adopt a freeze tolerance strategy. Wood frogs are among the most freeze-tolerant vertebrates and they can endure the conversion of $65-70 \%$ of their total body water into extracellular ice [2]. The freezing of the extracellular water leads to intracellular dehydration since water is withdrawn from cells to form extracellular ice crystals. Freezing also leads to an anoxic cellular environment due to the freezing of blood plasma and interruption in heartbeat, all of which reduce oxygen delivery to other organs [3]. Therefore, the 
freeze tolerant wood frog must endure freezing, dehydration and anoxia stresses to survive during the winter. As cryoprotective responses, wood frogs produce large quantities of cryoprotectants (glucose and urea) and suppress their metabolic rate to save energy [8]. Numerous studies have been done to illustrate how wood frogs regulate their carbohydrate metabolism by focusing on key enzymes involved in metabolism [4,9]. Given the potential importance of GAPDH and its pivotal role in carbohydrate metabolism and energy production, it was of interest to study this enzyme in wood frog liver under freezing and associated stresses.

Wood frog liver GAPDH was purified to homogeneity by using a combination of affinity and hydrophobic chromatography techniques. Results show a purified GAPDH band (Fig. 3.1) where the yield was $11 \%$ for control GAPDH, $8 \%$ for frozen GAPDH, $16 \%$ dehydrated GAPDH and 13\% anoxic GAPDH (Table 3.1). The purification scheme used in this study is comparable to those used in other studies in different animals, thereby demonstrating an effective way of isolating GAPDH from tissues [17,43-45].

Analysis of the kinetic parameters of purified GAPDH from liver of freeze, dehydrated and anoxia exposed wood frog showed several key differences in this enzyme. The kinetic parameters of purified GAPDH were tested at room temperature $22{ }^{\circ} \mathrm{C}$ and $5{ }^{\circ} \mathrm{C}$. Although this is not environmentally relevant to freezing (acclimated frogs were kept at $5{ }^{\circ} \mathrm{C}$ ), this temperature was chosen to avoid the freezing of assay reagents. In addition, assays run at $5{ }^{\circ} \mathrm{C}$ are relevant to dehydration and anoxic-treated frogs. A comparison between control and frozen frogs showed interesting results (Table 3.2). The $\mathrm{K}_{\mathrm{m}}$ for $\mathrm{NAD}^{+}$in the GAP-oxidizing direction was showed opposite trends for both temperatures where GAPDH from frozen frogs assayed at room temperature had higher affinity for $\mathrm{NAD}^{+}$compared to control (Table 3.2). This was reversed at $5{ }^{\circ} \mathrm{C}$, where GAPDH from frozen frogs had low affinity for $\mathrm{NAD}^{+}$compared to control (Table 
2). Furthermore, $V_{\max }$ of GAPDH in the GAP-oxidizing direction showed a significant increase at room temperature for enzyme isolated from frozen frogs but showed a significant decrease at 5 ${ }^{\circ} \mathrm{C}$. The results at $5{ }^{\circ} \mathrm{C}$ do coincide with the expected reduction of liver glycolysis as wood frogs slow down their glycolytic pathway. Indeed, it was shown that exposure to freezing inhibited glycolysis at the PFK step where levels of F2,6P2 decreased during freezing leading to the inhibition of PFK and ultimately of glycolysis $[12,14,15]$. In addition, pyruvate dehydrogenase was revealed to be suppressed during freezing and that further supports the overall decrease in glycolysis [46]. In the 1,3-BPG reducing direction, the maximal activities at both temperatures for the enzyme from freeze exposed frogs were significantly lower relative to control samples (Table 3.2). This suggests that GAPDH activity is also decreased in the gluconeogenic direction during freeze exposure. The higher activity and apparent affinity of frozen GAPDH versus controls for GAP and $\mathrm{NAD}^{+}$at the higher temperature may be important during periods of thawing since wood frogs can experience multiple freeze-thaw cycles over the winter. F2,6P2 levels increase during thawing (24 h-thaw) which would activate PFK and ultimately stimulate glycolysis $[13,15]$. In addition, PFK activity was found to increase during thawing (24 h-thaw) indicating that glucose catabolism was activated and/or reinstated in the liver of the thawed frogs [12].Current studies lack information on when exactly the wood frog switches from anaerobic to aerobic metabolism. In fact, restoration of the heartbeat is the first physiological function that resume during the first hour of thawing [47]. This would restore blood flow to different organs and causes metabolic demands to increase which would ultimately switch back to aerobic metabolism as the frogs are warming up [47]. Therefore, this might indicate that during brief period of thawing, frogs increase their energy demand causing a switch to aerobic metabolism 
and maybe increasing glycolytic rate which may explain the increase in GAPDH activity at higher temperature.

Kinetic parameters were also measured for purified GAPDH in tissues from dehydrated and anoxic frogs (Table 3.2). The decrease of GAPDH activity during dehydration exposure coincides well with previous investigations of wood frog liver, supporting that conclusion that glycolysis is inhibited at the PFK locus as seen by elevated levels of G6P and F6P but levels of F1,6P2 or triose phosphates that did not change during dehydration [6]. This appears to be a conserved regulatory response since the same regulation was observed in freezing frogs. In addition, a previous study found that three glycolytic enzymes including GAPDH (as well as pyruvate kinase and lactate dehydrogenase) decreased in activity in the liver of spadefoot toads, Scaphiopus couchi, during estivation [48]. At $5^{\circ} \mathrm{C}$, GAPDH from the anoxia treatment displayed a lower maximal activity in both directions relative to the control suggesting that GAPDH is suppressed as well during anoxia exposure (Table 3.2). Unlike dehydration, anoxia inhibits tissue oxygenation and promotes a switch to anaerobic energy production. Anoxia exposure also differs from freezing and dehydration conditions since it does not need the production of cryo/osmoprotectants (ie. glucose), and thereby an alternate mode of glycolytic control can be involved in the liver [3]. In general, it has been found that levels of F2,6P2 decreased in response to anoxia/ischemia in the liver of different organism, suggesting a strong glycolytic control acting at the PFK locus during oxygen deprivation [49,50]. Similarly, a strong reduction in PFK enzymatic activity in Otala lactea hepatopancreas occurred in response to anoxia [51]. The drop of F2,6P2 may be part of the overall mechanism of MRD during anoxia. Given these animals are anoxia tolerant, it highly likely that wood frogs regulate their glycolytic activities in a similar manner. Interestingly, a recent phosphoproteomic study revealed that there was no change in 
PFK phosphorylation level, and therefore, either other novel posttranslational modification are involved in regulating its activity, or wood frogs regulates their glycolysis at a level downstream of PFK during anoxia [52]. Further research is warranted to investigate this claim. In summary, the results for GAPDH at $5{ }^{\circ} \mathrm{C}$ support an overall decrease in glycolysis flux during freezing and its associated stressors $[14,15]$. The decrease in GAPDH activity would be beneficial to the wood frog as it will contribute to the overall MRD to conserve energy as well as limiting the consumption of cryoprotectant glucose by slowing the rate of glycolysis. A similar study showed that GAPDH is involved in regulating metabolism during hibernation in ground squirrels (Ictidomys tridecmlineatus) [17]. The study showed a reduction in $\mathrm{V}_{\max }$ at $5{ }^{\circ} \mathrm{C}$ in both directions (glycolytic and gluconeogenic) during hibernation, a finding that parallels the results seen in this study that demonstrate a decreased in GAPDH activity [17]. Therefore, a suppression of GAPDH activity may be a conserved regulatory response in animals that undergo MRD.

The differences in kinetic parameters of GAPDH between control, frozen, dehydrated and anoxia states suggest a potential regulation of this enzyme based on its structure. To test if the differences in kinetic parameters are related to changes in overall enzyme structure, DSF was used [17]. Current results show that GAPDH from livers of frozen and dehydrated frogs was significantly more stable compared to the control group (Fig 3.2). This indicates that GAPDH from frozen and dehydrated wood frogs is more structurally stable and more resistant to thermal denaturation. This provides further proof that GAPDH from control, frozen and dehydrated animals exhibit some structural differences that support the differences in kinetic properties of GAPDH under different conditions (Table 2). This may suggest that changes in protein stability and structure are influencing the kinetic properties of GAPDH in order to match the need of the wood frog stress response. Additionally, enzyme stability could be advantageous to wood frogs 
in order to aid cellular energy preservation. Indeed, protein synthesis and degradation are highly energy expensive processes and it has been estimated that the total energetic input for each peptide bond is as much as 7.5 unit of ATP [53]. Therefore, stabilizing an enzyme during undesirable conditions may contribute to overall energy savings. In addition, GAPDH from control, frozen, dehydrated and anoxic frogs showed a high degree of stability against urea where its structure remained stable up to $\sim 4 \mathrm{M}$ urea before showing any decrease in enzymatic activity (Table 3.3). At high concentrations, urea is commonly used as a chemical denaturant to determine the overall stability and structure of enzymes under different conditions. The concentration required to reduce the activity by half was greater for freeze exposed GAPDH than for controls (Table 3.2). This further suggests that the frozen variant of the enzyme exhibits higher stability as was also seen by the DSF results. The high stability of frozen GAPDH against urea denaturation supports the idea that there are structural differences between the two variants of the enzyme. Taken together, these data may suggest that protein stabilization is prioritized during hypometabolism.

The differences in kinetic parameters observed in GAPDH obtained from control and stress conditions suggests that perhaps this enzyme is regulated by alternative methods. This regulation of GAPDH could be changes in its PTMs, which could affect its enzymatic activity. In fact, regulation at the PTM level is an energy effective technique to regulate enzymatic activity under hypometabolic conditions and/or mainlining enzymes in their inactive form until needed $[17,38]$. Western blot analysis showed that most PTMs studied were not affected by the different treatment conditions (Fig. 3.3). There was an increase in tyrosine phosphorylation during freezing compared to control, suggesting perhaps the decrease in activity seen here could be due to this PTM (Fig. 3.3A). GAPDH has been shown to contain phospho-tyrosine residues but no 
enzymatic effect was reported to be associated with the phosphorylation event [54]. Additionally, phospho-tyrosine residues of GAPDH have been shown to be a targets for serval kinases such as muscle $\mathrm{Ca}^{2+} /$ calmodulin-dependent protein kinase (CAMK), protein kinase B (Akt) and protein kinase C (PKC)[25,55-58]. For example, tyrosine phosphorylation of GAPDH by atypical protein kinase $\mathrm{C}$ and Src kinases was found to be involved in vesicle trafficking $[56,59]$. While this was not measured in the wood frogs, it is possible that the increase seen in this study could be associated in this pathway. However, further investigation is warranted to test this hypothesis. In addition, current results show an increase in lysine methylation of GAPDH extracted from frozen liver (Fig. 3.3A). The importance of lysine modification to GAPDH has been investigated in different organism where several proteomic studies have identified 4 lysine residues in GAPDH that are targeted for post translational modification [60-62]. For example, lysine modification of GAPDH has been recently investigated in Salmonella, where acetylation on lysine residues of GAPDH favours glycolysis [63]. In addition, it was shown that lysine 225 and lysine 252 have a potent effect on controlling GAPDH activity since both of these residues sit within the catalytic cleft of GAPDH [60]. A previous study found a lysine residue from rabbit muscle GAPDH to be reactive toward pyridoxal 5'-phosphate, which was competitively inhibited by anions (phosphate) [64]. This suggested that residues might be important for GAPDH's catalytic activity and methylation at lysine residues might play a role in inhibiting GAPDH function by preventing it from interacting with inorganics [65]. Hence, the increase in methylation on lysine residues found in this study could potentially regulate this enzyme's activity given that current results showed a decrease in both substrate affinity and activity in response to freezing. 
There was significant increase in phosphorylation on serine residues of GAPDH extracted from dehydrated liver. It has been shown that cytoplasmic GAPDH is phosphorylated on Ser122 by activated 5'AMP-activated protein kinase (AMPK), and this allows GAPDH to translocate to the nucleus and play a pivotal role in activating autophagy initiation [66]. Under energy depletion, cytoplasmic GAPDH is phosphorylated on Ser122 by activated AMPK that causes GAPDH entry into the nucleus [66]. Phosphorylated GAPDH in the nucleus interacts directly with Sirtuin 1 (Sirt1) and is activated by disassociating Sirt1 from its repressor (DBC1) which ultimately initiates autophagy [66]. This function is possible given that AMPK activity was shown to increase by 2 -fold in liver of frozen frogs compare to controls, suggesting that perhaps AMPK is involved in GAPDH's translocation to the nucleus[67]. To test if GAPDH is translocated to the nucleus, a cytoplasmic/nuclear fractionation protocol was performed. Current results show a significant increase in nuclear GAPDH localization during dehydration (Fig. 3.5B). This provides evidence that GAPDH may be translocated to the nucleus during dehydration exposure.

PTM changes were also examined in response to anoxia treatment. Results show a significant decrease in threonine phosphorylation of GAPDH from anoxic liver compared to the control group (Fig. 3.3C). Phosphorylation on threonine residues was shown to be important in preventing nuclear translocation of GAPDH. This phosphorylation was mediated by Akt2 at Thr237, resulting in the inhibition of GAPDH nuclear translocation [25]. The present study showed a significant increase in the relative nuclear level of GAPDH during anoxia exposure (Fig. 3.5C). This further supports the idea that GAPDH is translocated to the nucleus under anoxia condition. The nuclear translocation of GAPDH plays a role in oxidative stress and initiation of apoptosis but also nuclear GAPDH can participate in DNA repair [32,55]. It was 
documented that there is an overall decrease in apoptosis in the liver during anoxia treatment [68]. This suggested that nuclear GAPDH might not be able to participate in initiation of apoptosis. However, the wood frog experiences ischemia-reperfusion events that are associated with the freeze-thaw cycle that correlate with the production of reactive oxygen species (ROS), especially during the first hours of recovery [7]. In addition, increasing levels of ROS can cause oxidative damage to DNA during this cycle [7]. Therefore, a decrease in threonine phosphorylation of GAPDH may induce its translocation to the nucleus and may play a role in protecting cells from oxidative damage to DNA during stress.

Studies showed that phosphorylation of Y94, S98 and T99 in the GAPDH binding pocket stabilizes this region and increases the protein's NAD binding affinity $[69,70]$. However, despite showing an increase in phosphorylation on serine, threonine and tyrosine residues for frozen, dehydrated and anoxic frogs (Fig. 3.3), this change was not associated with an increase in NAD affinity (Table 3.2). This could potentially suggest that phosphorylation of GAPDH is not associated with GAPDH catalytic activity or its role in glycolytic or gluconeogenic regulation. It appears that GAPDH phosphorylation in the wood frog liver may be significant during stress states. Therefore, GAPDH may be contributing in the regulation of non-glycolytic processes while suppressing its catalytic activity to save energy.

\subsection{Conclusion}

This study characterized the kinetic, physical and regulatory properties of wood frog liver GAPDH from $24 \mathrm{~h}$ freezing, $40 \%$ dehydrated and $24 \mathrm{~h}$ anoxic conditions. Kinetic parameters of this enzyme indicated a suppression of GAPDH activity during stress, which coincided with the decrease of glycolytic and gluconeogenic output during whole body freezing. Structural studies of the stability of GAPDH demonstrated that GAPDH from frozen and dehydrated livers is more 
stable than the control enzyme, and that GAPDH has a high degree of stability against urea, an osmolyte that is abundant during stress in wood frogs. GAPDH is regulated by phosphorylation and the effect of increasing phosphorylation is associated with GAPDH nuclear localization. 


\section{Tables}

Table 3.1: Representation of the purification of liver GAPDH in the wood frog (A) control, (B) freeze exposure, (C) dehydrated exposure and (D) anoxia exposure. Two steps were used to achieve the purification: (a) Cibacron Blue column chromatography with elution using a salt gradient 0-2 M KCl, and (b) Phenyl Sepharose hydrophobic column using 1.5-0 M KCl gradient. Activities were measured in the forward (GAP oxidizing direction of the reaction). This step was repeated $n \geq 5$ for each stress.

\begin{tabular}{|c|c|c|c|c|c|}
\hline Purification Step & $\begin{array}{c}\text { Total } \\
\text { protein (mg) }\end{array}$ & $\begin{array}{c}\text { Total } \\
\text { Activity } \\
\text { (U) }\end{array}$ & $\%$ Yield & $\begin{array}{c}\text { Specific } \\
\text { Activity } \\
\text { (U/mg) }\end{array}$ & $\begin{array}{c}\text { Fold } \\
\text { Purification }\end{array}$ \\
\hline \multicolumn{6}{|l|}{$\mathrm{A}$} \\
\hline Supernatant & 25.8 & 5.00 & - & 0.19 & - \\
\hline Cibacron Blue & 2.71 & 1.03 & 20.5 & 0.37 & 1.95 \\
\hline Phenyl & 0.03 & 0.54 & 11.0 & 15.3 & 79.0 \\
\hline \multicolumn{6}{|l|}{ Sepharose } \\
\hline \multicolumn{6}{|l|}{$\mathrm{B}$} \\
\hline Supernatant & 35.3 & 13.1 & - & 0.37 & - \\
\hline Cibacron Blue & 7.09 & 6.34 & 48.5 & 0.89 & 2.42 \\
\hline Phenyl & 0.03 & 1.06 & 8.15 & 40.0 & 108 \\
\hline \multicolumn{6}{|l|}{ Sepharose } \\
\hline \multicolumn{6}{|l|}{$\mathrm{C}$} \\
\hline Supernatant & 35.0 & 7.00 & - & 0.20 & - \\
\hline Cibacron Blue & 5.95 & 3.51 & 50.3 & 0.60 & 2.95 \\
\hline Phenyl & 0.10 & 1.09 & 15.5 & 11.4 & 56.8 \\
\hline \multicolumn{6}{|l|}{ Sepharose } \\
\hline \multicolumn{6}{|l|}{$\mathrm{D}$} \\
\hline Supernatant & 24.7 & 2.98 & - & 0.12 & - \\
\hline Cibacron Blue & 6.64 & 2.23 & 74.8 & 0.33 & 2.78 \\
\hline Phenyl & 0.05 & 0.37 & 12.5 & 7.33 & 61.0 \\
\hline Sepharose & & & & & \\
\hline
\end{tabular}


Table 3.2: Kinetic parameters of purified Rana sylvatica liver GAPDH from control, frozen, dehydrated and anoxic frogs exposed frogs in the GAP-oxidizing and 1,3-BPG-reducing directions at $22{ }^{\circ} \mathrm{C}$ and $5{ }^{\circ} \mathrm{C}$. The $\mathrm{K}_{\mathrm{m}}$ values were determined using saturating conditions for cosubstrate(s). Data are means \pm SEM, $n \geq 4$; the assay conditions were as described in the Method section.

\begin{tabular}{|c|c|c|c|c|}
\hline & Control & Frozen & Dehydration & Anoxia \\
\hline \multicolumn{5}{|c|}{ Kinetics at $22^{\circ} \mathrm{C}$ in the forward reaction } \\
\hline Km GAP (mM) & $1.28 \pm 0.02$ & $1.20 \pm 0.03$ & $0.73 \pm 0.002 *$ & $0.81 \pm 0.02 *$ \\
\hline Km NAD (mM) & $0.57 \pm 0.01$ & $0.37 \pm 0.02 *$ & $0.35 \pm 0.03 *$ & $0.27 \pm 0.01 *$ \\
\hline Vmax (U/mg) & $4.81 \pm 0.01$ & $19.6 \pm 0.19^{*}$ & $17.6 \pm 0.12^{*}$ & $11.9 \pm 0.09^{*}$ \\
\hline \multicolumn{5}{|c|}{ Kinetics at $5{ }^{\circ} \mathrm{C}$ in the forward reaction } \\
\hline Km GAP (mM) & $0.73 \pm 0.09^{a}$ & $0.75 \pm 0.01^{a}$ & $0.81 \pm 0.02$ & $0.89 \pm 0.09$ \\
\hline Km NAD (mM) & $0.19 \pm 0.02^{a}$ & $0.41 \pm 0.04 *$ & $0.20 \pm 0.02^{a}$ & $0.27 \pm 0.08$ \\
\hline Vmax (U/mg) & $6.23 \pm 0.06^{a}$ & $2.72 \pm 0.07 * a$ & $6.29 \pm 0.16^{a}$ & $5.34 \pm 0.22^{a}$ \\
\hline \multicolumn{5}{|c|}{ Kinetics at $22^{\circ} \mathrm{C}$ in the reverse reaction } \\
\hline Km 1,3BPG (mM) & $0.32 \pm 0.02$ & $0.22 \pm 0.01^{*}$ & $0.28 \pm 0.03$ & $0.38 \pm 0.005$ \\
\hline $\begin{array}{l}\text { reverse Vmax } \\
(\mathrm{U} / \mathrm{mg})\end{array}$ & $14.3 \pm 0.06$ & $6.73 \pm 0.007^{*}$ & $15.0 \pm 0.08^{*}$ & $9.54 \pm 0.06^{*}$ \\
\hline \multicolumn{5}{|c|}{ Kinetics at $5^{\circ} \mathrm{C}$ in the reverse reaction } \\
\hline Km 1,3BPG (mM) & $0.38 \pm 0.009$ & $0.37 \pm 0.005^{a}$ & $0.27 \pm 0.01^{*}$ & $0.54 \pm 0.005^{* a}$ \\
\hline $\begin{array}{l}\text { reverse Vmax } \\
(\mathrm{U} / \mathrm{mg})\end{array}$ & $8.27 \pm 0.06^{a}$ & $3.90 \pm 0.01 * a$ & $7.04 \pm 0.03 * a$ & $6.27 \pm 0.03 * a$ \\
\hline
\end{tabular}

Data are means $\pm S E M, n=4$ independent trials. *Significantly different from the corresponding control, $p<0.05,{ }^{a}$ indicates the parameters is significantly difference from the corresponding parameter at room temperature $\left(2{ }^{\circ} \mathrm{C}\right), p<0.05$ via student's $t$-test. 
Table 3.3: The effect of urea and salts on purified liver GAPDH activity from control and frozen, dehydrated and anoxic exposed frogs. GAPDH was assayed in the GAP-oxidizing direction at 22 ${ }^{0} \mathrm{C}$. The $\mathrm{I}_{50}$ values for inhibitors were determined using saturating conditions and data are means $\pm \mathrm{SEM}, \mathrm{n} \geq 4$ where the assay conditions were as described in the Methods section.

\begin{tabular}{lcccc}
\hline & Control & Frozen & Dehydration & Anoxia \\
\hline I50 $_{50}$ urea & $4.78 \pm 0.33$ & $5.90 \pm 0.04^{*}$ & $3.09 \pm 1.21$ & $5.68 \pm 0.29$ \\
\hline $\mathbf{I}_{50} \mathbf{~ K C l}$ & $0.66 \pm 0.07$ & $0.84 \pm 0.04$ & $0.72 \pm 0.04$ & $0.52 \pm 0.009$ \\
\hline I50 $_{\mathbf{N a C l}}$ & $0.44 \pm 0.01$ & $0.60 \pm 0.05$ & $0.59 \pm 0.02^{*}$ & $0.40 \pm 0.007$ \\
\hline
\end{tabular}

Data are mean $\pm S E M, n=4$ independent trials. *Significantly different from the corresponding control ( $p<0.05$, student's $t$-test) 


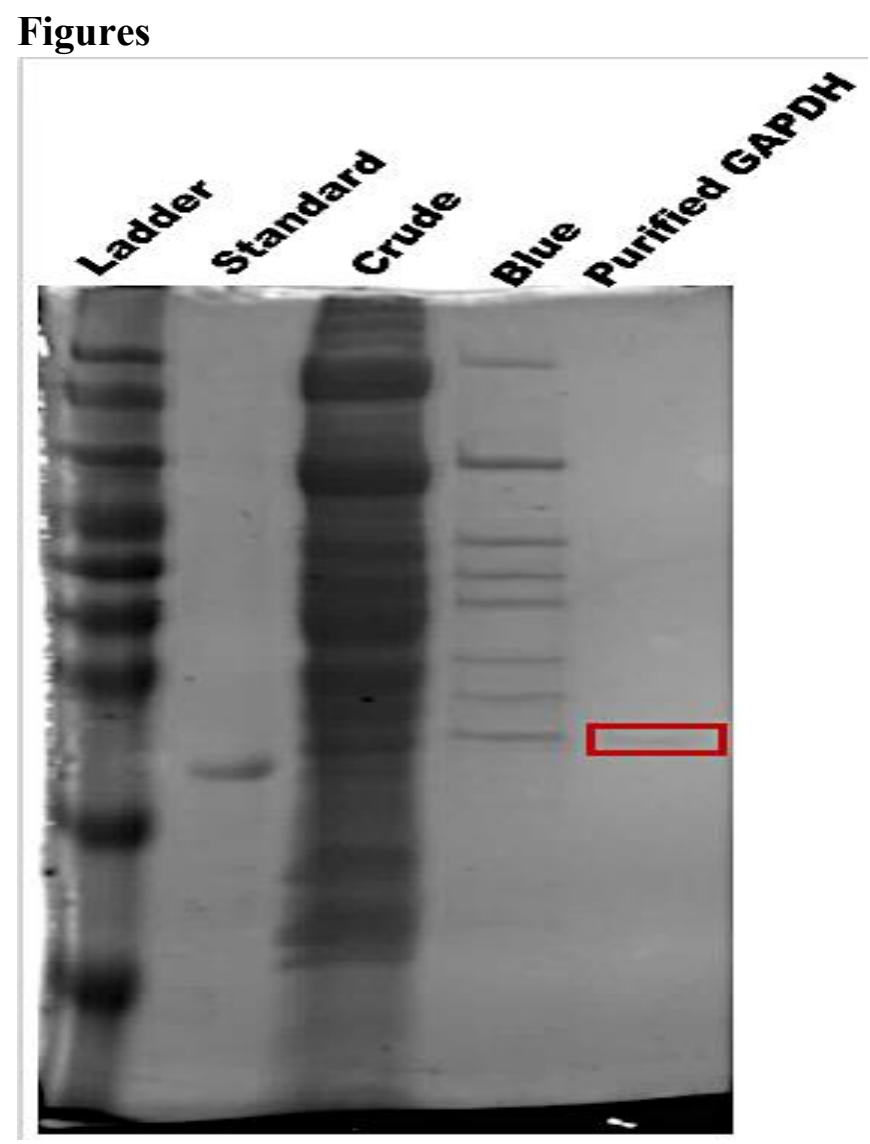

Figure 3.1: SDS-PAGE with Coomassie Blue stain shows the GAPDH purification from control wood frog liver tissue. From left to right lanes are, 1: piNK Plus Pre-stained Protein Ladder 10175kDa,2: rabbit GAPDH,3: crude sample, 4: pooled peak fractions eluted from the Cibacron blue column, 5: pooled peak fractions eluted from phenyl-Sepharose. 


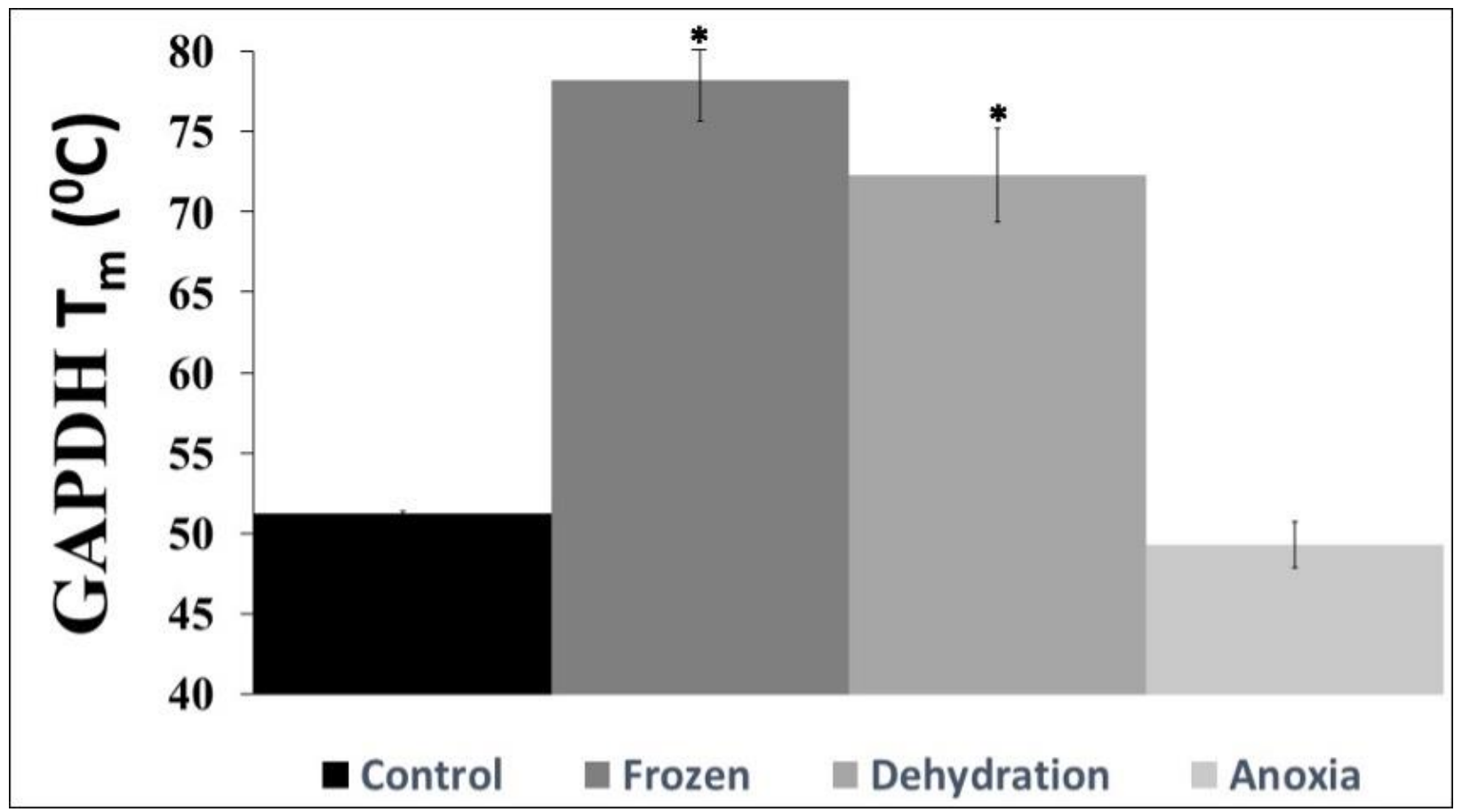

Figure 3.2: Differential scanning fluorimetry analysis of the relative thermal stability of purified GAPDH purified from liver of Rana sylvatica from control, frozen (A), dehydration (B) and anoxia (C). The experiment was performed with a concentration of $0.08 \mathrm{mg} / \mathrm{mL}$ of purified GAPDH in each assay well. The data were quantified as mean $\pm S E M, n \geq 4$, the statistical analysis was carried by Student's t-test with $p<0.05$ considered to be significant where $(*)$ denotes significant differences from control sample 

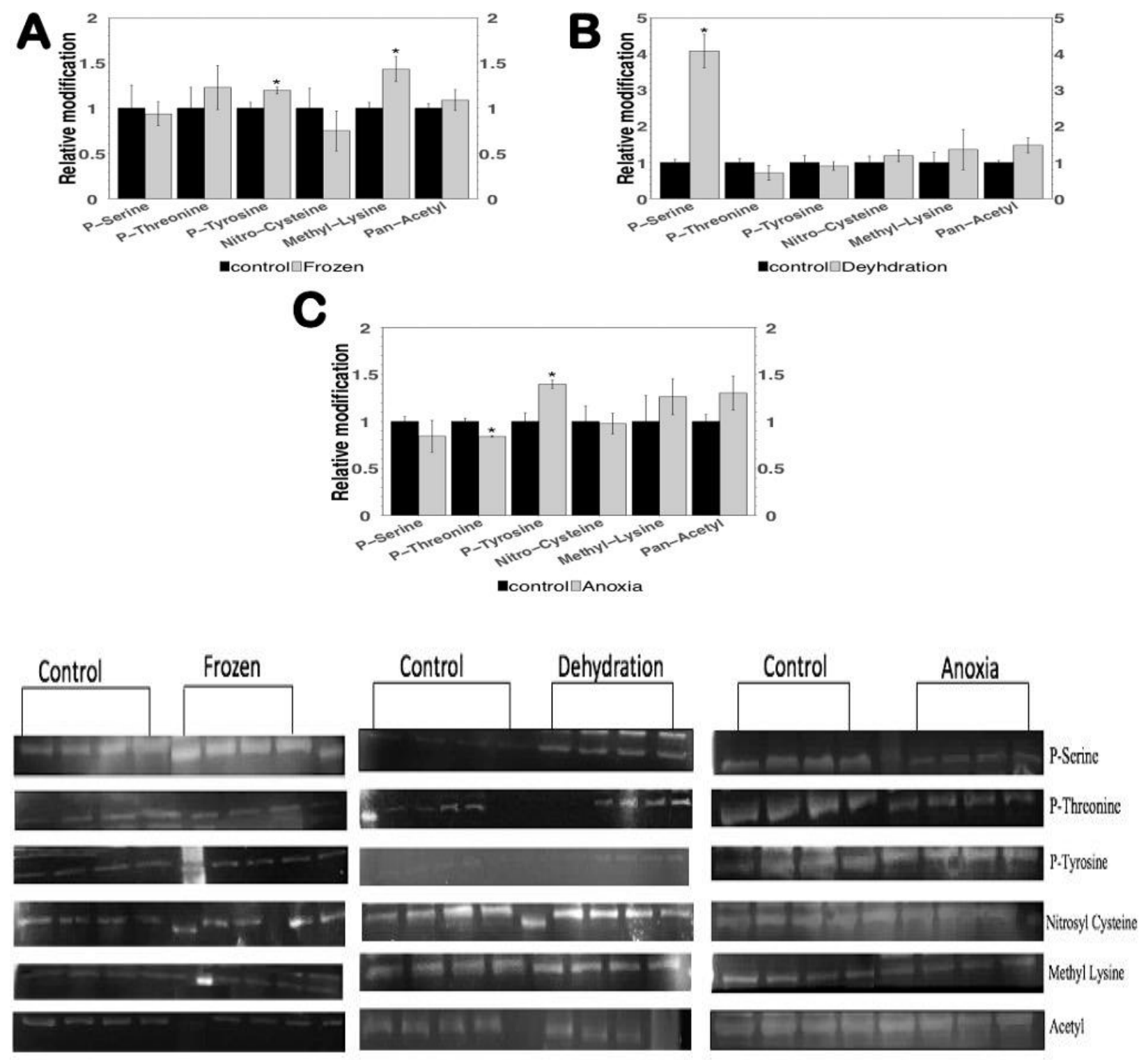

Figure 3.3: Western blot analysis of posttranslational modification of partially purified GAPDH from liver of Rana sylvatica under control, frozen (A), dehydration (B) and anoxia (C) conditions. The relative band intensity refers to the intensity of the chemiluminescent signal divided by the band intensity after staining with Coomassie brilliant blue. Data are mean \pm SEM, $\mathrm{n}=4 ;\left(^{*}\right)$ significantly different from the corresponding control value as determined by the Student's t-test, $p<0.05$. 


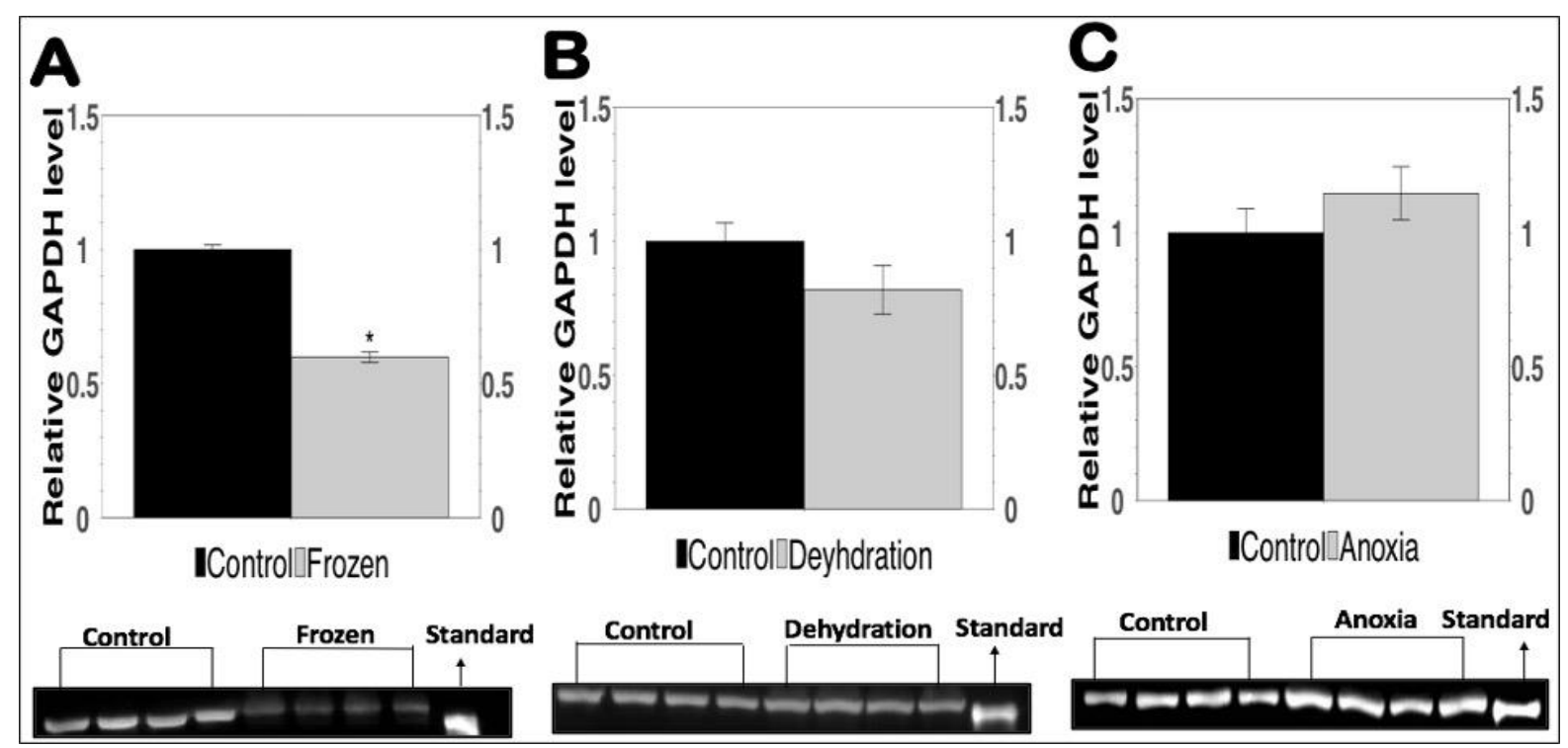

Figure 3.4: Relative GAPDH expression levels in liver of Rana sylvatica from control, frozen (A), dehydration (B) and anoxia (C) as determined by western blots. Relative GAPDH levels were determined by the intensity of the chemiluminescent signal divided by the band intensity after staining with Coomassie brilliant blue. Data are mean \pm SEM, $n=4$ independent biological replicates from different animals. (*) significantly different from the control as determined by the Student's t-test, $p<0.05$. 


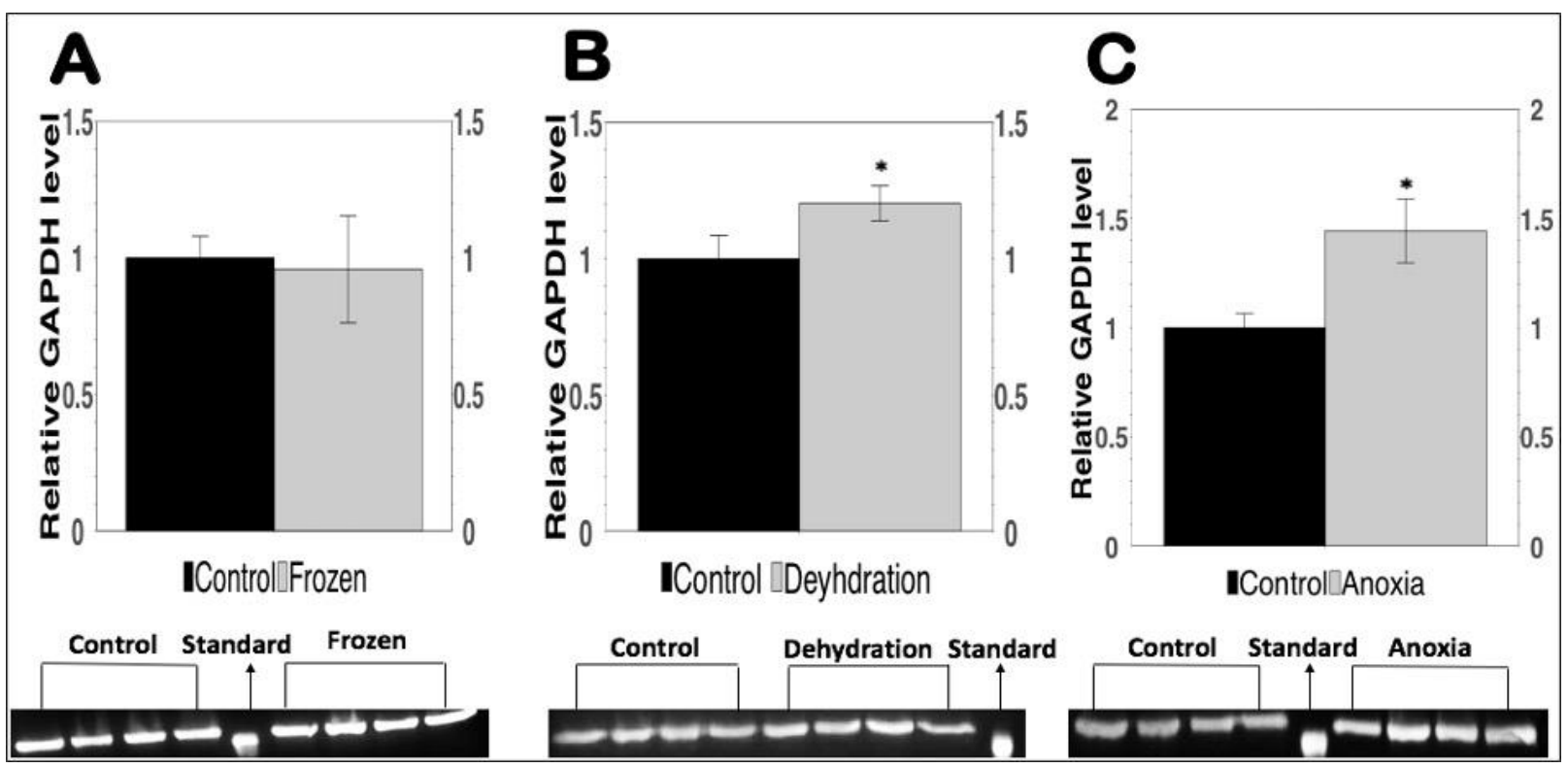

Figure 3.5: Relative nuclear GAPDH expression level in liver of Rana sylvatica from control, frozen (A), dehydration (B) and anoxia (C) frogs assessed by western blots. Other information as in Fig. 3.4. 


\section{References (Chapter 3)}

[1] K.B. Storey, J.M. Storey, Biochemical adaption for freezing tolerance in the wood frog, Rana sylvatica, J. Comp. Physiol. B. 155 (1984) 29-36. doi:10.1007/BF00688788.

[2] K.B. Storey, Life in a frozen state: Adaptive strategies for natural freeze tolerance in amphibians and reptiles, Am. J. Physiol. - Regul. Integr. Comp. Physiol. 258 (1990) 559568. doi:10.1152/ajpregu.1990.258.3.r559.

[3] K.B. Storey, J.M. Storey, Molecular physiology of freeze tolerance in vertebrates, Physiol. Rev. 97 (2017) 623-665. doi:10.1152/physrev.00016.2016.

[4] K.B. Storey, J.M. Storey, Molecular biology of freezing tolerance, Compr. Physiol. 3 (2013) 1283-1308. doi:10.1002/cphy.c130007.

[5] C.P. Holden, K.B. Storey, Second messenger and cAMP-dependent protein kinase responses to dehydration and anoxia stresses in frogs, J. Comp. Physiol. - B Biochem. Syst. Environ. Physiol. 167 (1997) 305-312. doi:10.1007/s003600050078.

[6] T.A. Churchill, K.B. Storey, Metabolic responses to dehydration by liver of the wood frog, Rana sylvatica, Can. J. Zool. 72 (1994) 1420-1425. doi:10.1139/z94-188.

[7] K.B. Storey, J.M. Storey, Metabolic rate depression in animals: Transcriptional and translational controls, Biol. Rev. Camb. Philos. Soc. 79 (2004) 207-233. doi:10.1017/S1464793103006195.

[8] J.P. Costanzo, A.M. Reynolds, M. Clara, F. Do Amaral, A.J. Rosendale, R.E. Lee, Cryoprotectants and extreme freeze tolerance in a subarctic population of the wood frog, PLoS One. 10 (2015) 1-23. doi:10.1371/journal.pone.0117234.

[9] K.B. Storey, J.M. Storey, Molecular physiology of freeze tolerance in vertebrates, Physiol. Rev. 97 (2017) 623-665. doi:10.1152/physrev.00016.2016.

[10] K.B. Storey, J.M. Storey, Freeze tolerant frogs: cryoprotectants and tissue metabolism during freeze-thaw cycles, Can. J. Zool. 64 (1986) 49-56. doi:10.1139/z86-008.

[11] J.P. Costanzo, R.E. Lee, P.H. Lortz, Glucose concentration regulates freeze tolerance in the wood frog Rana sylvatica., J. Exp. Biol. 181 (1993) 245-255.

[12] K.J. Cowan, K.B. Storey, Freeze-thaw effects on metabolic enzymes in wood frog organs, Cryobiology. 43 (2001) 32-45. doi:10.1006/cryo.2001.2338.

[13] K.B. Storey, Organ-specific metabolism during freezing and thawing in a freeze-tolerant frog, Am. J. Physiol. - Regul. Integr. Comp. Physiol. 253 (1987) 292-297. doi:10.1152/ajpregu.1987.253.2.r292.

[14] K.B. Storey, Glycolysis and the regulation of cryoprotectant synthesis in liver of the freeze tolerant wood frog, (1987) 373-380. doi:10.1007/BF00693364.

[15] M.D. Vazquez Illanes, K.B. Storey, 6-Phosphofructo-2-kinase and control of cryoprotectant synthesis in freeze tolerant frogs, BBA - Gen. Subj. 1158 (1993) 29-32. doi:10.1016/0304-4165(93)90092-M.

[16] M.A. Sirover, On the functional diversity of glyceraldehyde-3-phosphate dehydrogenase: Biochemical mechanisms and regulatory control, Biochim. Biophys. Acta - Gen. Subj. 1810 (2011) 741-751. doi:10.1016/j.bbagen.2011.05.010.

[17] R.A.V. Bell, J.C. Smith, K.B. Storey, Purification and properties of glyceraldehyde-3phosphate dehydrogenase fromthe skeletalmuscle of the hibernating ground squirrel, ictidomys tridecemlineatus, PeerJ. 2014 (2014) 1-20. doi:10.7717/peerj.634.

[18] S.J. Humphrey, D.E. James, M. Mann, Protein phosphorylation: a major switch mechanism for metabolic regulation, Trends Endocrinol. Metab. 26 (2015) 676-687. 
doi:10.1016/j.tem.2015.09.013.

[19] C.A. Dieni, K.B. Storey, Regulation of glucose-6-phosphate dehydrogenase by reversible phosphorylation in liver of a freeze tolerant frog, J. Comp. Physiol. B Biochem. Syst. Environ. Physiol. 180 (2010) 1133-1142. doi:10.1007/s00360-010-0487-5.

[20] C.A. Dieni, K.B. Storey, Regulation of hexokinase by reversible phosphorylation in skeletal muscle of a freeze-tolerant frog, Comp. Biochem. Physiol. - B Biochem. Mol. Biol. 159 (2011) 236-243. doi:10.1016/j.cbpb.2011.05.003.

[21] N.J. Dawson, B.A. Katzenback, K.B. Storey, Free-radical first responders: The characterization of $\mathrm{CuZnSOD}$ and MnSOD regulation during freezing of the freezetolerant North American wood frog, Rana sylvatica, Biochim. Biophys. Acta - Gen. Subj. 1850 (2015) 97-106. doi:10.1016/j.bbagen.2014.10.003.

[22] M. Crerar, E. David, K. Storey, Electrophoretic analysis of liver glycogen phosphorylase activation in the freeze-tolerant wood frog, 971 (1988) 72-84.

[23] N.J. Dawson, K.B. Storey, A hydrogen peroxide safety valve: The reversible phosphorylation of catalase from the freeze-tolerant North American wood frog, Rana sylvatica, Biochim. Biophys. Acta - Gen. Subj. 1860 (2016) 476-485. doi:10.1016/j.bbagen.2015.12.007.

[24] C. Tristan, N. Shahani, T.W. Sedlak, A. Sawa, The diverse functions of GAPDH: Views from different subcellular compartments, Cell. Signal. 23 (2011) 317-323. doi:10.1016/j.cellsig.2010.08.003.

[25] Q. Huang, F. Lan, Z. Zheng, F. Xie, J. Han, L. Dong, Y. Xie, F. Zheng, Akt2 kinase suppresses glyceraldehyde-3-phosphate dehydrogenase (GAPDH)-mediated apoptosis in ovarian cancer cells via phosphorylating gapdh at threonine 237 and decreasing its nuclear translocation, J. Biol. Chem. 286 (2011) 42211-42220. doi:10.1074/jbc.M111.296905.

[26] L. Guarente, The logic linking protein acetylation and metabolism, Cell Metab. 14 (2011) 151-153. doi:10.1016/j.cmet.2011.07.007.

[27] K.L. Guan, Y. Xiong, Regulation of intermediary metabolism by protein acetylation, Trends Biochem. Sci. 36 (2011) 108-116. doi:10.1016/j.tibs.2010.09.003.

[28] M. Ventura, F. Mateo, J. Serratosa, I. Salaet, S. Carujo, O. Bachs, M.J. Pujol, Nuclear translocation of glyceraldehyde-3-phosphate dehydrogenase is regulated by acetylation, Int. J. Biochem. Cell Biol. 42 (2010) 1672-1680. doi:10.1016/j.biocel.2010.06.014.

[29] J.Y. Zhang, F. Zhang, C.Q. Hong, A.E. Giuliano, X.J. Cui, G.J. Zhou, G.J. Zhang, Y.K. Cui, Critical protein GAPDH and its regulatory mechanisms in cancer cells, Cancer Biol. Med. 12 (2015) 10-22. doi:10.7497/j.issn.2095-3941.2014.0019.

[30] C.M. Grant, Metabolic reconfiguration is a regulated response to oxidative stress, J. Biol. 7 (2008) 6-9. doi:10.1186/jbiol63.

[31] M. Ralser, M.M. Wamelink, A. Kowald, B. Gerisch, G. Heeren, E.A. Struys, E. Klipp, C. Jakobs, M. Breitenbach, H. Lehrach, S. Krobitsch, Dynamic rerouting of the carbohydrate flux is key to counteracting oxidative stress, J. Biol. 6 (2007). doi:10.1186/jbiol61.

[32] Z. Dastoor, J.L. Dreyer, Potential role of nuclear translocation of glyceraldehyde-3phosphate dehydrogenase in apoptosis and oxidative stress, J. Cell Sci. 114 (2001) 16431653.

[33] J.M. Storey, K.B. Storey, Triggering of cryoprotectant synthesis by the initiation of ice nucleation in the freeze tolerant frog, Rana sylvatica, J. Comp. Physiol. B. 156 (1985) 191-195. doi:10.1007/BF00695773.

[34] T.A. Churchill, K.B. Storey, Metabolic responses to dehydration by liver of the wood 
frog, Rana sylvatica, Can. J. Zool. 72 (1994) 1420-1425. doi:10.1139/z94-188.

[35] R. Al-Attar, K.B. Storey, Effects of anoxic exposure on the nuclear factor of activated T cell (NFAT) transcription factors in the stress-tolerant wood frog, Cell Biochem. Funct. 36 (2018) 420-430. doi:10.1002/cbf.3362.

[36] S.P.J. Brooks, A simple computer program with statistical tests for the analysis of enzyme kinetics, Biotechniques. 13 (1992) 906-911. https://www.ncbi.nlm.nih.gov/pubmed/1476744 (sccessed April 19, 2020).

[37] R. Al-Attar, C.W. Wu, K.K. Biggar, K.B. Storey, Carb-loading: Freeze-induced activation of the glucose-responsive chrebp transcriptional network in wood frogs, Physiol.

Biochem. Zool. 93 (2020) 49-61. doi:10.1086/706463.

[38] J. Abboud, K.B. Storey, Novel control of lactate dehydrogenase from the freeze tolerant wood frog: Role of posttranslational modifications, PeerJ. 2013 (2013) 1-23.

doi:10.7717/peerj.12.

[39] K.K. Biggar, N.J. Dawson, K.B. Storey, Real-time protein unfolding: A method for determining the kinetics of native protein denaturation using a quantitative real-time thermocycler, Biotechniques. 53 (2012) 231-238. doi:10.2144/0000113922.

[40] F.H. Niesen, H. Berglund, M. Vedadi, The use of differential scanning fluorimetry to detect ligand interactions that promote protein stability, Nat. Protoc. 2 (2007) 2212-2221. doi:10.1038/nprot.2007.321.

[41] S.R. Green, K.B. Storey, Regulation of crayfish, Orconectes virilis, tail muscle lactate dehydrogenase $(\mathrm{LDH})$ in response to anoxic conditions is associated with alterations in phosphorylation patterns, Comp. Biochem. Physiol. Part - B Biochem. Mol. Biol. 202 (2016) 67-74. doi:10.1016/j.cbpb.2016.08.004.

[42] J. Zhang, K.B. Storey, RBioplot: an easy-to-use R pipeline for automated statistical analysis and data visualization in molecular biology and biochemistry., PeerJ. 4 (2016) e2436. doi:10.7717/peerj.2436.

[43] A. Soukri, A. Serrano, Evidence for a posttranslational covalent modification of liver, 1292 (1996) 177-187.

[44] L. Fourrat, A. Iddar, A. Soukri, Purification and characterization of cytosolic glyceraldehyde-3-phosphate dehydrogenase from the dromedary camel, Acta Biochim. Biophys. Sin. (Shanghai). 39 (2007) 148-154. doi:10.1111/j.1745-7270.2007.00256.x.

[45] T. Baibai, L. Oukhattar, A. Moutaouakkil, A. Soukri, Purification and characterization of glyceraldehyde-3-phosphate dehydrogenase from European Pilchard Sardina pilchardus, Acta Biochim. Biophys. Sin. (Shanghai). 39 (2007) 947-954. doi:10.1111/j.17457270.2007.00357.x.

[46] R. Al-attar, S. Wijenayake, K.B. Storey, Metabolic reorganization in winter: Regulation of pyruvate dehydrogenase (PDH) during long-term freezing and anoxia, Cryobiology. 86 (2019) 10-18. doi:10.1016/j.cryobiol.2019.01.006.

[47] J.R. Layne, R.E. Lee, T.L. Heil, Freezing-induced changes in the heart rate of wood frogs (Rana sylvatica), Am. J. Physiol. - Regul. Integr. Comp. Physiol. 257 (1989) 0-3. doi:10.1152/ajpregu.1989.257.5.r1046.

[48] K.J. Cowan, J.A. MacDonald, J.M. Storey, K.B. Storey, Metabolic reorganization and signal transduction during estivation in the spadefoot toad, Exp. Biol. Online. 5 (2000) 125. doi:10.1007/s00898-000-0001-8.

[49] B. Storey, Fructose 2,6-bisphosphate and anaerobic metabolism in marine molluscs, 181 (1985) 245-248. 
[50] L. Hue, M.H. Rider, Role of fructose 2,6-bisphosphate in the control of glycolysis in mammalian tissues, 245 (1987) 313-324.

[51] R. Whitwam, K. Storey, Regulation of phosphofructokinase during estivation and Anoxia in the Land Snail, Otala lactea, Comp. Biol. (1991).

[52] L.J. Hawkins, M. Wang, B. Zhang, Q. Xiao, H. Wang, K.B. Storey, Glucose and urea metabolic enzymes are differentially phosphorylated during freezing, anoxia, and dehydration exposures in a freeze tolerant frog, Comp. Biochem. Physiol. - Part D Genomics Proteomics. 30 (2019) 1-13. doi:10.1016/j.cbd.2019.01.009.

[53] F.W.T.P. De Vries, The cost of maintenance processes in plant cells, Ann. Bot. 39 (1975) 77-92. doi:10.1093/oxfordjournals.aob.a084919.

[54] E.A. Sergienko, A.I. Kharitonenkov, T. V. Bulargina, V. V. Muronetz, N.K. Nagradova, D-Glyceraldehyde-3-phosphate dehydrogenase purified from rabbit muscle contains phosphotyrosine, FEBS Lett. 304 (1992) 21-23. doi:10.1016/0014-5793(92)80580-A.

[55] C. Nicholls, H. Li, J.P. Liu, GAPDH: A common enzyme with uncommon functions, Clin. Exp. Pharmacol. Physiol. 39 (2012) 674-679. doi:10.1111/j.1440-1681.2011.05599.x.

[56] E.J. Tisdale, C.R. Artalejo, A GAPDH mutant defective in Src-dependent tyrosine phosphorylation impedes Rab2-mediated events, Traffic. 8 (2007) 733-741. doi:10.1111/j.1600-0854.2007.00569.x.

[57] T. Baba, H. Kobayashi, H. Kawasaki, R. Mineki, H. Naito, D. Ohmori, Glyceraldehyde-3phosphate dehydrogenase interacts with phosphorylated Akt resulting from increased blood glucose in rat cardiac muscle, FEBS Lett. 584 (2010) 2796-2800. doi:10.1016/j.febslet.2010.05.015.

[58] G. Yogalingam, S. Hwang, J.C.B. Ferreira, D. Mochly-Rosen, Glyceraldehyde-3phosphate dehydrogenase (GAPDH) phosphorylation by protein kinase $\mathrm{C} \delta(\mathrm{PKC} \delta)$ inhibits mitochondria elimination by lysosomal-like structures following ischemia and reoxygenation-induced injury, J. Biol. Chem. 288 (2013) 18947-18960. doi:10.1074/jbc.M113.466870.

[59] E.J. Tisdale, Glyceraldehyde-3-phosphate dehydrogenase is phosphorylated by protein kinase $\mathrm{C} \imath \lambda$ and plays a role in microtubule dynamics in the early secretory pathway, $\mathrm{J}$. Biol. Chem. 277 (2002) 3334-3341. doi:10.1074/jbc.M109744200.

[60] S.T. Bond, K.F. Howlett, G.M. Kowalski, S. Mason, T. Connor, A. Cooper, V. Streltsov, C.R. Bruce, K.R. Walder, S.L. McGee, Lysine post-translational modification of glyceraldehyde-3-phosphate dehydrogenase regulates hepatic and systemic metabolism, FASEB J. 31 (2017) 2592-2602. doi:10.1096/fj.201601215R.

[61] J.B. Olsen, X.J. Cao, B. Han, L.H. Chen, A. Horvath, T.I. Richardson, R.M. Campbell, B.A. Garcia, H. Nguyen, Quantitative profiling of the activity of protein lysine methyltransferase SMYD2 using silac-based proteomics, Mol. Cell. Proteomics. 15 (2016) 892-905. doi:10.1074/mcp.M115.053280.

[62] P. Mertins, J.W. Qiao, J. Patel, N.D. Udeshi, K.R. Clauser, D.R. Mani, M.W. Burgess, M.A. Gillette, J.D. Jaffe, S.A. Carr, Integrated proteomic analysis of post-translational modifications by serial enrichment, Nat. Methods. 10 (2013) 634-637.

doi:10.1038/nmeth.2518.

[63] Q. Wang, Y. Zhang, C. Yang, H. Xiong, Y. Lin, Acetylation of metabolic enzymes and metabolic Flux, Science (80-. ). 327 (2010) 1004-1007. doi:10.1126/science.1179687.

[64] B.G. Forcina, G. Ferri, M.C. Zapponi, S. Ronchi, Identification of lysines reactive with pyridoxal 5'-phosphate in glyceraldehyde-3-phosphate dehydrogenase, Eur. J. Biochem. 
20 (1971) 535-540. doi:10.1111/j.1432-1033.1971.tb01424.x.

[65] M. Reis, C.N. Alves, J. Lameira, I. Tuñón, S. Martí, V. Moliner, The catalytic mechanism of glyceraldehyde 3-phosphate dehydrogenase from Trypanosoma cruzi elucidated via the QM/MM approach, Phys. Chem. Chem. Phys. 15 (2013) 3772-3785.

doi:10.1039/c3cp43968b.

[66] C. Chang, H. Su, D. Zhang, Y. Wang, Q. Shen, B. Liu, R. Huang, T. Zhou, C. Peng, C.C.L. Wong, H.M. Shen, J. Lippincott-Schwartz, W. Liu, AMPK-dependent phosphorylation of GAPDH triggers Sirt1 activation and is necessary for autophagy upon glucose starvation, Mol. Cell. 60 (2015) 930-940. doi:10.1016/j.molcel.2015.10.037.

[67] M.H. Rider, N. Hussain, S. Horman, S.M. Dilworth, K.B. Storey, Stress-induced activation of the AMP-activated protein kinase in the freeze-tolerant frog Rana sylvatica, Cryobiology. 53 (2006) 297-309. doi:10.1016/j.cryobiol.2006.08.001.

[68] V.E.M. Gerber, S. Wijenayake, K.B. Storey, Anti-apoptotic response during anoxia and recovery in a freeze-tolerant wood frog (Rana sylvatica), PeerJ. 2016 (2016) 1-21. doi: $10.7717 /$ peerj. 1834 .

[69] F.C.M. Meng He, Proteome-wide characterization of phosphorylation-induced conformational changes in breast cancer, Physiol. Behav. 176 (2017) 139-148. doi:10.1016/j.physbeh.2017.03.040.

[70] M. Phadke, Disruption of $\mathrm{NAD}^{+}$binding site in glyceraldehyde 3-phosphate dehydrogenase affects its intranuclear interactions, World J. Biol. Chem. 6 (2015) 366. doi:10.4331/wjbc.v6.i4.366. 


\section{Chapter 4}

\section{General Discussion}


Animals that live in the wild can experience unforgiving environmental conditions such as limited food, water loss, fluctuations in environmental oxygen level and fluctuation in temperatures. Survival of harsh environmental conditions requires that animals to depend on their endogenous fuel reserves as well establish a new balance between ATP-consuming and ATP-producing processes. These requirements necessitate major biochemical and physiological adaptations including reorganization and reprioritization of energy use, altered expression of various proteins, differential regulation of enzymes, and strong reduction in overall metabolic rate $[1,2]$.

Metabolic rate depression (MRD) is a key biochemical mechanism that is essential for animal survival during harsh environmental conditions [2]. Metabolic rate can be dropped by 5$40 \%$ of their resting rate depending on the animal [2]. MRD is carried out in a selective manner where ATP-expensive and non-essential cellular processes are suppressed whereas processes needed for cellular survival are upregulated [2]. The transition into MRD, also called entrance into a hypometabolism state, provides animals with a chance to extend their survival time by conserving fuel reserves. Many factors are involved in regulating the metabolic transition from a normal resting state to a hypometabolic state $[2,3]$. For example, control of enzymes plays an essential role in controlling anabolic and catabolic processes [2,3]. Moreover, the changing nature of environments requires changes to metabolic systems that are rapid and energetically inexpensive. Synthesis and degradation of proteins are energy demanding and overall restructuring of cellular metabolic enzymes that control ATP-consuming and ATP-producing pathways are energy expensive under stress conditions [2,3]. Therefore, key metabolic enzymes involved in different aspects of metabolism can be differentially regulated through PTMs instead. This mechanism is rapid, energy-inexpensive and can be easily reversed by an 
appropriate phosphatases or kinases depending on the cell status. Indeed, multiple studies have shown metabolic regulation of enzymes through PTMs in hypometabolic animals in order to sustain life [2-6].

The North American wood frog, Rana sylvatica, undergoes whole body freezing when confronted with harsh winter conditions. They can endure freezing of up to $65 \%$ of total body water as extracellular ice [7]. Freezing is associated with the reduction and cessation of various vital physiological functions such as breathing, heartbeat, muscle movement and nerve conductivity $[7,8]$. Freezing also imposes stress on all cells including dehydration due to the loss of water from cells into extracellular ice crystals and anoxia due to the freezing of the blood plasma that interrupts oxygen delivery to organs [7,9]. Wood frogs have the ability to endure dehydration and anoxia where they develop dehydration resistance (enduring the loss of up to $60 \%$ of total body water), and anoxia resistance of at least $48 \mathrm{~h}$ exposure of $\mathrm{N}_{2}$ gas at $5^{0} \mathrm{C}$, independently of freezing $[7,10,11]$. Therefore, it is important to investigate each of those stresses independently to see if they regulate their pathways in similar manner as freezing.

Both freezing and dehydration can cause damage to cell membranes and, as a result, wood frogs have developed several adaptations to prevent or overcome any damage. One of the important mechanisms is the production of a high amount of glucose that is used as a cryo- or osmo-protectant agent [12,13]. Glucose functions in retaining enough water inside the cell to prevent any damage to subcellular architecture. Previous studies have shown that blood glucose can rise from $5 \mathrm{mM}$ to as high as $300 \mathrm{mM}$ in response to freezing and liver glucose content was shown to increase 3.8-fold in response to dehydration [7,11]. Recently, urea has also been shown to be a significant metabolite that contributes to protection in the wood frog to aid cells from 
freeze/thaw injuries and from excessive dehydration $[13,14]$. It was noted that urea content increases in liver during freezing and the level of urea can rise up to $90 \mathrm{mM}$ in wood frogs under dry conditions $[13,15]$. Given that anoxia is one of the stressors associated with freezing in wood frogs, it is important to investigate independently. There is no accumulation of cryoprotective agents in wood frogs under anoxia since they do not experience interruption of blood flow or water loss from cells [7]. However, the wood frog needs to switch from oxidative phosphorylation for ATP synthesis to anaerobic fermentative glycolysis due to the oxygen deprivation during freezing or anoxia exposures and, to a lesser extent, during dehydration when water loss reaches a high level that impairs blood circulation. Anaerobic glycolysis has been proven to be used as the pathway to produce energy due to the accumulation of lactate under freezing or anoxia conditions [16]. However, the amount of ATP produce anaerobically is much less than the amount of ATP generated under aerobic condition. Therefore, cells need to reduce their metabolic rates to conserve energy and balance ATP production with ATP consumption on. Entry into a hypometabolic state requires the coordination and integration of various signaling pathways that allow survival under harsh conditions [7]. While metabolic rates in response to dehydration and anoxia have not been measured in wood frogs, studies in other amphibian and non-amphibian models suggest that exposure to these stresses result in suppression of overall metabolic rates [3]. For example, during estivation, the spadefoot toad reduces its metabolic rate to just $20 \%-30 \%$ of its normal resting metabolism in order to survive extended periods of dry conditions [17] Another example is anoxia-tolerant vertebrates, such as some turtles, that can depress their metabolic rate by $80 \%-90 \%$ when faced with hypoxia or anoxia conditions $[18,19]$. Additionally, a study of mitochondria from skeletal muscle of a hypoxic frog, Rana temporaria, showed reduced metabolic rates when oxygen was limiting [20]. These further supports the 
suppression of metabolic rate during dehydration and anoxia exposure. Wood frogs have been shown to selectively regulate the activities and expression levels of metabolic enzymes that are involved in glycolysis, TCA cycle, gluconeogenesis, amino acid catabolism, and fatty acid oxidization to survive harsh conditions $[3,4,21]$. Reversible protein phosphorylation has been a commonly reported modification in the wood frog under stress [22-24]. Recent studies showed the importance of reversible protein phosphorylation in regulating enzyme activities involved in glycolysis and the urea cycle in wood frogs in response to freezing, dehydration or anoxia [25]. Hence, enzyme regulation via PTMs seems to play a critical role in the entrance into a hypometabolic state by the wood frog when energy resources are limited.

Metabolic reactions require the help of an enzymes in order to maintain life. Therefore, the study presented in this thesis investigated the regulation of two enzymes that have fundamental roles in metabolism. Chapter 2 looked into the regulation of GDH in the liver of the wood frog in response to dehydration and anoxia treatment. Chapter 3 focused on the regulation of GAPDH in the liver of the wood frog in response to freezing, dehydration and anoxia treatment. These studies provide an insight into how these different enzymes are regulated during hypometabolic states and their contribution to the overall energy metabolism to aid with the survival of the wood frog during undesirable conditions.

\subsection{The role of GDH in wood frog liver during dehydration and anoxia}

GDH is a critical enzyme in many organisms that link amino acid, carbohydrate metabolism and urea cycle. Chapter 2 of this thesis investigated GDH from liver of wood frogs in response to dehydration and anoxia stresses, as compared with control frogs. The study revealed significant difference between the three enzyme states. The data determined that GDH 
from dehydration exposed frogs was more active in the glutamate-oxidizing direction while the glutamate-synthesizing reaction was less active in the dehydrated condition compared to controls. The increase of GDH activity in the glutamate-oxidizing direction during dehydration was expected since GDH is a chief generator of $\mathrm{NH}_{4}{ }^{+}$to feed into the urea cycle. As was mention earlier, urea helps with water retention during periods of dehydration [26]. It has been noted that urea concentrations in the wood frog liver increase during dehydration [13]. An increase in glutamate breakdown via GDH and subsequence urea production have been documented in several anurans that encounter dry environments [27,28]. Majority of the energy used in estivated animals such as spadefoot toads is primarily based upon lipid oxidation and protein catabolism [3]. It was shown that potein oxidation occurs in proportion to the need for urea production [3]. Interestingly, glutamate levels increased in the liver of estivated spadefoot toads [17]. In additon, a previous study showed an increase in the levels of plasma amino acids during dehydration in Xenopus laevis [29]. This increase in amino acids during dehydrating conditions might be associated with protein breakdown to provide an energy source. Therefore, the increase in maximal activity of GDH in the oxidizing direction suggests that wood frogs may be breaking down protein to provide a source of energy during dehydration, as seen in other animals under dehydration. The reduced activity of the glutamate synthesizing reaction also corresponded with an overall suppression of anabolic processes during dehydration. In general, animals that experience dehydration (e.g. frogs and pulmonate land snails have received most attention) reduce their metabolic rate, particularly targeting energy expensive processes such as protein synthesis [30,31]. Thus, it makes sense that synthesis of glutamate through GDH in order to participate in the production of protein is suppressed during dehydration. GDH isolated from dehydration-treated frogs was noted to display a decreased level of post-translational acetylation 
and ADP-ribosylation as well as an increase in phosphorylated serine residues. This is thought to be related to the increased activity of GDH under dehydrated treatment as it was seen in other studies [32,33]. Previous studies showed that liver GDH had much lower phosphorylation of residues during hibernation whereas GDH from foot muscle in an estivated animal revealed an increase in phosphorylation [34,35]. Therefore, protein phosphorylation of GDH seems to play an important role for animals that enter hypometabolic states.

Based on kinetic analysis, GDH from anoxia-exposed frogs was significantly less active in both directions as compared to the controls. The reduced GDH activity in the glutamateoxidizing direction coincides with the suppression of oxygen-based metabolism (TCA cycle and ETC). Thereby, shuttling of $\alpha-\mathrm{KG}$ into the TCA cycle would be useless and unnecessary during anaerobiosis. On the other hand, the decrease in GDH activity in the glutamate-synthesising direction correlated with the fact that synthesis processes are largely suppressed in hypometabolic states [3]. Therefore, GDH suppression helps to prevent nonessential energy expenditure under anoxia exposure. It was revealed that GDH phosphorylation states differed between the two forms of the enzyme. Particularly, GDH isolated from anoxia treated frogs revealed a decrease in phosphorylated serine residues compared to controls. It has been well established that reversible protein phosphorylation is associated with regulation of metabolic pathways and plays a role in activating or suppressing enzymatic activity. Therefore, based on the kinetic analysis data we can conclude that protein phosphorylation plays a role in the regulation GDH to decrease its activity and help prevent a build-up of TCA cycle intermediates and inhibit the synthesis of amino acids in anoxic conditions. 


\subsection{Role of GAPDH in wood frog liver during freezing, dehydration and anoxia}

GAPDH is a pivotal enzyme that plays an important role in both glycolytic and gluconeogenic pathways. Analysis of the kinetic properties of liver GAPDH in both directions revealed statistically significant changes. Freeze exposure of the wood frog showed a slowdown in the glycolytic pathway where glycolysis was inhibited at the PFK step [4,36,37]. This was proven by the decreased levels of F2,6P2 during freezing [36]. Additionally, pyruvate dehydrogenase also was also suppressed during freezing, further supporting the overall decrease in glycolysis [21]. Interestingly, glycolysis was also inhibited at the PFK level in the liver of wood frogs during dehydration [11]. Levels of F2,6P2 have been shown to be reduced in response to anoxia/ischemia in different organisms in the liver, indicating a strong glycolytic control, during oxygen deprivation in anoxia-tolerant organisms [38,39]. Moreover, a strong reduction in PFK enzymatic activity in Otala lactea hepatopancreas was also documented in response to anoxia [40]. The suppression of GAPDH in the wood frog in response to freezing, dehydration or anoxia stresses illustrated in this thesis coincides well with the overall reduction/suppression of liver glycolysis. Wood frog GAPDH was determined to be regulated by reversible protein phosphorylation as there was a substantial difference in phosphorylation state between stress conditions and controls. The protein phosphorylation of GAPDH in the liver of a wood frog is associated with nuclear localization where it contributes to non-glycolytic processes. In addition, there was an increase in lysine methylation of GAPDH extracted from frozen liver. The increase in methylation on lysine residues could potentially regulate this GAPDH activity given that current results showed a decrease substrates affinity and activity in response to freezing. The regulation of GAPDH through lysine modification has been shown in other organism to be associated in regulating GAPDH catalytic activity [41,42]. 


\subsection{Conclusion}

The wood frog is an amazing animal model to study due to its adaptations to extreme environments. The wood frog needs to endure freezing, dehydration and anoxia [7]. These stressors are managed on a metabolic scale which requires a major change to the biochemistry of the frogs [43]. Particularly, the suppression of metabolic enzymes that play a major role in the transition into a hypometabolic state and support the need of the cells for long term survival during stress condition [43]. The research conducted in this thesis demonstrated the importance of GDH and GAPDH to energy metabolism in the liver during hypometabolic states in the wood frog. These enzymes have demonstrated that there are stress-specific responses in the wood frog. As it was seen in chapter 2, GDH isolated from dehydration-exposed frogs had different biochemical properties compared to GDH from anoxia-exposed. The activation of GDH in response to dehydration helps to provide another source of cellular energy from the catabolism of amino acids as well supporting the synthesis of a high level of urea that is an important protectant in anuran dehydration survival [27]. However, the suppression of GDH in response to anoxia agrees with the overall suppression of aerobic metabolism when oxygen is lacking [3]. GAPDH was found to be suppressed under all the stressors to support the overall decrease in glycolytic flux and contribute to the overall MRD to conserve energy.

The reduction or activation of both enzymes was mediated by various factors and correlated with altered PTMs on the enzymes. PTMs are known to influence enzyme function in the cell. Reversible protein phosphorylation was shown to play a role in regulating both GDH and GAPDH properties. GDH from dehydrated frogs showed significantly increased phosphorylation at serine residues that agrees with the increased affinity for glutamate whereas GDH from anoxia-exposed frogs showed reduced phosphorylation at serine residues that also 
agrees with the reduced affinities for its substrate. The efficient method of phosphorylation/dephosphorylation may be crucial to regulate enzyme activity during stress to serve cell/organ needs as well as to mediate the functional switch of GDH during dehydration/rehydration and anoxia/reoxygenation. Increased protein phosphorylation at serine, threonine and tyrosine residues was also seen in GAPDH in response to freezing, dehydration and anoxia. Based on the literature, GAPDH phosphorylation facilitates the nuclear translocation of GAPDH in order to allow the enzyme to participate in non-glycolytic processes $[44,45]$. Protein phosphorylation might be responsible for the altered kinetic properties that were seen in this study. For example, studies of glycolytic enzymes have shown that protein phosphorylation is responsible for the altered kinetic properties that affect the catalytic activity of most of these enzymes $[23,46,47]$. Therefore, protein phosphorylation might play a role is suppressing GAPDH activity during stress to support the overall decrease in glycolysis.

Interestingly, other PTMs were also shown to be involved in regulating GDH including acetylation and ADP-ribosylation. Protein lysine acetylation has emerged as a key PTM in cellular regulation, practically in mediating metabolism $[48,49]$. GDH activation and regulation via protein acetylation and ADP-ribosylation has also been seen in other vertebrates where GDH activity increased in relation to starvation stress $[32,33,48,50]$. The results presented in this thesis showed that the energetic needs differ for each stress and required stress-specific regulation of key metabolic enzymes. This study highlighted the importance of the control of metabolic enzymes through PTMs in order to serve specific cellular needs in each hypometabolic state. In conclusion, this thesis provides a novel insight on the dynamic regulation of metabolism in the liver of the wood frog during hypometabolic states. 


\subsection{Future directions}

The studies described in this thesis identified the regulation and role of GDH and GAPDH in the metabolism of wood frog liver under different stressors. These studies also revealed new research directions that can be pursued in the future. First, specific kinetic parameters can be further investigated. For example, GTP and ATP are known to be allosteric inhibitors of GDH and the enzyme is also known to be activated by succinyl-CoA and by some amino acids such as isoleucine, leucine and valine [51-55]. Given that GDH can uses $\mathrm{NAD}^{+}$or $\mathrm{NADP}^{+}$as a cofactor, it would be interesting to study its kinetic parameters in liver of the wood frog using $\mathrm{NADP}^{+}$as the cofactor $[35,56]$. In addition, kinetics parameters for GAPDH could be investigated in the presence versus absence added high levels of glucose or urea to replicate physiological conditions of the wood frog during freezing and dehydration. Another direction to expand these studies would be to expose these enzymes in incubation studies to different kinases and protein phosphatases to determine if these changed phosphorylation states of the enzymes. Such a study would further support the proposal that reversible protein phosphorylation was in fact involved in modulating the enzymes under stress conditions [35]. Possible effects by additional PTMs (ubiquitination, SUMOlyation, carbonylation, and S-glutathionylation) could also be examined for both enzymes in order to determine the involvement of these PTMs in supporting enzyme regulation during hypometabolic states, providing further evidence that enzymatic responses to stress are coordinated by covalent modification. Similar studies could also be performed on these enzymes isolated from different animal models that undergo hypometabolism such as the ground squirrel (Ictidomys tridecemlineatus), the marine snail (Littorina littorea) and dehydration tolerant and estivating African clawed frog (Xenopus laevis) and/or from other tissues such as muscle. It would also be interesting to examine the effects of 
urea on GDH other anurans such as Xenopus laevis, that undergo bouts of dehydration and where urea is needed to maintain osmatic balance [29]. Another way to expand this study is to look at other key enzymes in the liver of the wood frog that play a role in energy metabolism such as PFK, hexokinase, $\alpha$-ketoglutarate dehydrogenase, citrate synthase and many others. 


\section{References (Chapter 4)}

[1] K.B. Storey, Regulation of hypometabolism: Insights into epigenetic controls, J. Exp. Biol. 218 (2015) 150-159. doi:10.1242/jeb.106369.

[2] K.B. Storey, J.M. Storey, Metabolic rate depression in animals: Transcriptional and translational controls, Biol. Rev. Camb. Philos. Soc. 79 (2004) 207-233. doi:10.1017/S1464793103006195.

[3] K.B. Storey, J.M. Storey, Metabolic rate depression and biochemical adaptation in anaerobiosis, hibernation and estivation, 65 (1990) 145-174. doi:10.1086/416717.

[4] K.J. Cowan, K.B. Storey, Freeze-thaw effects on metabolic enzymes in wood frog organs, Cryobiology. 43 (2001) 32-45. doi:10.1006/cryo.2001.2338.

[5] C.J. Ramnanan, K.B. Storey, Glucose-6-phosphate dehydrogenase regulation during hypometabolism, Biochem. Biophys. Res. Commun. 339 (2006) 7-16. doi:10.1016/j.bbrc.2005.10.036.

[6] K.B. Storey, Regulation of liver metabolism by enzyme phosphorylation during mammalian hibernation., J. Biol. Chem. 262 (1987) 1670-1673.

[7] K.B. Storey, J.M. Storey, Molecular physiology of freeze tolerance in vertebrates, Physiol. Rev. 97 (2017) 623-665. doi:10.1152/physrev.00016.2016.

[8] K.B. Storey, J.M. Storey, Natural freezing survival in animals, Annu. Rev. Ecol. Syst. 27 (1996) 365-386. doi:10.1146/annurev.ecolsys.27.1.365.

[9] K.B. Storey, J.M. Storey, Molecular biology of freezing tolerance, Compr. Physiol. 3 (2013) 1283-1308. doi:10.1002/cphy.c130007.

[10] C.P. Holden, K.B. Storey, Second messenger and cAMP-dependent protein kinase responses to dehydration and anoxia stresses in frogs, J. Comp. Physiol. - B Biochem. Syst. Environ. Physiol. 167 (1997) 305-312. doi:10.1007/s003600050078.

[11] T.A. Churchill, K.B. Storey, Metabolic responses to dehydration by liver of the wood frog, Rana sylvatica, Can. J. Zool. 72 (1994) 1420-1425. doi:10.1139/z94-188.

[12] K.B. Storey, J.M. Storey, Freeze tolerant frogs: cryoprotectants and tissue metabolism during freeze-thaw cycles, Can. J. Zool. 64 (1986) 49-56. doi:10.1139/z86-008.

[13] J.P. Costanzo, A.M. Reynolds, M. Clara, F. Do Amaral, A.J. Rosendale, R.E. Lee, Cryoprotectants and extreme freeze tolerance in a subarctic population of the wood frog, PLoS One. 10 (2015) 1-23. doi:10.1371/journal.pone.0117234.

[14] J.P. Costanzo, R.E. Lee, Urea loading enhances freezing survival and postfreeze recovery in a terrestrially hibernating frog, J. Exp. Biol. 211 (2008) 2969-2975.

doi:10.1242/jeb.019695.

[15] J.P. Costanzo, Cryoprotection by urea in a terrestrially hibernating frog, J. Exp. Biol. 208 (2005) 4079-4089. doi:10.1242/jeb.01859.

[16] K.B. Storey, J.M. Storey, Biochemical adaption for freezing tolerance in the wood frog, Rana sylvatica, J. Comp. Physiol. B. 155 (1984) 29-36. doi:10.1007/BF00688788.

[17] K.J. Cowan, J.A. MacDonald, J.M. Storey, K.B. Storey, Metabolic reorganization and signal transduction during estivation in the spadefoot toad, Exp. Biol. Online. 5 (2000) 1- 
25. doi:10.1007/s00898-000-0001-8.

[18] D.C. Jackson, G.R. Ultsch, Physiology of hibernation under the ice by turtles and frogs, J. Exp. Zool. Part A Ecol. Genet. Physiol. 313 A (2010) 311-327. doi:10.1002/jez.603.

[19] K.B. Storey, Anoxia tolerance in turtles: Metabolic regulation and gene expression, Comp. Biochem. Physiol. - A Mol. Integr. Physiol. 147 (2007) 263-276. doi:10.1016/j.cbpa.2006.03.019.

[20] J. St-Pierre, M.D. Brand, R.G. Boutilier, The effect of metabolic depression on proton leak rate in mitochondria from hibernating frogs, J. Exp. Biol. 203 (2000) 1469-1476.

[21] R. Al-attar, S. Wijenayake, K.B. Storey, Metabolic reorganization in winter: Regulation of pyruvate dehydrogenase (PDH) during long-term freezing and anoxia, Cryobiology. 86 (2019) 10-18. doi:10.1016/j.cryobiol.2019.01.006.

[22] C.A. Dieni, K.B. Storey, Regulation of glucose-6-phosphate dehydrogenase by reversible phosphorylation in liver of a freeze tolerant frog, J. Comp. Physiol. B Biochem. Syst. Environ. Physiol. 180 (2010) 1133-1142. doi:10.1007/s00360-010-0487-5.

[23] C.A. Dieni, K.B. Storey, Regulation of hexokinase by reversible phosphorylation in skeletal muscle of a freeze-tolerant frog, Comp. Biochem. Physiol. - B Biochem. Mol. Biol. 159 (2011) 236-243. doi:10.1016/j.cbpb.2011.05.003.

[24] M. Crerar, E. David, K. Storey, Electrophoretic analysis of liver glycogen phosphorylase activation in the freeze-tolerant wood frog, 971 (1988) 72-84.

[25] L.J. Hawkins, M. Wang, B. Zhang, Q. Xiao, H. Wang, K.B. Storey, Glucose and urea metabolic enzymes are differentially phosphorylated during freezing, anoxia, and dehydration exposures in a freeze tolerant frog, Comp. Biochem. Physiol. - Part D Genomics Proteomics. 30 (2019) 1-13. doi:10.1016/j.cbd.2019.01.009.

[26] H.A. Sampson, S.H. Sicherer, Urea and amphibian water economy, Immunol. Allergy Clin. North Am. 19 (1999) 495-517. doi:10.1016/S0889-8561(05)70104-1.

[27] A.R. Lee, M. Silove, U. Katz, J.B. Balinsky, Urea cycle enzymes and glutamate dehydrogenase in Xenopus laevis and Bufo viridis adapted to high salinity, J. Exp. Zool. 221 (1982) 169-172. doi:10.1002/jez.1402210207.

[28] J.B. Balinsky, Adaptation of nitrogen metabolism to hyperosmotic environment in amphibia, J. Exp. Zool. 215 (1981) 335-350. doi:10.1002/jez.1402150311.

[29] J.B. Balinsky, E.L. Choritz, C.G.L. Coe, G.S. van der Schans, Amino acid metabolism and urea synthesis in naturally aestivating Xenopus laevis, Comp. Biochem. Physiol. 22 (1967) 59-68. doi:10.1016/0010-406X(67)90166-1.

[30] K.B. Storey, Life in the slow lane: Molecular mechanisms of estivation, Comp. Biochem. Physiol. - A Mol. Integr. Physiol. 133 (2002) 733-754. doi:10.1016/S10956433(02)00206-4.

[31] J.L. Pakay, P.C. Withers, A.A. Hobbs, M. Guppy, In Vivo downregulation of protein synthesis in the snail Helix apersa during estivation, Am. J. Physiol. - Regul. Integr. Comp. Physiol. 283 (2002) 197-204. doi:10.1152/ajpregu.00636.2001.

[32] D.B. Lombard, F.W. Alt, H.-L. Cheng, J. Bunkenborg, R.S. Streeper, R. Mostoslavsky, J. Kim, G. Yancopoulos, D. Valenzuela, A. Murphy, Y. Yang, Y. Chen, M.D. Hirschey, 
R.T. Bronson, M. Haigis, L.P. Guarente, R. V. Farese, S. Weissman, E. Verdin, B. Schwer, Mammalian Sir2 Homolog SIRT3 regulates global mitochondrial lysine acetylation, Mol. Cell. Biol. 27 (2007) 8807-8814. doi:10.1128/mcb.01636-07.

[33] N. Ahuja, B. Schwer, S. Carobbio, D. Waltregny, B.J. North, V. Castronovo, P. Maechler, E. Verdin, Regulation of insulin secretion by SIRT4, a mitochondrial ADPribosyltransferase, J. Biol. Chem. 282 (2007) 33583-33592. doi:10.1074/jbc.M705488200.

[34] R.A. V. Bell, N.J. Dawson, K.B. Storey, Insights into the In Vivo regulation of glutamate dehydrogenase from the foot muscle of an estivating land snail, Enzyme Res. 2012 (2012) 1-10. doi:10.1155/2012/317314.

[35] R.A.V. Bell, K.B. Storey, Regulation of liver glutamate dehydrogenase by reversible phosphorylation in a hibernating mammal, Comp. Biochem. Physiol. - B Biochem. Mol. Biol. 157 (2010) 310-316. doi:10.1016/j.cbpb.2010.07.005.

[36] K.B. Storey, Glycolysis and the regulation of cryoprotectant synthesis in liver of the freeze tolerant wood frog, (1987) 373-380. doi:10.1007/BF00693364.

[37] M.D. Vazquez Illanes, K.B. Storey, 6-Phosphofructo-2-kinase and control of cryoprotectant synthesis in freeze tolerant frogs, BBA - Gen. Subj. 1158 (1993) 29-32. doi:10.1016/0304-4165(93)90092-M.

[38] B. Storey, Fructose 2,6-bisphosphate and anaerobic metabolism in marine molluscs, 181 (1985) 245-248.

[39] L. Hue, M.H. Rider, Role of fructose 2,6-bisphosphate in the control of glycolysis in mammalian tissues, 245 (1987) 313-324.

[40] R. Whitwam, K. Storey, Regulation of phosphofructokinase during estivation and anoxia in the land snail, Otala lactea, Comp. Biol. (1991).

[41] S.T. Bond, K.F. Howlett, G.M. Kowalski, S. Mason, T. Connor, A. Cooper, V. Streltsov, C.R. Bruce, K.R. Walder, S.L. McGee, Lysine post-translational modification of glyceraldehyde-3-phosphate dehydrogenase regulates hepatic and systemic metabolism, FASEB J. 31 (2017) 2592-2602. doi:10.1096/fj.201601215R.

[42] B.G. Forcina, G. Ferri, M.C. Zapponi, S. Ronchi, Identification of lysines reactive with pyridoxal 5'-phosphate in glyceraldehyde-3-phosphate dehydrogenase, Eur. J. Biochem. 20 (1971) 535-540. doi:10.1111/j.1432-1033.1971.tb01424.x.

[43] K.B. Storey, J.M. Storey, Putting life on "pause" - Molecular regulation of hypometabolism, J. Exp. Biol. 210 (2007) 1700-1714. doi:10.1242/jeb.02716.

[44] M.A. Sirover, On the functional diversity of glyceraldehyde-3-phosphate dehydrogenase: Biochemical mechanisms and regulatory control, Biochim. Biophys. Acta - Gen. Subj. 1810 (2011) 741-751. doi:10.1016/j.bbagen.2011.05.010.

[45] C. Nicholls, H. Li, J.P. Liu, GAPDH: A common enzyme with uncommon functions, Clin. Exp. Pharmacol. Physiol. 39 (2012) 674-679. doi:10.1111/j.1440-1681.2011.05599.x.

[46] Z.J. Xiong, K.B. Storey, Regulation of liver lactate dehydrogenase by reversible phosphorylation in response to anoxia in a freshwater turtle, Comp. Biochem. Physiol. - B Biochem. Mol. Biol. 163 (2012) 221-228. doi:10.1016/j.cbpb.2012.06.001. 
[47] C.L. Childers, K.B. Storey, Post-translational regulation of hexokinase function and protein stability in the aestivating frog Xenopus laevis, Protein J. 35 (2016) 61-71. doi:10.1007/s10930-016-9647-0.

[48] K.L. Guan, Y. Xiong, Regulation of intermediary metabolism by protein acetylation, Trends Biochem. Sci. 36 (2011) 108-116. doi:10.1016/j.tibs.2010.09.003.

[49] Q. Wang, Y. Zhang, C. Yang, H. Xiong, Y. Lin, Acetylation of metabolic enzymes and metabolic Flux, Science (80-. ). 327 (2010) 1004-1007. doi:10.1126/science.1179687.

[50] M.C. Haigis, R. Mostoslavsky, K.M. Haigis, K. Fahie, D.C. Christodoulou, A.J.J. Murphy, D.M. Valenzuela, G.D. Yancopoulos, M. Karow, G. Blander, C. Wolberger, T.A. Prolla, R. Weindruch, F.W. Alt, L. Guarente, SIRT4 inhibits glutamate dehydrogenase and opposes the effects of calorie restriction in pancreatic $\beta$ cells, Cell. 126 (2006) 941954. doi:10.1016/j.cell.2006.06.057.

[51] X. Zhou, J.R. Thompson, Regulation of glutamate dehydrogenase by branched-chain amino acids in skeletal muscle from rats and chicks, Int. J. Biochem. Cell Biol. 28 (1996) 787-793. doi:10.1016/1357-2725(96)00019-2.

[52] R.A.. Bell, K.B. Storey, Regulation of liver glutamate dehydrogenase from an anoxiatolerant freshwater turtle, HOAJ Biol. 1 (2012) 3. doi:10.7243/2050-0874-1-3.

[53] S.R. Green, K.B. Storey, Regulation of glutamate dehydrogenase (GDH) in response to whole body freezing in wood frog liver linked to differential acetylation and ADPribosylation, Arch. Biochem. Biophys. 636 (2017) 90-99. doi:10.1016/j.abb.2017.10.010.

[54] L.A. Fahien, E.H. Kmiotek, G. Woldegiorgis, M. Evenson, E. Shrago, M. Marshall, Regulation of aminotransferase-glutamate dehydrogenase interactions by carbamyl phosphate synthase-I, $\mathrm{Mg}^{2+}$ plus leucine versus citrate and malate, J. Biol. Chem. 260 (1985) 6069-6079.

[55] L.A. Fahien, M.J. MacDonald, J.K. Teller, B. Fibich, C.M. Fahien, Kinetic advantages of hetero-enzyme complexes with glutamate dehydrogenase and the $\alpha$-ketoglutarate dehydrogenase complex, J. Biol. Chem. 264 (1989) 12303-12312.

[56] K.B. Male, K.B. Storey, Regulation of coenzyme utilization by bovine liver glutamate dehydrogenase: Investigations using thionicotinamide analogues of NAD and NADP in a dual wavelength assay, Int. J. Biochem. 14 (1982) 1083-1089. doi:10.1016/0020$711 \mathrm{X}(82) 90165-3$. 


\section{Appendix I: Representative western blots}




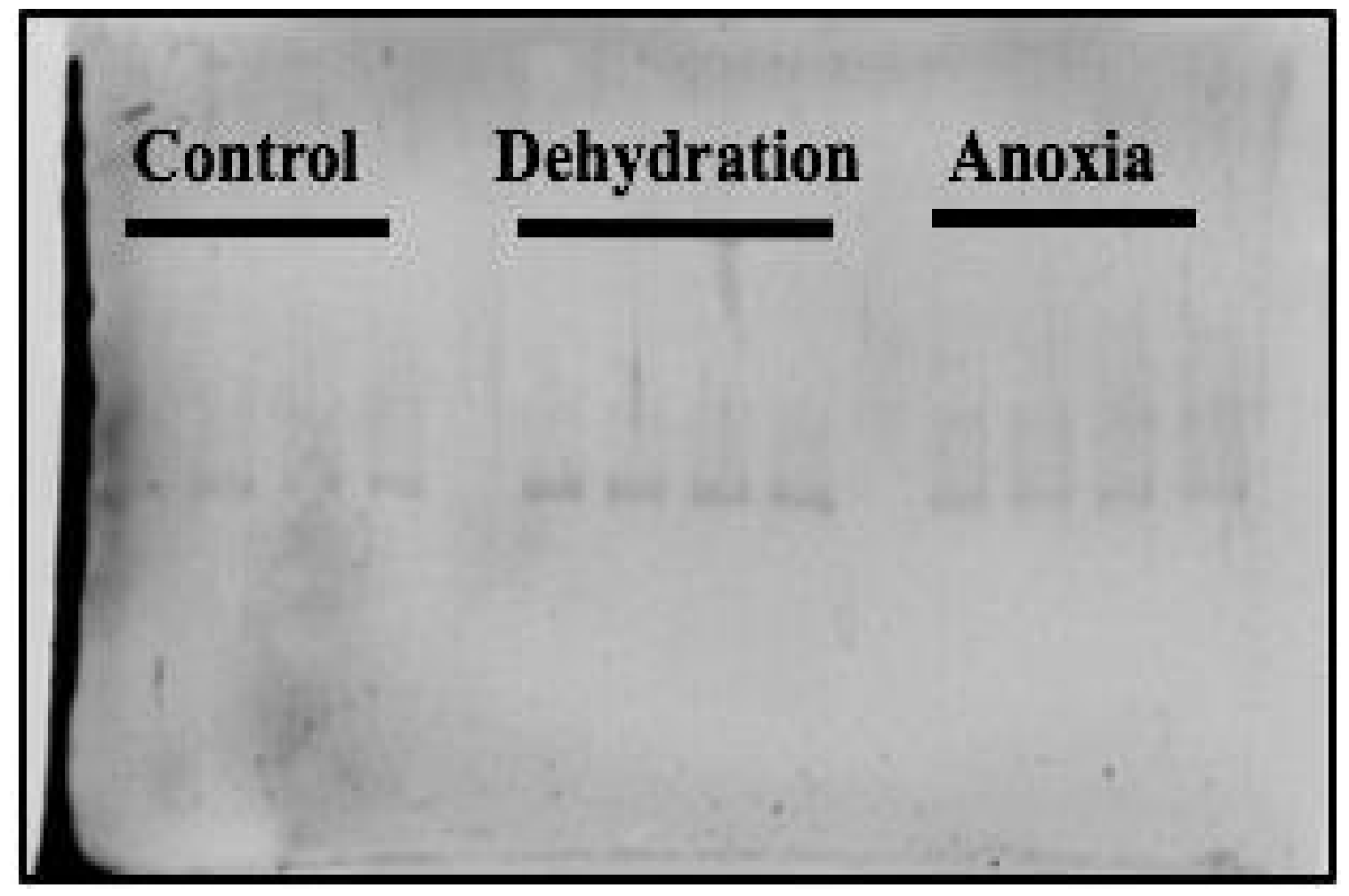

Figure S1: Whole image of ECL-detected membrane using the control, dehydration and anoxia liver GDH samples probed with anti-phosphoserine antibody 


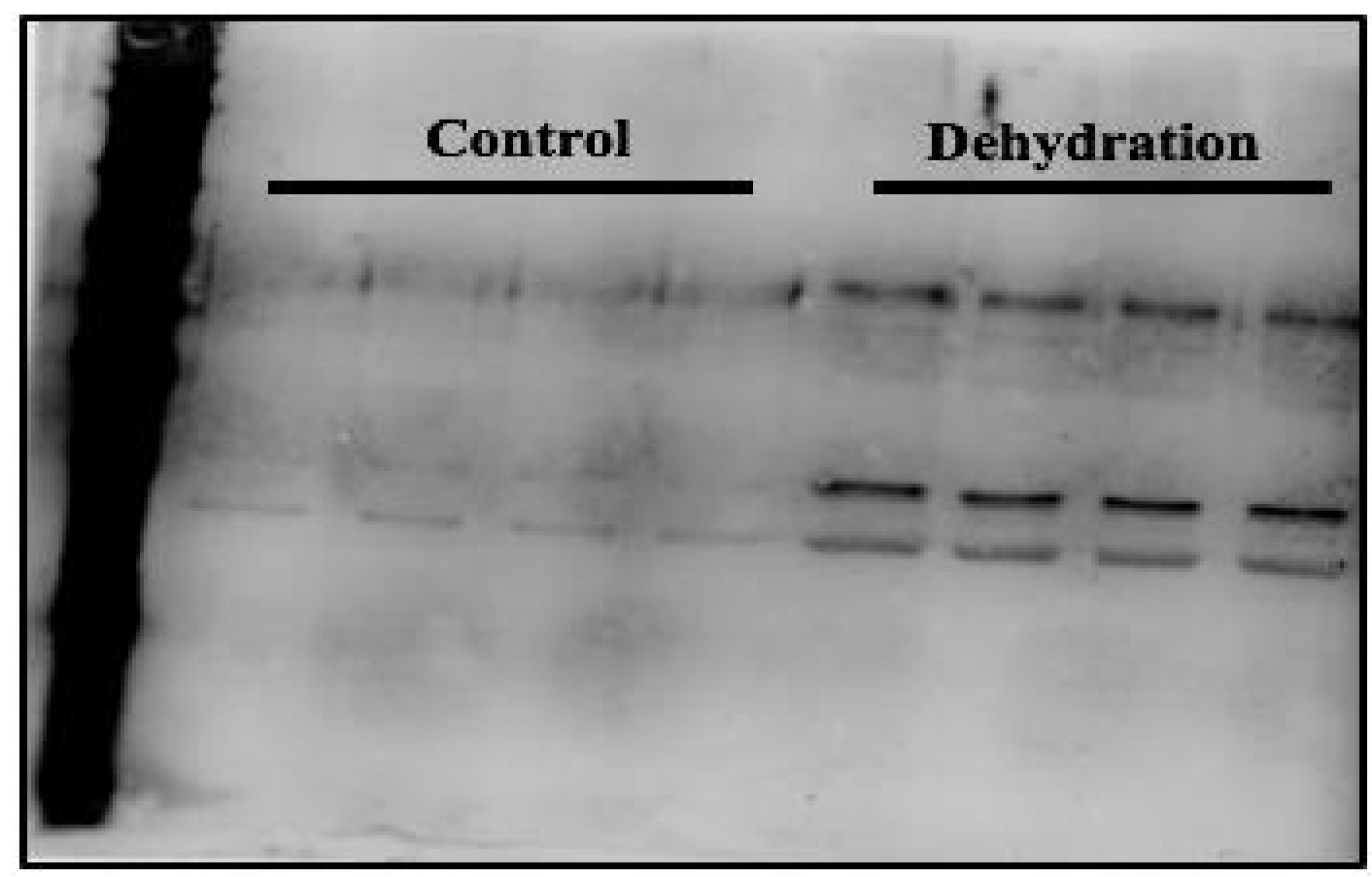

Figure S2: Whole image of ECL-detected membrane using the control and dehydration liver GAPDH samples probed with anti-phosphoserine antibody 


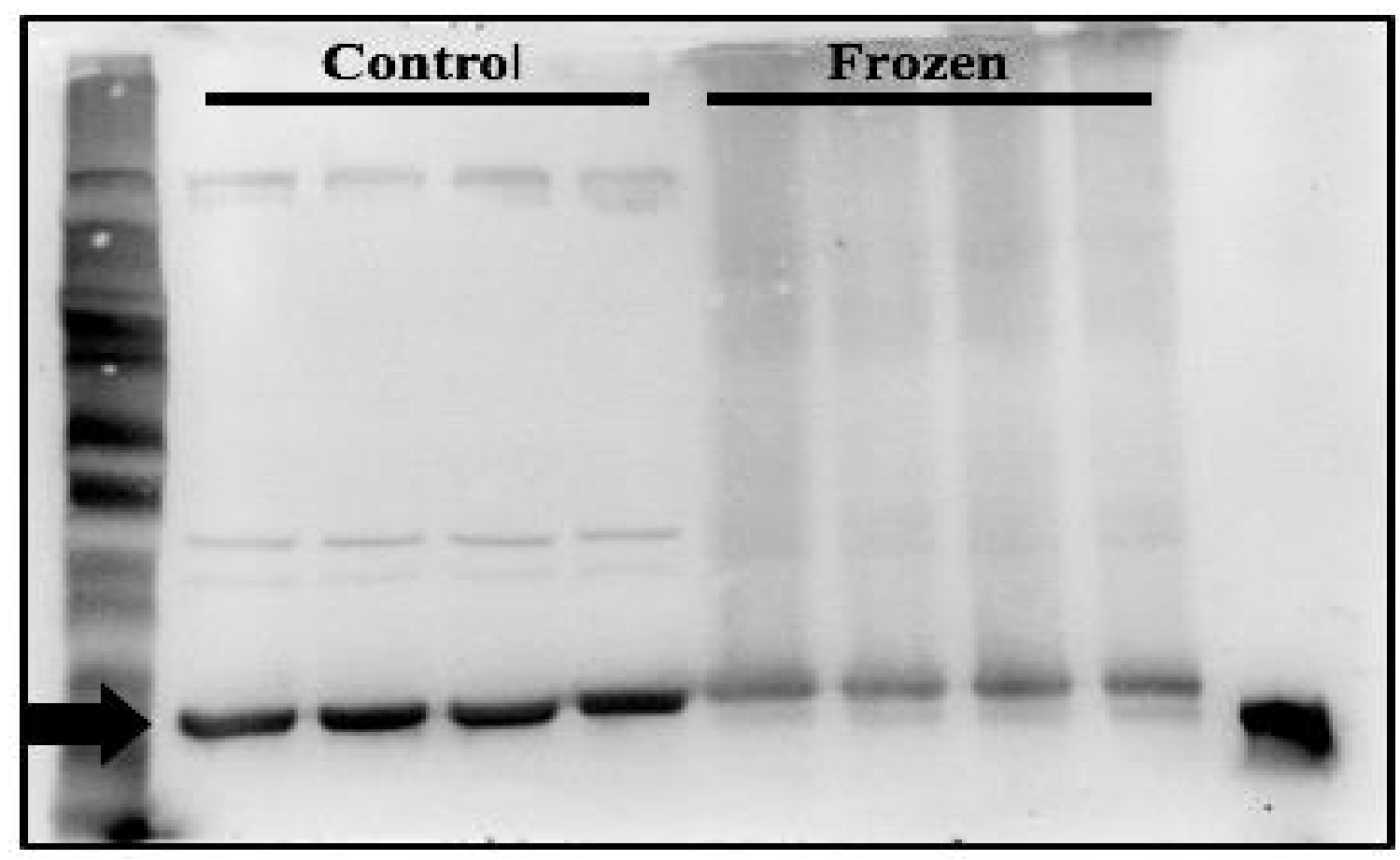

Figure S3: Whole image of ECL-detected membrane using the control and frozen liver samples probed with anti-GAPDH antibody 


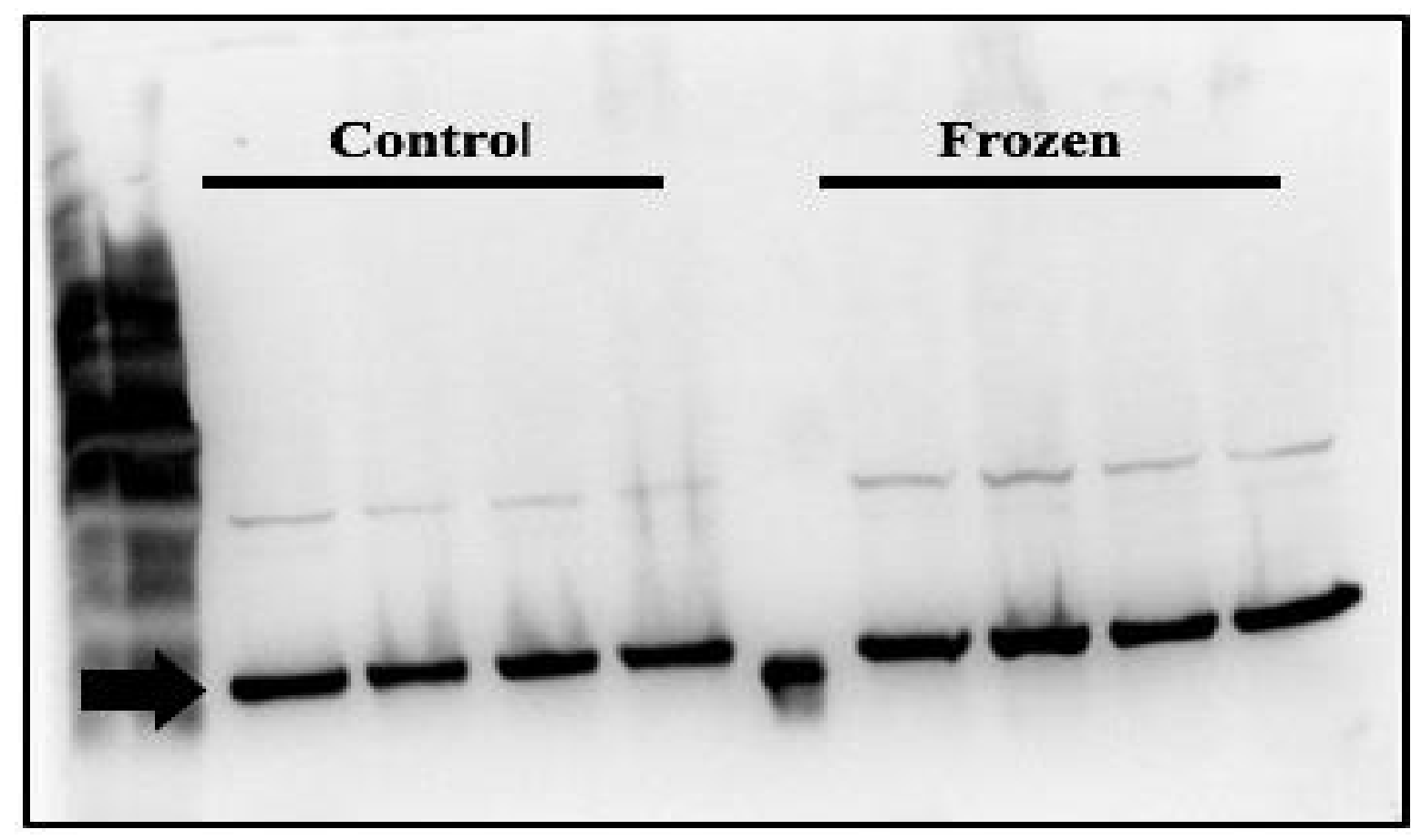

Figure S4: Whole image of ECL-detected membrane using the control and frozen liver nuclear samples probed with anti-GAPDH antibody 


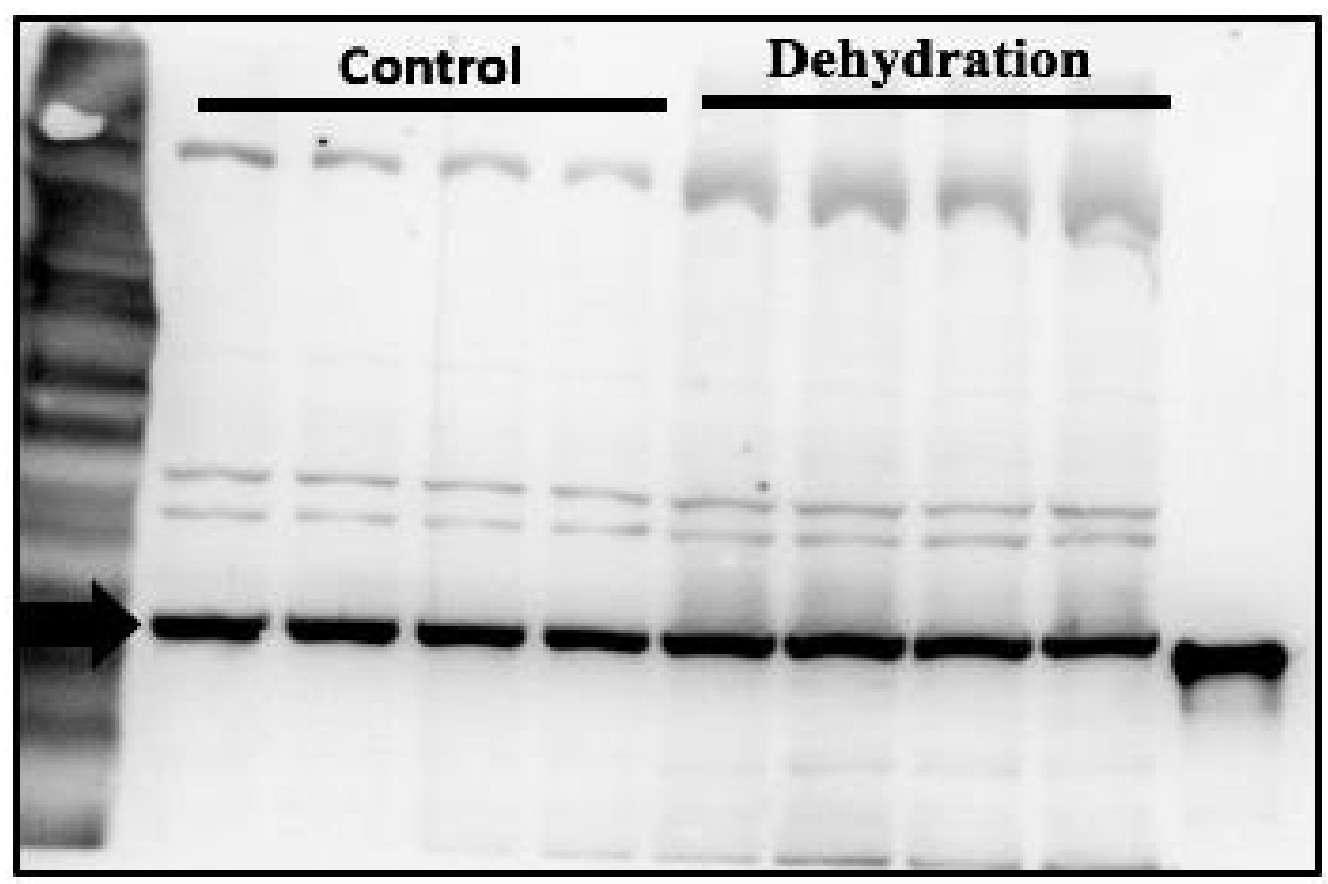

Figure S5: Whole image of ECL-detected membrane using the control and dehydration liver samples probed with anti-GAPDH antibody 


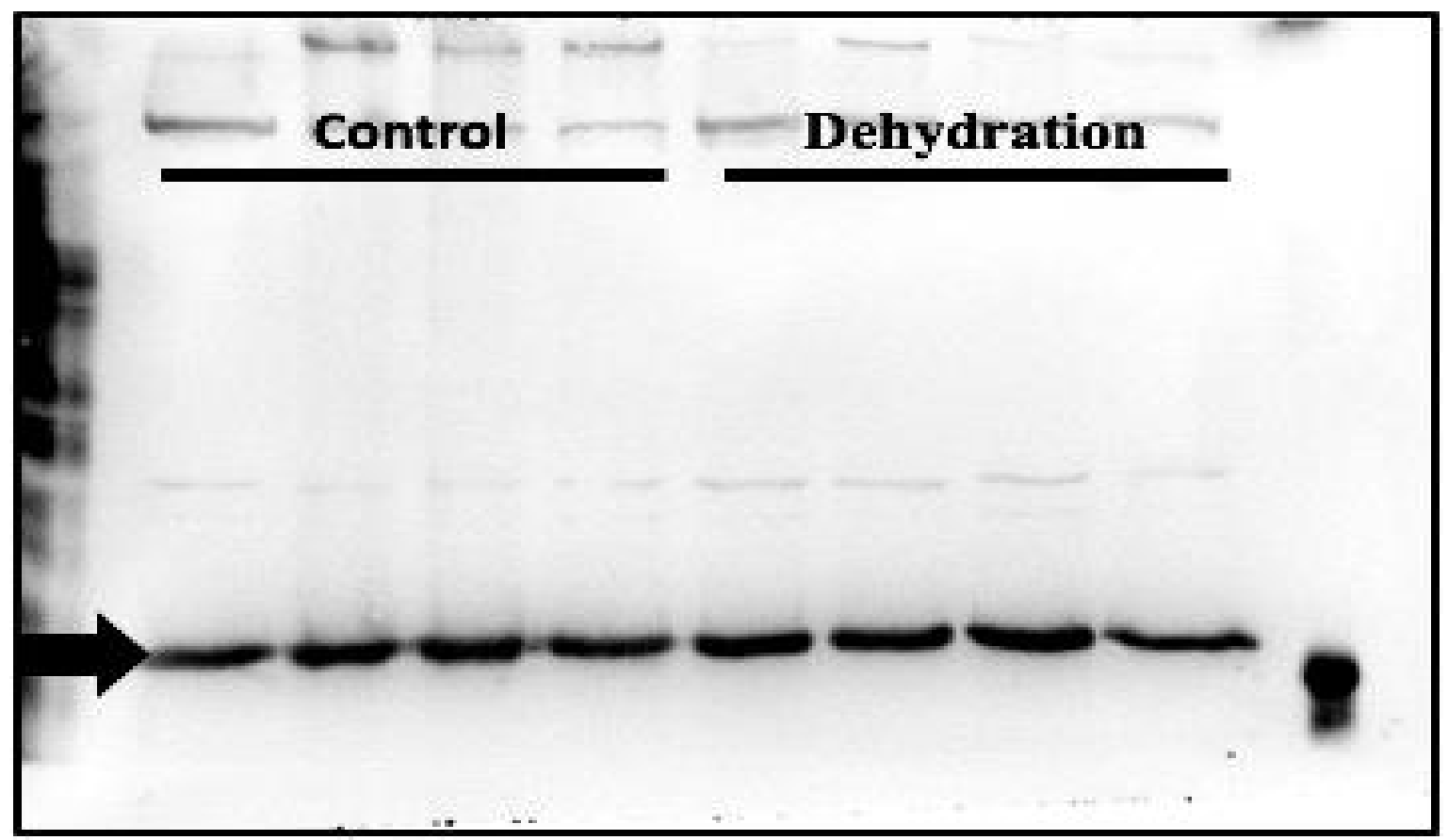

Figure S6: Whole image of ECL-detected membrane using the control and dehydration nuclear liver nuclear samples probed with anti-GAPDH antibody 


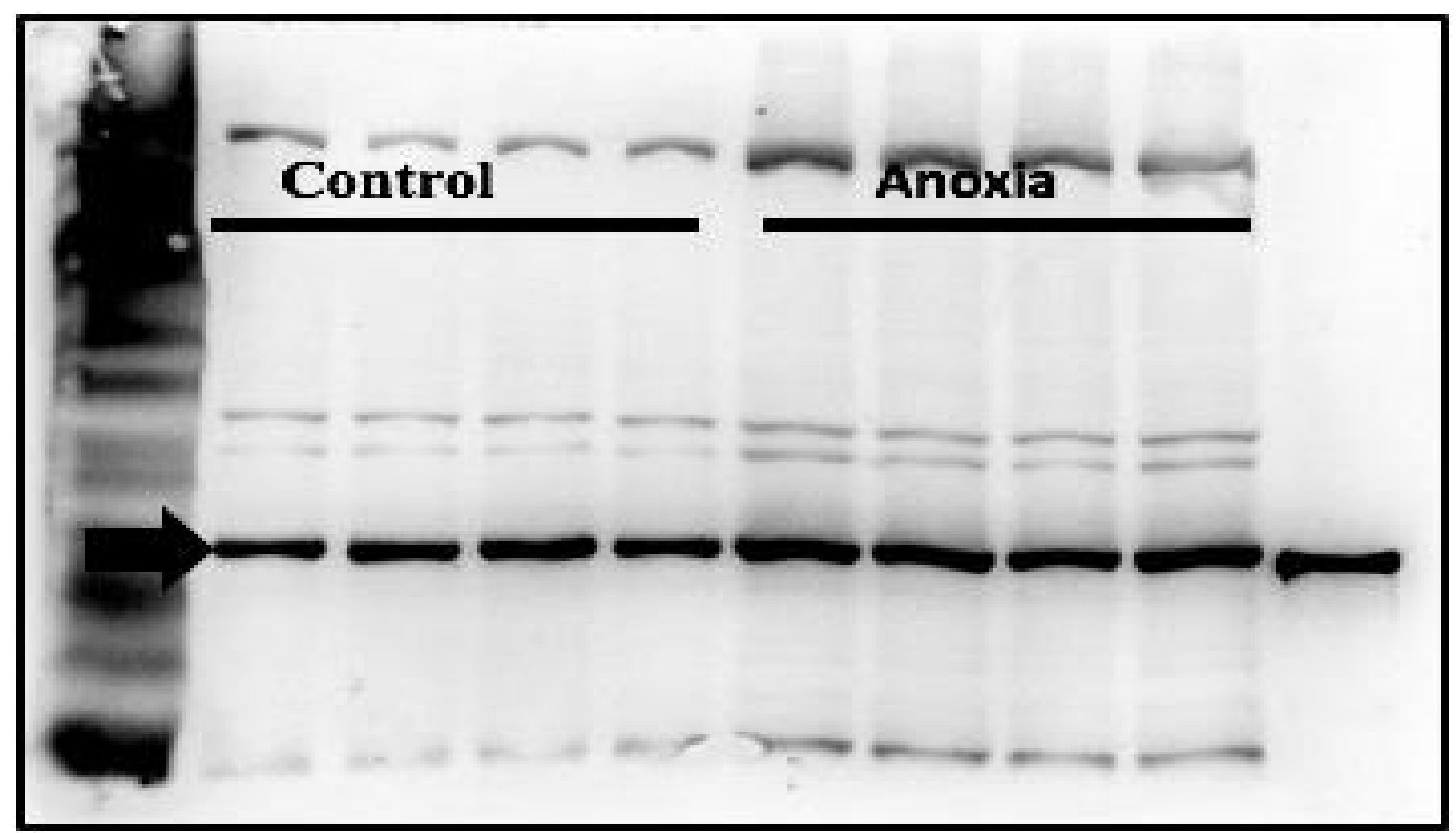

Figure S7: Whole image of ECL-detected membrane using the control and anoxia liver samples probed with anti-GAPDH antibody 


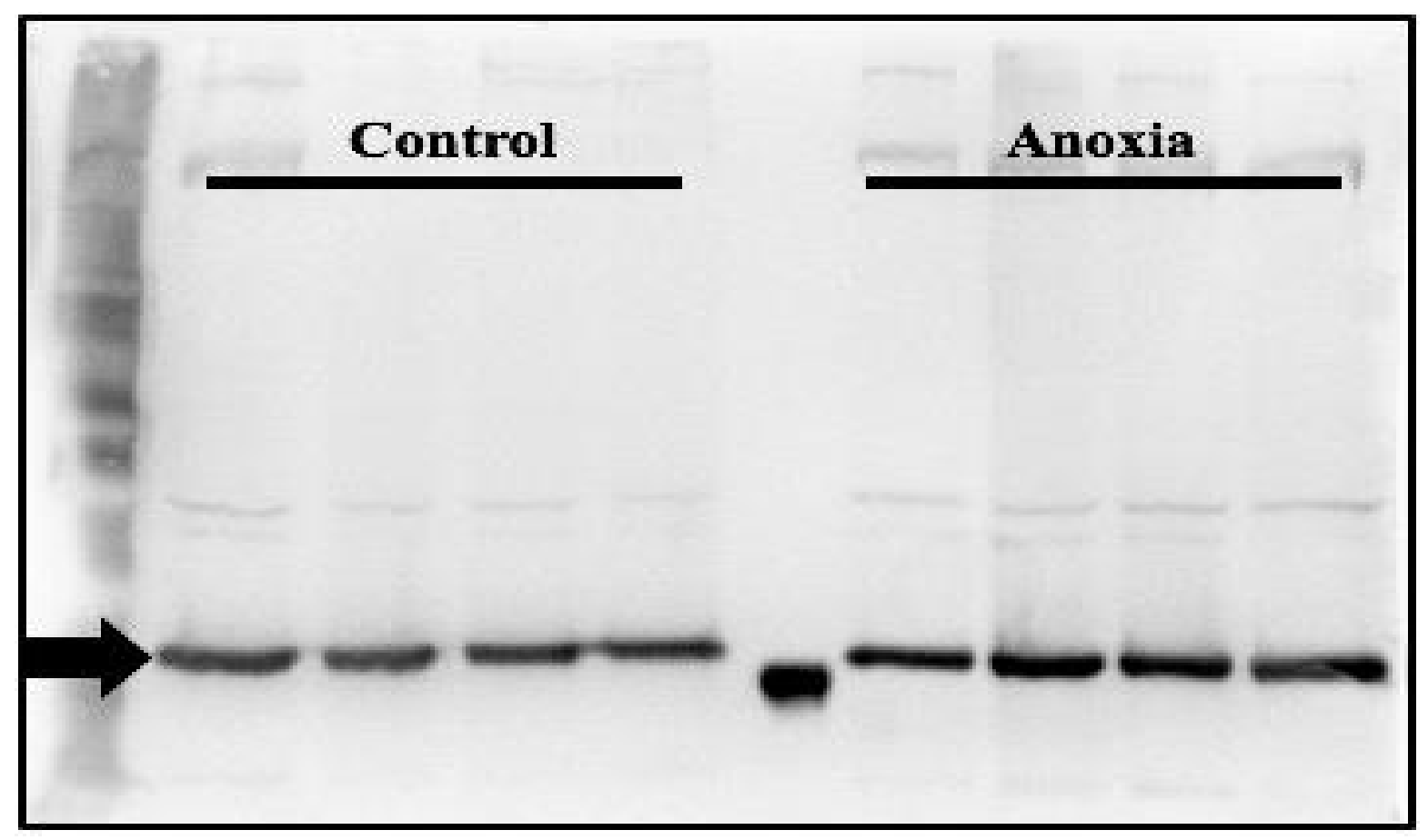

Figure S8: Whole image of ECL-detected membrane using the control and anoxia liver nuclear samples probed with anti-GAPDH antibody 


\section{Appendix II: mass spectroscopy}




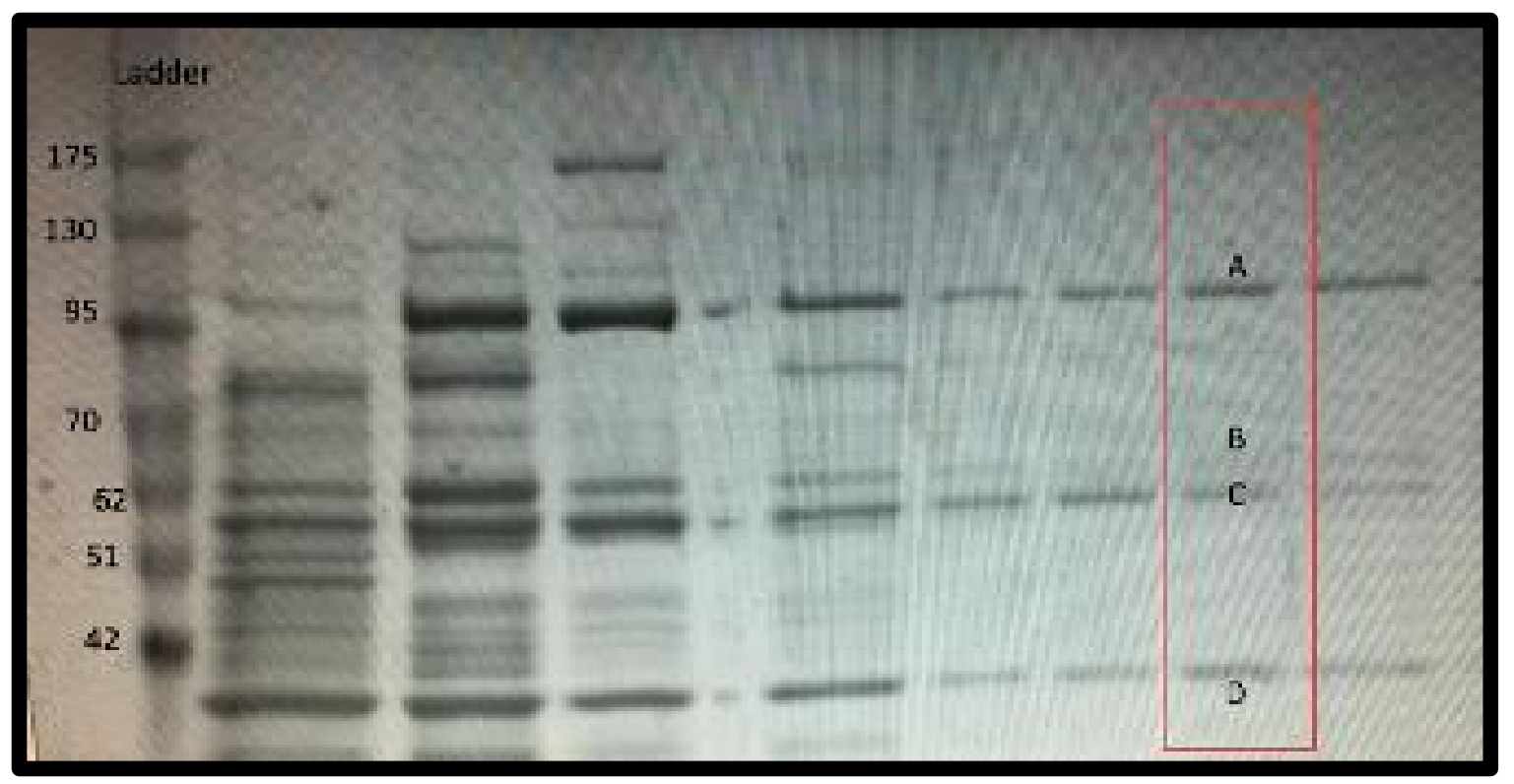

Figure S9: Protein bands excised (boxed outline) from 10\% resolving SDS-PAGE for mass spectrometry (Proteomics Core Facility, CHU de Quebec Research Center, Laval University). The mass spectrometry provided identification of proteins bands to be: (A) Alpha-1,4 glucan phosphorylase at $98.4 \mathrm{KDa},(\mathrm{B})$ : catalase at $60.2 \mathrm{KDa},(\mathrm{C})$ : glutamate dehydrogenase at $62 \mathrm{KDa}$ and (D): uncharacterized protein 


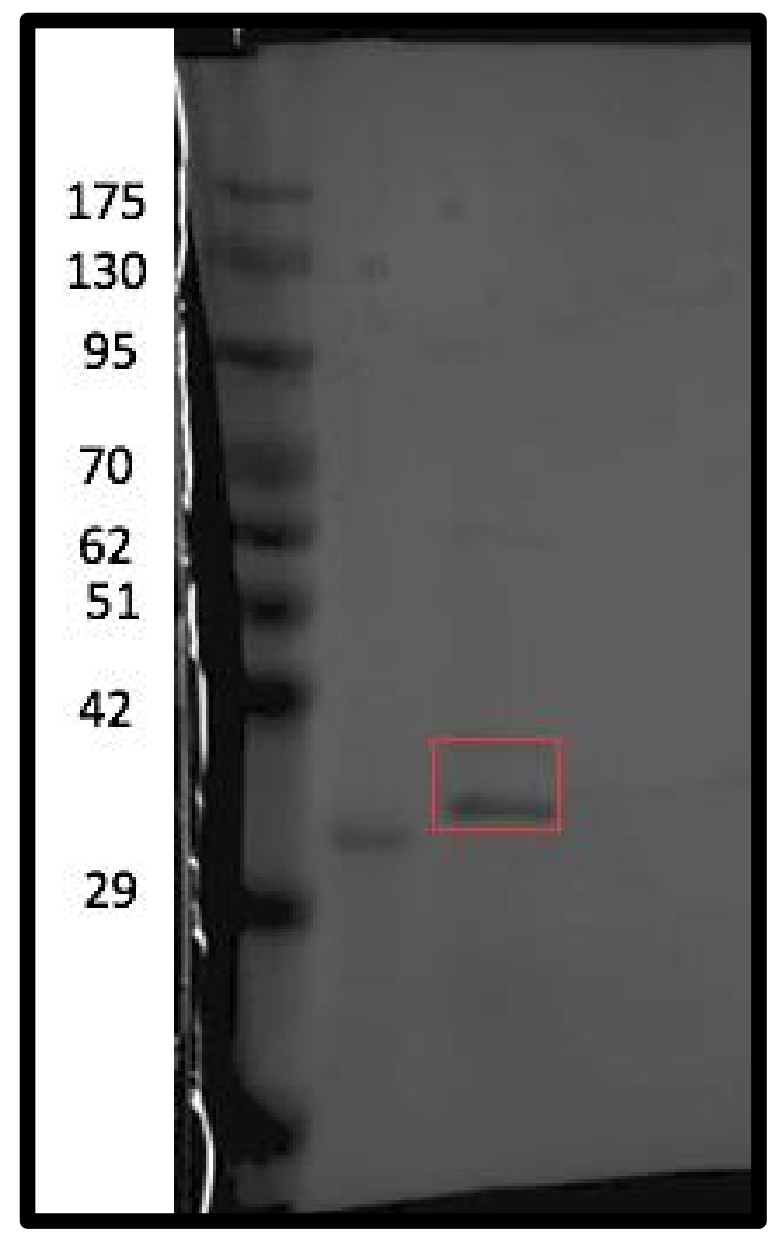

Figure S10: Protein bands excised (boxed outline) from 10\% resolving SDS- PAGE for mass spectrometry (Proteomics Core Facility, CHU de Quebec Research Center, Laval University). Commasie Blue stain show the GAPDH purification of control wood frog liver tissue. From left to right, 1: piNK Plus Pre-stained Protein Ladder 10-175KDa,2: pooled peak fractions eluted from phenyl Sepharose. Mass spectrometry confirmed that protein band to be GAPDH at 37 $\mathrm{kDa}$. 
Appendix III: Conferences \& Publications 


\section{Conferences}

- ICCPB: Presented poster on chapter from thesis concerning GDH regulation in the wood frog

\section{Publications}

- Saleem, R,. Al-attar, R., Storey, KB. The Activation of Pro-Survival Pathways of the North American Myotis lucifugus, during hibernation. Cryobiology. CRYO_2020_16, 15/01/2020 (Under Review) 